\title{
It's in the way that you use it : usage behavior, sales performance, and their interrelationships
}

Citation for published version (APA):

Datta, H. (2014). It's in the way that you use it : usage behavior, sales performance, and their interrelationships. [Doctoral Thesis, Maastricht University]. Maastricht University. https://doi.org/10.26481/dis.20140207hd

Document status and date:

Published: 01/01/2014

DOI:

10.26481/dis.20140207hd

Document Version:

Publisher's PDF, also known as Version of record

\section{Please check the document version of this publication:}

- A submitted manuscript is the version of the article upon submission and before peer-review. There can be important differences between the submitted version and the official published version of record.

People interested in the research are advised to contact the author for the final version of the publication, or visit the DOI to the publisher's website.

- The final author version and the galley proof are versions of the publication after peer review.

- The final published version features the final layout of the paper including the volume, issue and page numbers.

Link to publication

\footnotetext{
General rights rights.

- You may freely distribute the URL identifying the publication in the public portal. please follow below link for the End User Agreement:

www.umlib.nl/taverne-license

Take down policy

If you believe that this document breaches copyright please contact us at:

repository@maastrichtuniversity.nl

providing details and we will investigate your claim.
}

Copyright and moral rights for the publications made accessible in the public portal are retained by the authors and/or other copyright owners and it is a condition of accessing publications that users recognise and abide by the legal requirements associated with these

- Users may download and print one copy of any publication from the public portal for the purpose of private study or research.

- You may not further distribute the material or use it for any profit-making activity or commercial gain

If the publication is distributed under the terms of Article $25 \mathrm{fa}$ of the Dutch Copyright Act, indicated by the "Taverne" license above, 


\title{
It's in the Way That You Use It
}

\author{
Usage Behavior, \\ Sales Performance, \\ and Their Interrelationships
}

Hannes Datta 
It's in the Way That You Use It-Usage Behavior, Sales Performance, and Their Interrelationships

(C) Hannes Datta, 2014

All rights reserved. No part of this publication may be reprinted or utilized in any form or by electronic, mechanical, or other means, now known or hereafter invented, including photocopying and recording or in any information storage retrieval system, without written permission of the copyright owner.

ISBN: 978-94-6167-179-0 


\title{
IT'S IN THE WAY \\ THAT YOU USE IT
}

\author{
Usage Behavior, \\ Sales Performance, \\ and Their Interrelationships
}

PROEFSCHRIFT

ter verkrijging van de graad van doctor

aan de Universiteit Maastricht,

op gezag van de Rector Magnificus, Prof. dr. L.L.G. Soete

volgens het besluit van het College van Decanen,

in het openbaar te verdedigen

op vrijdag 7 februari 2014 om 10.00 uur

door

Hannes Datta 


\section{Promotores}

Prof. dr. Martin Wetzels

Prof. dr. Harald J. van Heerde (Massey University, Nieuw Zeeland)

\section{Copromotor}

dr. Bram Foubert

\section{Beoordelingscommissie}

Prof. dr. Ko de Ruyter (voorzitter)

Prof. dr. Els Gijsbrechts (Universiteit van Tilburg)

Prof. dr. Jos Lemmink

Prof. dr. Werner Reinartz (Universität zu Köln, Duitsland) 


\section{Acknowledgements}

The past three years have been a challenging journey, and I am grateful for the continuous support of many who have been there for me during this time. You have all left marks on me, and I am thankful that our ways have crossed.

The fact that I've reached this academic milestone is mainly attributable to my advisors who have helped me grow both personally and professionally. First, I am greatly indebted to dr. Bram Foubert. Bram, your sense for detail and rigor is unprecedented. I am extremely thankful for your sincere dedication-day in and day out, your brilliant ideas, and your personal care for my well-being. Your humble opinion has been and always will be of highest value to me. You are a true rock star, in your work and as a person, whether in the spotlight on stage or as the brain in the background.

An equally important person during my PhD has been Prof. dr. Harald van Heerde. Harald, I feel privileged to have become your student. Your senior guidance has taken my research to a higher level. Your pragmatism has helped me out when I was stuck. Your sharp senses for "what's hot" honed my own intuition to pursue interesting research questions. I greatly remember our hiking trips in New Zealand, and your personal care in guiding my future career. Thank you for your hospitality, and for your effortful dedication during each and every step of my PhD. Kia ora koe!

I am also indebted to Prof. dr. Dominik Papies. Dominik, you became a de facto advisor when we started working on "the music project". You trusted in me and my ideas, and were always available for in-depth discussions and personal advice. You and your family received 
me warmly in your own home-something I consider extraordinary. You are an inspiring co-author, and working with you is a real pleasure.

Next, I would like to thank Prof. dr. Martin Wetzels for unconditionally supporting me and my research. Martin, thanks for your substantial trust and administrative support, and for always being approachable. The same holds for Prof. dr. Ko de Ruyter, who provided me with many opportunities to grow and shine. In addition, Ko served as the chairman of my evaluation committee, together with Prof. dr. Els Gijsbrechts, Prof. dr. Jos Lemmink, and Prof. dr. Werner Reinartz. I feel honored to have such a distinguished faculty to evaluate my work. Thank you very much for your excellent suggestions and comments.

Thanks also to my new colleagues at Tilburg University, who started contributing to my academic development early on. Bart B., you opened up the Tilburg modeling world by letting me fill up empty seats at the annual Christmas camp dinner. Arjen, although officially my academic uncle, you're more my academic brother and a great partner to discuss research. Marnik, thanks for always having an open ear and screening my manuscripts with great care. To all new colleagues at Tilburg University: thanks for the warm welcome! I look forward to the coming years!

On a much more personal note, I would like to thank my friends from Maastricht. It's you who are responsible for five wonderful years. Stephan, living together with you has been a blast, and your opinion on many aspects (including, but not at all limited to work) has been extremely valuable. Junge, mit dir kann ich Ikea Stoff stehlen! Matthias, du Kölsche Frohnatur, the wolf pack wouldn't be the same without you. Dominik, thanks for saving my life when I came under fire. Thanks also to all other participants of the legendary research camps at Rijeka, Budapest, and Bruges. Yolo. Jessie, from day one, you've been a source of great personal support (both in the sky, and on ground)!

Thanks also to other colleagues at Maastricht University. Johannes, we share a common background, were roommates. You've always been a great partner to talk to! Nadine and Marleen, you've been superb office mates. Anne, thanks for your care in my career development and support in our final PhD stages. Hans, thanks for being classy, and for supporting us PhDs on stage. Lisa, thanks for your moral support and teaching ROM! Thanks also to Eefje and Pascalle, Liz, Jan M. (Portugal, Istanbul!), Kathleen, Ahmed, and each and every 
one whose computers I (knowingly or secretly-sorry) hijacked to run my statistical models. Maastricht has coined me. Thank you.

The University Choir of Maastricht is largely responsible for my successful integration in the Dutch society. Bedankt voor de avonden op het podium, en in de Tribunaal. Lucas (voor je support met veel dagelijkse dingen), Sophia (geen smoesjes)! Buvons bien, allemaal! Heiner, thanks for a great time, and for punking Matthias. Edgar, jij bent een geduldige leraar Nederlands geweest voor me, en het was prima met je te gaan hardlopen. Yuri and the Ludwig family in Auckland: thanks for support and hosting me on the weekends! I also would like to thank dr. Fr. John Suresh, Nandhini, and all the hearts and souls from Neerpair campus; you have given meaning to my life. எல்லோருக்கும் நன்றி!

Philipp, as a best friend, you've always been a source of inspiration and tremendous support in each and every aspect of life. Dank dir, dass du immer da bist. Martin, sapitaja? Thanks for entertaining phone calls, lots of travel adventures, and a good friendship. Thanks also to Balajee and his wonderful family, the Ingolstadt crew (Torben-wir gehn mit Sand in den Schuhen!), and my native soil Himmelsthür-never forget!

Auch möchte ich meinen Eltern und meiner Schwester Swantje samt ihrer Familie danken. Ihr habt mich auf diesem oft sehr steinigen Weg mit viel Aufmerksamkeit begleitet. Eure Worte der Unterstützung haben mich getragen. Mama und Papa, ich danke euch für die vielen Möglichkeiten, die ihr mir schon in jungen Jahren gegeben habt.

Last, I'd like to thank Laura: Ohne dich hätte ich dies alles hier niemals geschafft. Dir ist es immer wieder gelungen, mich durch Ablenkung und viele Ruhephasen zu motivieren. Dass auch dich die letzten drei Jahre viel Kraft gekostet haben werde ich niemals vergessen. Zeit mit dir zu verbringen ist ein Geschenk, und ich bin glücklich, mit dir durchs Leben zu gehen.

Thank you | Bedankt | Danke | நன்றி.

Tilburg, January 2, 2014 



\section{Contents}

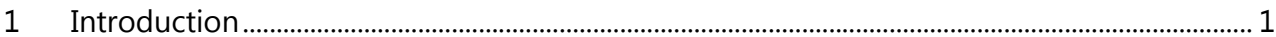

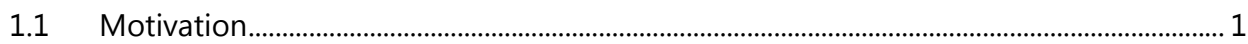

$1.2 \quad$ Theoretical and Practical Relevance ........................................................................................ 3

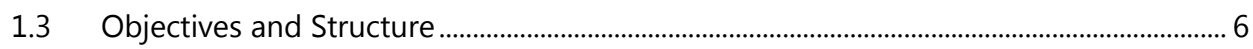

2 The Impact of Free-Trial Acquisition on Customer Usage, Retention,

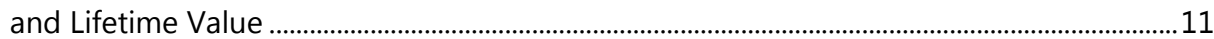

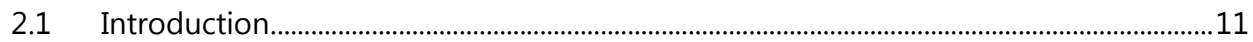

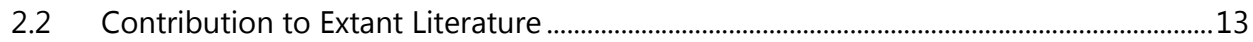

2.3 Conceptual Framework and Hypotheses .........................................................................18

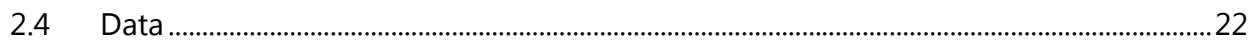

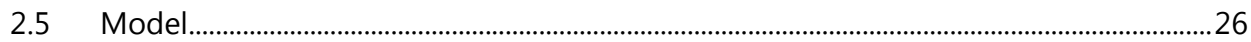

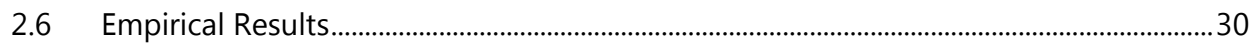

2.7 Implications for Customer Lifetime Value..................................................................................36

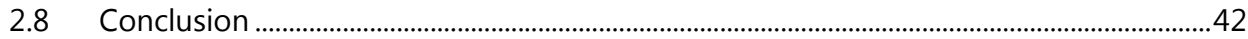

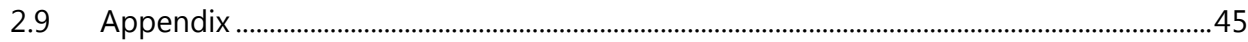


3 Usage Rates, Facebook Likes, and Online Piracy:

Using Big Data to Manage Entertainment Products . .47

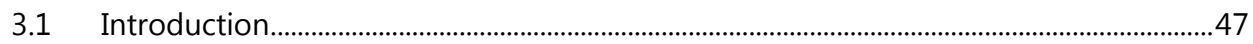

3.2 Contribution to the Literature …………..............................................................................49

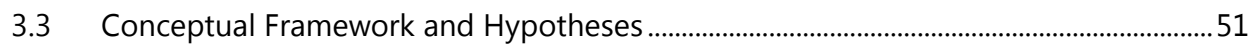

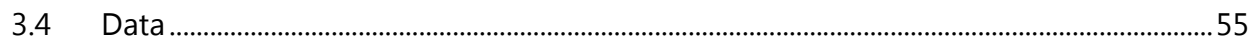

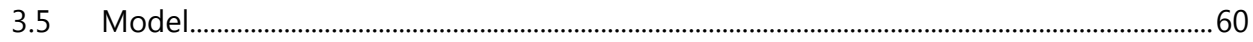

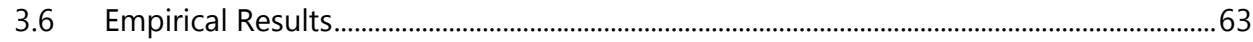

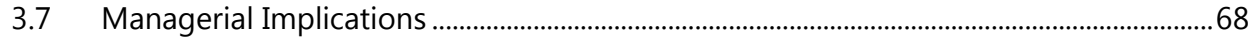

3.8 Discussion and Conclusion ....................................................................................................

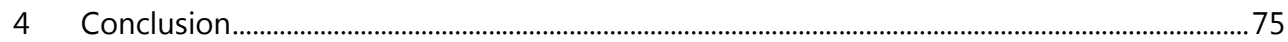

4.1 Contributions of this Research ................................................................................................. 75

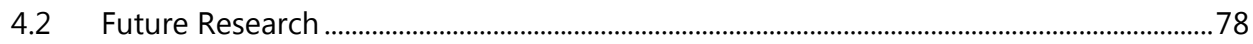

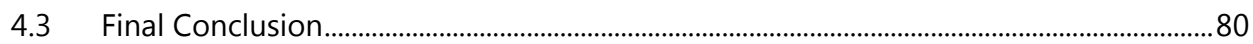

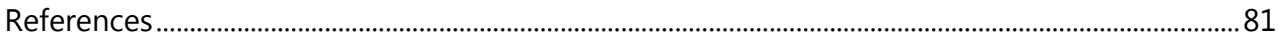

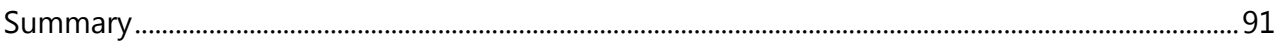




\section{List of Tables}

Table 1.1: Selected types of usage behaviors ....................................................................................... 2

Table 1.2: Differences and communalities between the studies ......................................................10

Table 2.1: Comparison of this paper with existing studies on the relationship between acquisition mode and customer behavior ....................................17

Table 2.2: Descriptive statistics for free-trial and regular customers................................................25

Table 2.3: Correlation matrix .....................................................................................................................25

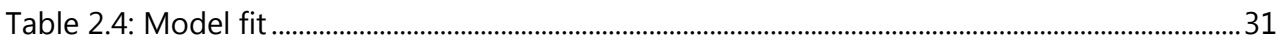

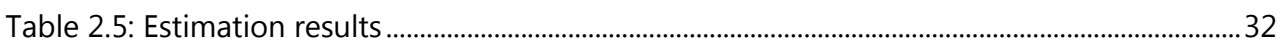

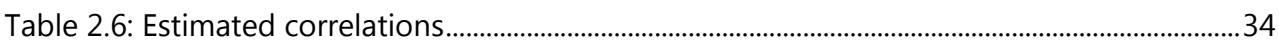

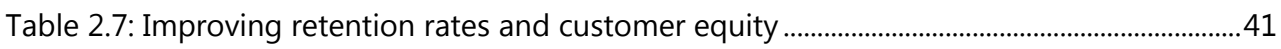

Table 3.1: Correlations among the dependent and independent variables.....................................58

Table 3.2: Data collection and descriptive statistics ..................................................................................59

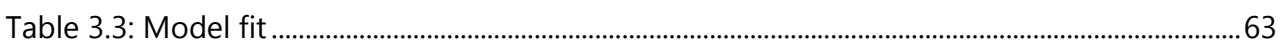

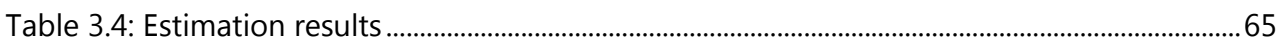

Table 3.5: Estimated correlations..........................................................................................................6 


\section{List of Figures}

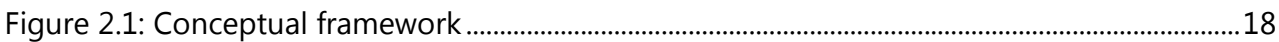

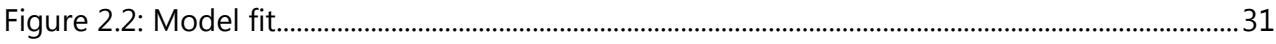

Figure 2.3: Survival distribution functions with customer heterogeneity...........................................38

Figure 2.4: Net customer lifetime value for free-trial and regular customers .................................38

Figure 2.5: Responsiveness to marketing communication ..................................................................... 39

Figure 2.6: Responsiveness to usage

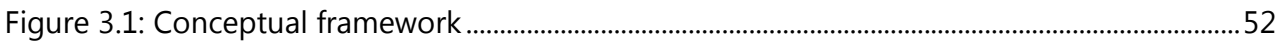

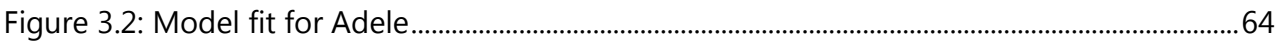

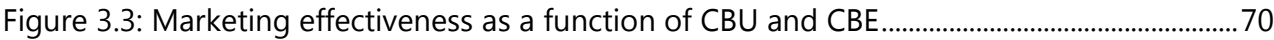

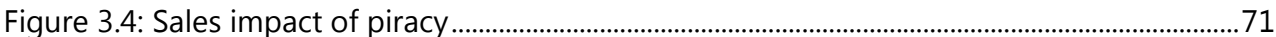




\section{Chapter 1}

\section{Introduction}

\subsection{Motivation}

Facilitated by the widespread adoption of online social networks and smart devices that accompany consumers through their daily lives, the past few years have seen an unprecedented growth in the availability of detailed consumer data. For example, $61 \%$ of European consumers leave behind digital traces of their online purchase trips, accumulating to hundreds of terabytes worth of information in companies' data centers (McKinsey 2013). Because of the data's volume (i.e., size), variability (i.e., different data types), and velocity (i.e., required speed of analysis), this data is frequently referred to as Big Data.

Indeed, Big Data looms at the top of most CEOs' agendas. A recent report reveals that $64 \%$ of organizations worldwide already invest or are planning to invest in big data technology by 2013 (Gartner 2013). Similarly, academics have followed suit by making big data a highpriority research topic (Aral et al. 2013; MSI 2012). Overall, the economic potential of analyzing big data is tremendous (McAfee and Brynjolfsson 2012). For example, a McKinsey survey suggests that across industries, big data analytics could unleash productivity and profit gains of 5-6\% (McKinsey 2013). For US retailers alone, productivity gains could amount to US\$30US\$55 billion per year (Lund et al. 2013). 
The economic significance of big data is largely fueled by the detailed insights it gives into consumers' usage behavior of products and services. While the additional value of usage data beyond purchase data is limited when these behaviors co-occur, usage potentially contains additional information in situations where products or services are used long after adoption. In this dissertation, we focus on the latter (see Table 1.1). For example, online streaming providers such as Spotify or Netflix track the songs and movies that consumers play, along with information on when, where, and on which device content was accessed. Based on this data, these companies can precisely target information on newly released music albums or movies to consumers who are interested in the content. Also, Netflix uses data on consumers' service usage to develop new TV shows that will predictably do well, thereby keeping users engaged with their content and building loyalty (Bulygo 2013). Similarly, digital TV providers track viewing patterns of customers, along with information on when, where, and how the service is accessed (e.g., at home on the TV screen, or on the go via a mobile device). If service usage unexpectedly drops, TV providers can prevent defection by personalized direct marketing interventions.

Table 1.1: Selected types of usage behaviors

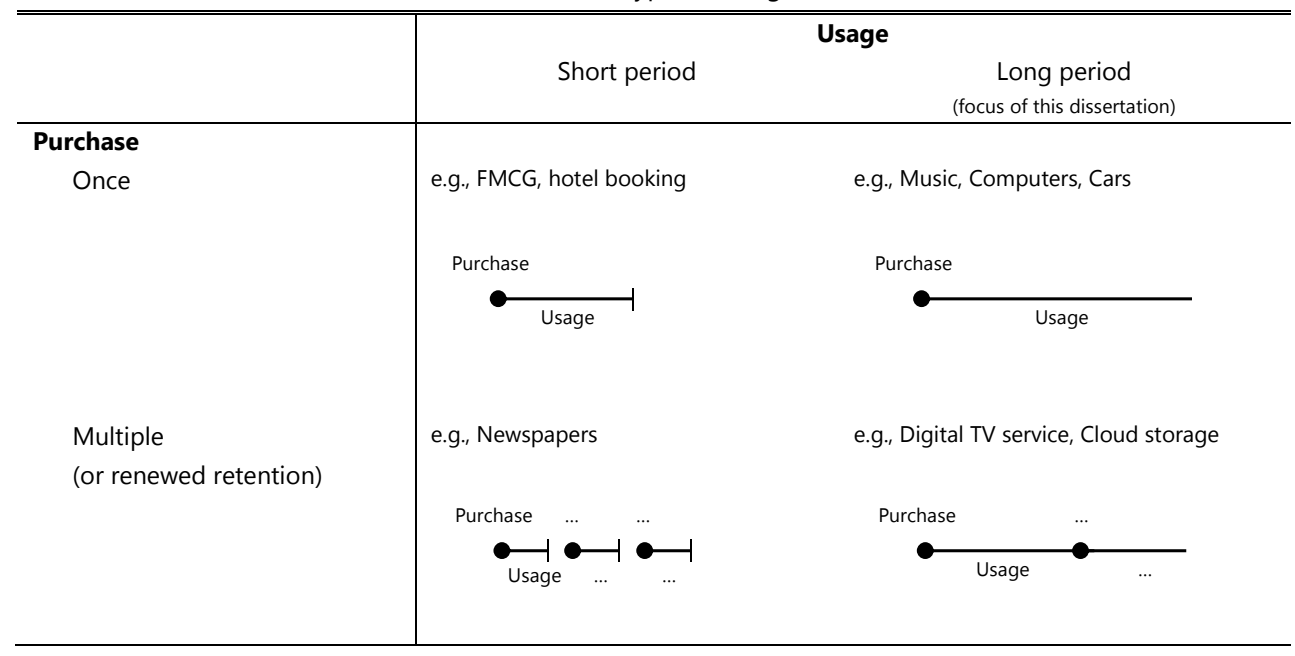

Millions of consumers around the globe are using online services or smart devices that monitor consumers' interactions with products and services. The digital traces of usage that consumers leave behind are a true treasure trove, which to find and dig out, likely will become a determinant of corporate success in the coming decade. Accordingly, researchers from many disciplines have started to explore this information source-ranging from computer scientists 
to deal with the technical obstacles of analyzing big usage data, to engineers who use consumers' usage data to optimize the performance of electronic grids ("smart grids").

Despite the widespread accessibility of consumers' usage data, e.g., via online social networks or smart devices, the knowledge about how marketers can utilize this data for decision-making is shockingly scarce. In fact, companies are only slowly starting to take advantage of big usage data. Accordingly, the central theme of this dissertation is to analyze consumers' usage data to improve managerial decisions.

\subsection{Theoretical and Practical Relevance}

\subsubsection{Usage drives business performance}

Consumers' usage behavior is relevant for business performance because it has direct and indirect revenue implications (e.g., Bolton and Lemon 1999; Lemon, White, and Winer 2002). In fact, many businesses charge consumers proportionally to their usage intensity. For example, digital TV providers bill customers according to the number of videos-on-demand they watch, thereby generating revenues beyond recurring subscription fees. In other situations, usage frequently determines the number of ad exposures and thus directly drives advertising revenue (Wilbur 2008). For example, music streaming provider Spotify subsidizes the "free" version of its service by exposing consumers to ads. The higher consumers' usage of the service (e.g., in terms of time spent listening to music), the more ads can be served and revenue be gained. Similarly, usage increasingly serves as a basis to distribute royalties. Due to advances in digital tracking technology, services like Spotify pay music artists relative to the number of song plays that accrue on their service. In other words, more and more businesses monetize users and usage instead of actually selling products (Blau 2013).

However, usage also indirectly drives revenue streams. For example, a company's active customer base can be a powerful signal to potential investors. Consider businesses whose largest asset is not a healthy balance sheet, but rather an engaged customer base (e.g., Twitter prior to its IPO). Likewise, several music artists have become popular through their (non-paying) YouTube fan base before moving into mainstream media and turning into a huge commercial success. 


\subsubsection{Studying usage is conceptually insightful}

From a conceptual point of view, studying usage behavior advances our understanding of consumption behavior. Studies initially investigated the consequences of consumers' usage behavior. Specifically, these studies consider situations in which consumers' usage patterns determine a product's or service's value-for-money (e.g., Ascarza and Hardie 2013; Lambrecht and Skiera 2006; Lemon, White, and Winer 2002). Research in this tradition has shown that higher usage levels increase perceived utility and customer retention for continuously provided services (e.g., Bolton and Lemon 1999; Danaher 2002; Lemon, White, and Winer 2002).

Another stream of research on the consequences of consumers' usage behavior conceptualizes usage as an opportunity for consumers to learn about the product or service used (e.g., Lakshmanan and Krishnan 2011). For example, consumers update their beliefs about the service's quality through usage, which informs their subsequent retention and choice decisions (Ghose and Han 2011; Goettler and Clay 2011; Iyengar, Ansari, and Gupta 2007). Similarly, other studies refer to consumption as the driver of quality learning in the context of fast-moving consumer goods (Erdem and Keane 1996; Osborne 2011; Szymanowski and Gijsbrechts 2012).

Surprisingly, the literature has devoted much less attention to the hedonic facets of usage behavior. However, theoretical work in this domain explicitly identifies usage as a way to evoke emotions and fantasies (Hirschman and Holbrook 1982; Holbrook and Hirschman 1982; Holt 1995). This work suggests that experiential consumption creates strong associations between consumers and products, and strengthens consumers' attachment via repeated usage and experiencing a wide range of (brand)-related emotions (Park et al. 2010). These associations and consumers' attachment, in turn, impact consumer behavior.

Much fewer studies shed light on the antecedents of consumers' usage behavior, despite the fact that usage drives firm revenue. Some research investigates the effects of customer satisfaction on usage (Bolton and Lemon 1999), interruptions in the adoption process (Lambrecht, Seim, and Tucker 2011), and adoption timing in the product life cycle (Prins, Verhoef, and Franses 2009). Other studies focus on factors that are in more direct control of a manager, such as price level and price structure (e.g., Ascarza, Lambrecht, and Vilcassim 2012; Danaher 2002; Lambrecht, Seim, and Skiera 2007).

Last, consumers' usage behavior could enhance or attenuate the sales effects of other variables (e.g., marketing activities). For example, intensive users may pay more attention to 
brand-related communication, making them more responsive to marketing messages and thereby increasing sales. Similarly, intensive users may build up expertise about a product or service, which may lead them to learn quicker from new information (Alba and Hutchinson 1987; Hutchinson and Eisenstein 2008; Johnson and Russo 1984). ${ }^{1}$ However, to the best of our knowledge, no study to date has investigated the moderating role of usage-despite companies' increasing efforts to improve the performance of their products and services.

\subsubsection{Studying usage is methodologically challenging}

Studying usage behavior involves a series of methodological steps, which offer researchers many opportunities to improve existing methods or develop new ones. At first, obtaining access to usage data is a challenging task. In general, this seems counterintuitive, because usage data is frequently publicly available on the internet, freeing the researcher from negotiating nondisclosure agreements with data providers (e.g., Mela 2011). However, the development of tailor-made scraping software to collect this information on a large scale can be demanding. For example, researchers have to deal with a wide range of problems: IP address blocking or frequent website updates may cause data collections to fail, which threatens the quality of continuous data collections. A method extremely valuable to researchers uses Application Protocol Interfaces (APIs), which give direct access to a company's databases through standardized and authenticated web requests. However, even in situations where data retrieval is straightforward, the researcher faces challenges, e.g., how to randomly sample users from a social network whose entire population is unknown (Ebbes, Huang, and Rangaswamy 2012).

Next, data storage and processing can be methodologically challenging because usage involves continuous behavior measured at high frequency (McAfee and Brynjolfsson 2012). Equally important, usage is a multifaceted concept that does not only entail how much, but also where, when, and how users consume. All these aspects may be tracked, but need to be stored and made retrievable through efficient database management systems. Processing large data sets is computationally intensive, and researchers usually split and distribute tasks across multiple computers. Reducing the sample size to only a few consumers is not an optimal

\footnotetext{
${ }^{1}$ For complex products and extreme levels of expertise, consumers could also become overconfident and therefore less receptive to new signals. However, while expertise can inhibit learning, consumers still remain interested in the product, keeping information - e.g., about new product introductions - highly relevant (Johnson and Russo 1984).
} 
solution. For example, the choice set of consumers listing to music is gigantic, such that thousands of customers are required to reach sufficient coverage among less popular artists. ${ }^{2}$

Last, analyzing usage data requires an understanding of computer clusters to cope with the computational burden of modern econometric methods. The time required to estimate a single model easily takes several thousands of computing hours, and hence also needs to be distributed to many computers. At the same time, statistical models need to deal with the same econometric difficulties as models estimated on smaller data sets. However, methods frequently applied to smaller data sets (e.g., bootstrapping to yield corrected standard errors) are simply not feasible due to the time required to re-estimate these models.

In sum, studying consumers' usage behavior can yield relevant business insights, offers room for conceptual contribution, and requires methodological rigor. The appeal of studying consumers' usage is also witnessed by the surging academic interest in this topic (e.g., Albuquerque and Nevskaya 2012; Ascarza and Hardie 2013).

\subsection{Objectives and Structure}

The objective of this dissertation is to examine the role of consumers' usage behavior in two contexts that are managerially relevant and have sparked recent academic interest. While each of the studies has its own objectives and contributions, their overarching goal lies in uncovering the pivotal role of usage in settings where consumers interact with products and services.

\subsubsection{Study 1: The Impact of Free-Trial Acquisition on Customer Usage, Retention, and Lifetime Value}

The first study investigates the effectiveness of acquiring new customers with free trials. Free-trial promotions are a very popular way to acquire new customers, especially for new services (e.g., digital TV, but also popular web-based services such as Dropbox or Netflix). While an emerging literature stream demonstrates that the conditions under which customers are acquired influence ensuing customer behavior (e.g., Reinartz, Thomas, and Kumar 2005; Schweidel, Fader, and Bradlow 2008), no study to date has systematically examined the implications of customer recruitment through free trials. For managers of these services,

\footnotetext{
${ }^{2}$ For example, the music rights management organization BMI alone represents 8.5 million songs that consumers could potentially choose from (BMI 2013).
} 
however, it is crucial to know whether customers acquired with free trials systematically differ from customers not attracted with free trials ("regular customers").

To address this gap, we analyze a customer's retention decision process and investigate how it is influenced by free-trial acquisition. Because many companies digitally monitor consumers' usage intensities, we are able to zoom in on how service usage drives consumers' retention decisions. Free-trial customers, for example, may not only churn quicker than regular customers, but may also use the service more or less intensively. Similarly, free-trial customers may weigh their own usage behavior differently when making retention decisions. A factor common to many services is that consumers can engage into different types of service usage (e.g., Bolton and Lemon 1999). We therefore distinguish between usage of a flat-rate component (e.g., watching TV) and usage of a pay-per-use component (e.g., watching videoon-demand). While both types of usage behavior drive retention, usage of the pay-per-use component, in addition, directly generates revenue.

Based upon panel data from a large European digital TV provider for 16,500 customers, we find that free-trial customers churn earlier and make less use of the flat-rate component of the service. However, while the resulting lifetime value of free-trial customers is lower compared to regular customers, free-trial customers are more responsive to marketing activities, care more about their own usage behavior, and make more intense use of the payper-use service. Our results clearly demonstrate the value-generating role of customers' usage behavior, and offer managers opportunities to improve retention rates and customer lifetime value through targeting efforts.

\subsubsection{Study 2: Usage Rates, Facebook Likes, and Online Piracy: Using Big Data to Manage Entertainment Products}

The second study deals with the rapidly progressing digitization of the entertainment goods industry (e.g., music albums, home videos, or computer games). The resulting decline in marketing effectiveness (e.g., Sethuraman, Tellis, and Briesch 2011) and the rapid emergence of online piracy posit a considerable challenge and continue to be a heavy burden to the profitability of many entertainment products (Danaher et al. 2013). At the same time, digitization offers new opportunities. For example, consumers increasingly leave behind digital traces that show how they engage with brands after purchase-information that is potentially 
valuable to improve managerial decision-making (e.g., Van Doorn et al. 2010; Verhoef, Reinartz, and Krafft 2010).

In this study, we show how insights into brand usage can improve marketing effectiveness and curb the negative sales effects of online piracy. Because of the prevalence of online brand endorsement via Facebook Likes, the study also systematically compares the sales performance implications of brand usage (i.e., usage rates) with those of consumers' brand endorsement (i.e., Facebook Likes). Brand usage and brand endorsement both reflect engagement levels among existing customers, and hence may influence the effectiveness of marketing investments. For example, if brands have high usage or endorsement levels, the sales effect of new product releases or promotions may be enhanced. In addition, managers of entertainment goods keep wondering whether pirated goods only cannibalize legal sales or also trigger a sampling effect that leads to new sales, thereby (partially) offsetting losses (Gopal, Bhattacharjee, and Sanders 2006). By jointly investigating the impact of piracy on sales, brand usage and brand endorsement, we shed light on this crucial question. Finally, because brand usage and brand endorsement are vital business metrics with strong revenue implications, we investigate how they are influenced by marketing activities (e.g., new product launches, promotion).

We develop a conceptual framework and calibrate our model on a large data set from the U.S. music industry. Specifically, we program web scrapers to track brand sales, and consumers' corresponding usage, endorsement, and piracy levels for 569 music artists over a period of 66 weeks. Our results show that brand usage enhances the sales impact of marketing activities, and positively mediates the impact of piracy. Simulations reveal that the immediate negative impact of piracy on sales is reduced by about 55\% when taking into account piracy's indirect effect on usage and endorsement. The negative effect of piracy can be reduced even more when increasing the intensity of marketing activities (e.g., promotion). Interestingly, the role of brand usage is consistently more important than the role of brand endorsement, which lends further credence to the notion that usage plays a pivotal role in the management of entertainment products. 


\subsubsection{Summary}

While the two studies described above differ greatly in terms of data and research methodology, both carefully attend to the various roles that consumers' usage behavior takes on in these settings. Specifically, study 1 demonstrates the role of usage as a driver of retention, and distinguishes between two types of usage: flat-rate usage and pay-per-use usage. In addition, the study allows for differences in the retention process depending on how a customer was acquired (i.e., free-trial acquisition, or not). The study also investigates the antecedents of usage behavior, and identifies free-trial acquisition to permanently influence usage levels. Last, the study shows that usage mediates the impact between free-trial acquisition and retention. For example, free-trial customers, on average, churn earlier. However, higher usage of the paid service component partly mitigates their lower value.

Compared to the role of consumers' usage behavior in study 1, study 2 additionally investigates whether usage moderates the sales impact of marketing activities. As we show, companies can use digitally tracked usage behavior to enhance the effectiveness of these marketing activities (e.g., promotion, new product releases). To the best of our knowledge, we are the first to empirically show the moderating role of usage. Further, we demonstrate how usage compares to other popular metrics that have recently become available through online social networks and smart devices (e.g., Facebook Likes).

Table 1.2 summarizes the differences and communalities between the two studies. In what follows, chapters 2 and 3 correspond to the studies described above. Chapter 4 concludes this dissertation with an integrative view on the studies' main contributions and directions for further research. 
Table 1.2: Differences and communalities between the studies

\begin{tabular}{|c|c|c|}
\hline & $\begin{array}{l}\text { Study 1: } \\
\text { "The Impact of Free-Trial } \\
\text { Acquisition on Customer Usage, } \\
\text { Retention, and Lifetime Value" }\end{array}$ & $\begin{array}{l}\text { Study 2: } \\
\text { "Usage Rates, Facebook Likes, } \\
\text { and Online Piracy: Using Big } \\
\text { Data to Manage Entertainment } \\
\text { Products" }\end{array}$ \\
\hline Objective & $\begin{array}{l}\text { Investigate service usage and } \\
\text { retention behavior, and the } \\
\text { resulting value implications for } \\
\text { customers acquired with free } \\
\text { trials, compared to customers not } \\
\text { acquired with free trials. }\end{array}$ & $\begin{array}{l}\text { Compare consumers' usage rates } \\
\text { (brand usage) to Facebook Likes } \\
\text { (brand endorsement), and } \\
\text { investigate their impact on sales } \\
\text { and marketing effectiveness, and } \\
\text { their role as mediators in the } \\
\text { relationship between piracy and } \\
\text { sales. }\end{array}$ \\
\hline \multicolumn{3}{|l|}{ Conceptual relevance of usage } \\
\hline Usage as a driver of sales & $\checkmark$ & $\checkmark$ \\
\hline Antecedents of usage & $\checkmark$ & $\checkmark$ \\
\hline Usage as a mediator & $\checkmark$ & $\checkmark$ \\
\hline Usage as a moderator & & $\checkmark$ \\
\hline $\begin{array}{l}\text { Benchmarking usage } \\
\text { against other metrics }\end{array}$ & & $\checkmark$ \\
\hline \multicolumn{3}{|l|}{ Data and methodology } \\
\hline Setting & Digital TV provider from Europe & $\begin{array}{l}\text { Entertainment goods (music) in } \\
\text { the United States }\end{array}$ \\
\hline Data collection & Proprietary & $\begin{array}{l}\text { Public from various online } \\
\text { databases and websites }\end{array}$ \\
\hline $\begin{array}{l}\text { Unit of analysis and } \\
\text { sample composition }\end{array}$ & $\begin{array}{l}\text { Individual-level } \\
\text { (16,500 customers) }\end{array}$ & $\begin{array}{l}\text { Aggregated ( } 569 \text { music artists and } \\
\text { the corresponding usage behavior } \\
\text { of } 9,000 \text { U.S.-based consumers) }\end{array}$ \\
\hline Measurement of usage & $\begin{array}{l}\text { Flat-rate service usage (number of } \\
\text { TV channel zaps); Pay-per-use } \\
\text { service usage (number of videos- } \\
\text { on-demand) }\end{array}$ & $\begin{array}{l}\text { Consumer Brand usage ( } \mathrm{CBU} \text {; } \\
\text { number of song plays for an artist) }\end{array}$ \\
\hline
\end{tabular}




\section{Chapter 2}

\section{The Impact of Free-Trial Acquisition on Customer Usage, Retention, and Lifetime Value*}

\subsection{Introduction}

A very popular way to acquire new customers, especially among service providers, is to offer free-trial promotions. Customers on a free trial are allowed to try the service for a limited amount of time at no charge. Well-known examples are the free trials offered by mobile telephone operators (e.g., AT\&T in the U.S.), video streaming websites (e.g., Hulu Plus in the U.S.), and digital TV providers (e.g., Sky television in Australia and New Zealand). While these free trials may be popular with consumers, a key question for a firm reviewing its customer base is whether customers attracted with free trials are systematically different from other customers. For example, free-trial acquisition may affect customer's attitude towards the service (provider) and, as a consequence, influence usage and retention behavior and customer lifetime value (CLV).

\footnotetext{
* The article presented in this chapter is based on Hannes Datta, Bram Foubert, and Harald J. van Heerde (2013), "The Impact of Free-Trial Acquisition on Customer Usage, Retention, and Lifetime Value." Preliminary work for this article was carried out for the first author's Master thesis at Maastricht University. The authors acknowledge Charlotte Rolef for her involvement in collecting the data used in this study. The authors also gratefully acknowledge Sungho Park, and wish to thank Johannes Boegershausen, Marnik Dekimpe, Kelly Geyskens, Caroline Goukens, Anne Klesse, and Arjen van Lin for helpful comments on an earlier draft. This work was carried out on the Dutch national einfrastructure with the support of the SURF Foundation.
} 
An emerging literature stream has demonstrated that the conditions under which customers are acquired influence ensuing customer behavior (e.g., Reinartz, Thomas, and Kumar 2005; Schweidel, Fader, and Bradlow 2008). For example, studies have documented the role of the acquisition channel (e.g., Gensler, Leeflang, and Skiera 2012) and acquisition through referral (e.g., Villanueva, Yoo, and Hanssens 2008). However, no study to date has systematically examined the implications of customer recruitment through free trials.

To address this gap, we analyze a customer's retention decision process and investigate how it is influenced by free-trial acquisition. Based on principles from social psychology and buyer-seller relationship theory, we develop hypotheses on how free-trial acquisition affects this process. Specifically, we focus on how usage of the service drives the retention decisions of free-trial and regular customers. Usage is a crucial element in the decision process because it enables customers to value the service and decide whether to retain it (e.g., Bolton and Lemon 1999). However, free-trial customers may differ from regular customers in the extent to which usage informs them about the value of the service.

In many settings, a service involves different types of usage behaviors. For example, consumers may use the flat-rate service (e.g., a regular TV subscription) and the pay-per-use service (e.g., video-on-demand). While both types of usage enhance the likelihood a customer remains subscribed, pay-per-use services are a direct source of revenues (e.g., Danaher 2002; Iyengar et al., 2011), and hence a direct source of customer lifetime value. Therefore, we not only study how the usage of flat-rate and pay-per-use services drive retention decisions for free-trial and regular customers, but also analyze these usage levels as dependent variables.

Another important question is whether free-trial customers differ from regular customers in how they respond to marketing communication efforts. We therefore also develop and test hypotheses on the moderating role of free-trial acquisition on the effect of marketing communication on retention. If free-trial and regular customers differ in terms of their marketing responsiveness, firms may decide to target retention efforts to the most receptive group to reduce churn. Despite the growing interest in customer relationship management (e.g., Reinartz, Thomas, and Kumar 2005; Schweidel, Fader, and Bradlow 2008), the impact of acquisition mode on customers' response to the firm's subsequent retention activities has remained unaddressed. 
To test the hypotheses, we build econometric models for the usage of the flat-rate service, the pay-per-use service, and the retention decision, allowing for unobserved heterogeneity, self-selection effects, and the endogeneity of marketing instruments. On the basis of consumer panel data from a large European digital TV provider for more than 16,500 customers, we find that free-trial customers have lower retention rates and use the firm's flatrate service less intensively than regular customers. As a result, the Net CLV (revenue - costs) of free-trial customers is, on average, 55\% lower than that of regular customers. However, freetrial customers are much more responsive to marketing communication, and are more likely to rely on their usage behavior when deciding whether or not to retain the service. These findings offer managers opportunities to improve retention rates and customer lifetime value through targeting efforts.

In what follows, we first explain how our study contributes to the existing literature and then introduce our conceptual framework and hypotheses. Subsequently, we describe our data and develop our model. We then present our estimation results and calculate their implications for customer lifetime value. Finally, we discuss the academic and managerial implications of our work, and point out limitations and future research directions.

\subsection{Contribution to Extant Literature}

An emerging body of research has shown that the conditions under which customers are acquired have implications for subsequent consumer behavior (e.g., Garrett and Gopalakrishna 2010; Reinartz, Thomas, and Kumar 2005; Schweidel, Fader, and Bradlow 2008). A first stream of studies documents the role of the sales channel through which customers have been attracted. For example, Verhoef and Donkers (2005) find that acquisition through direct mail or direct-response commercials leads to lower retention probabilities than acquisition through the Internet. The relative efficacy of the Internet channel has also been illustrated by other studies, showing that it yields customers with greater loyalty (Shankar, Smith, and Rangaswamy 2003), higher transaction amounts (Steffes, Murthi, and Rao 2011), and more frequent transactions (Gensler, Leeflang, and Skiera 2012).

A second set of papers addresses the impact of customer referral. Villanueva, Yoo, and Hanssens (2008) find that customers acquired through word-of-mouth (WOM) referral stay longer with the firm and generate more future referrals than other customers. The difference in retention between WOM-referred and other customers persists even when WOM is the 
result of a firm-initiated referral program (Schmitt, Skiera, and Van den Bulte 2011). Finally, Chan, Wu, and Xie (2011) demonstrate that customers referred from Google search advertising have greater retention and transaction rates than other customers.

A third stream of research has examined the effects of the pricing structure under which customers were acquired. Iyengar et al. (2011) find that customers of a telecommunication company who were acquired under a two-part tariff structure have lower usage and retention rates than customers charged on a pay-per-use basis. Lewis (2006) shows that acquisition discounts lead to lower retention rates, while Anderson and Simester (2004) indicate that promotionally acquired customers choose cheaper products but buy more.

Our work fits in this last stream and contributes in three ways. First, while previous work has examined the impact of promotional customer acquisition on subsequent behavior, the effects of free-trial promotion have remained largely unaddressed. However, a free trial involves a distinct type of sales promotion which enables consumers to start using a service without a financial commitment and to revise their initial adoption decision if they are not satisfied (Rogers and Shoemaker 1971). Research has shown that consumers who receive the opportunity to reconsider an earlier decision may become more uncertain and pay more attention to potential drawbacks of the decision outcome (e.g., Gilbert and Ebert 2002; Lowe and Steiner 1968). As a result, we will argue that customers that are attracted with a free trial may behave differently from regular customers.

Although some research has attended to the effects of free trials and sampling, most of the studies investigate the impact on aggregate sales (e.g., Heiman et al. 2001; Jain, Mahajan, and Muller 1995; Kannan, Pope, and Jain 2009; Lammers 1991; Pauwels and Weiss 2008) or focus on immediate purchase effects (e.g., Heilman, Lakishyk, and Radas 2011; Scott 1976). The two studies that do consider cross-time customer behavior after trial still do not shed full light on the consequences of customer acquisition with free trials. Gedenk and Neslin (1999) conclude that sampling in the mineral water category reinforces brand choice probabilities, during as well as after the promotion period, but the authors do not study customer retention, as this is not a relevant concept in a fast-moving consumer goods setting. Research by Bawa and Shoemaker (2004), in turn, shows that free samples attract new buyers who may remain customers in subsequent periods. Yet, it is unclear whether the retention rates of customers attracted with a sample differ from those of regular customers. 
Our second contribution addresses the lack of insights on the role of usage behavior. In fact, Iyengar et al. (2011), in their research on the effects of different pricing regimes, are the only ones to include service usage; the few articles on the consequences of promotional acquisition ignore usage altogether. However, usage may fulfill a crucial role in the customer value generation process. Specifically, usage intensity can be an important driver of retention because it indicates to consumers the personal value of the service (e.g., Bolton and Lemon 1999; Bolton, Lemon, and Verhoef 2004; Prins, Verhoef, and Franses 2009). Hence, we examine how free-trial acquisition influences the relationship between usage and retention. For example, if this relationship turns out to be particularly strong for customers acquired via free trial, it is in the firm's interest to encourage usage especially among these customers. In addition, we consider the revenue-generating role of usage. In particular, while flat-rate usage is covered by a fixed (e.g., monthly) fee, pay-per-use services generate extra revenue because they are charged on a per-unit basis.

Third, although the interrelationships between acquisition and retention have been the focus of several studies, a crucial question that has remained unexplored is whether acquisition mode affects customers' responsiveness to the firm's marketing communication efforts. Therefore, we evaluate the differences in marketing response between free-trial and regular customers. Specifically, we consider customers' reaction to direct marketing and traditional advertising because of the growing interest in marketing communication as a way to actively manage customers' value. For example, Reinartz and Kumar (2003) and Reinartz, Thomas, and Kumar (2005) observe that direct marketing increases a customer's lifetime. Furthermore, Polo, Sese, and Verhoef (2011) find a positive effect of mass advertising on retention. Understanding how free-trial and regular customers differ in terms of response to direct marketing and advertising enables firms to improve their communication mix.

To achieve these contributions, we develop econometric models for usage and retention that account for selection effects. Indeed, consumers who are attracted by a free trial may be intrinsically different from those who accept the regular offer. For example, free trials may attract customers who hold lower valuations for the service (Lewis 2006; Neslin and Shoemaker 1989) or customers who primarily want to learn. However, because we are interested in the free trial's treatment effects on customer behavior, we need to correct for these selection effects (e.g., Gensler, Leeflang, and Skiera, 2012; Steffes, Murthi, and Rao, 2011). In theory, one could also avoid selection bias by randomly distributing customers across 
acquisition conditions. However, this is not feasible in most cases, as one cannot force a consumer to accept a (non)promotional offer. Instead, we use a selection model for whether or not a customer has been acquired via a free trial.

In sum, we investigate whether, after controlling for selection effects, free-trial acquisition (1) influences retention behavior and CLV, and (2) moderates how retention is driven by service usage (flat-rate and pay-per-use) and marketing communication. Table 2.1 pits our paper against the available studies on the impact of acquisition mode on customer behavior. 


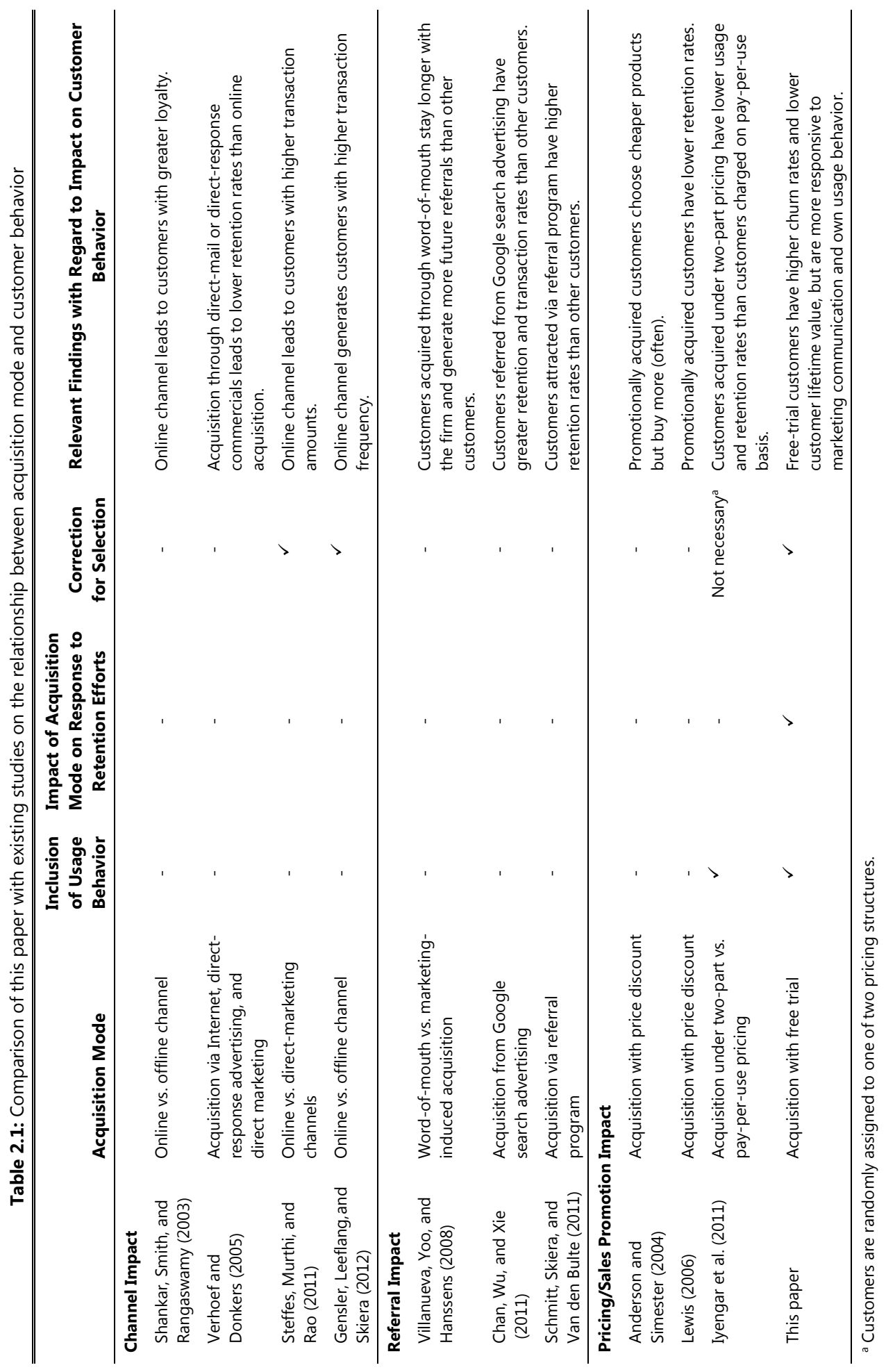




\subsection{Conceptual Framework and Hypotheses}

Figure 2.1 presents the conceptual framework for our research. The core, shown in thin lines, involves a customer's usage and retention decisions. We first describe this decision process and then develop hypotheses with regard to the influence of the acquisition mode, i.e., free-trial versus regular acquisition.

Figure 2.1: Conceptual framework

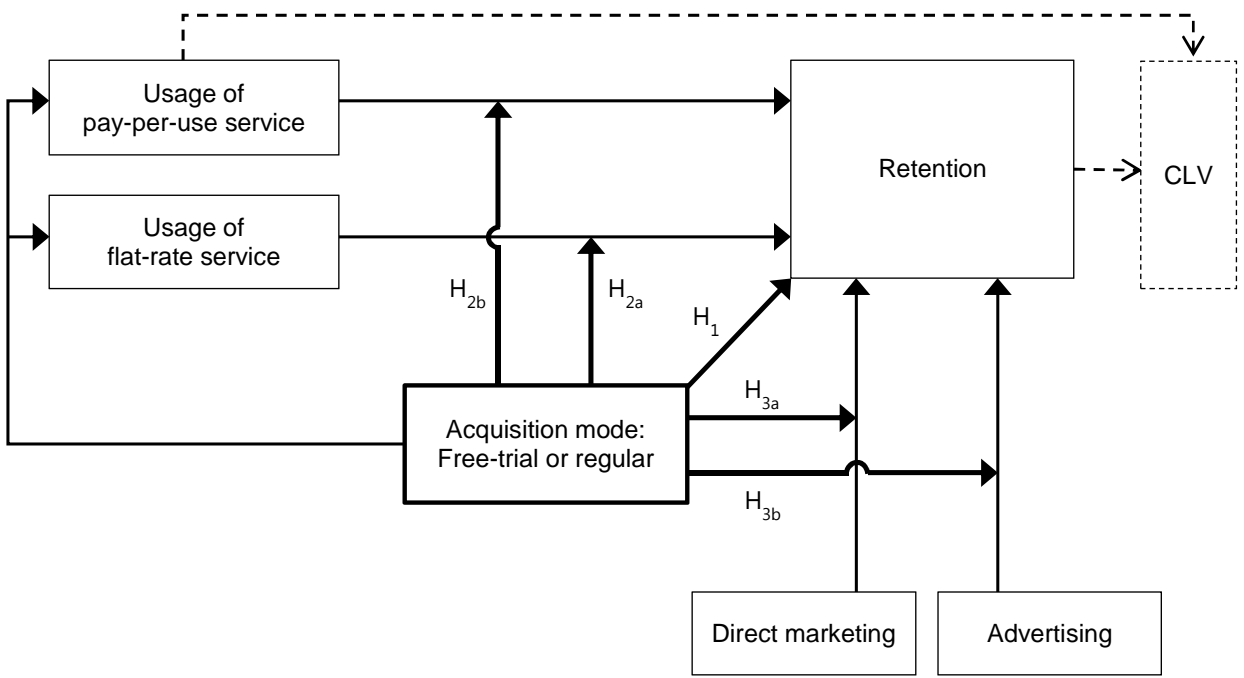

\subsubsection{Core Decision Process}

The core decision process involves two types of periodic (e.g., monthly) decisions. Every period, consumers decide how intensively they use the service and whether they retain the service or not. The key drivers for the retention decision are consumers' usage levels and the company's marketing communication mix.

Service usage. Following Bolton and Lemon (1999), we identify two types of service usage that are common for subscription services: (1) usage of a flat-rate service, which is included in the subscription charges, and (2) usage of a pay-per-use service, for which consumers pay per unit of consumption. Including both types of usage is important because they fulfill different roles in the value generation process. While both may foster retention, consumption of the pay-per-use service, in addition, directly generates revenue. 
Service retention. In every period, consumers decide whether to retain the service or not. Consistent with past research, we distinguish between two sets of drivers for this retention decision. First, consumers rely on their usage intensity for the flat-rate and pay-per-use component to assess the utility of retaining the service (Bolton and Lemon 1999). As a result, a high usage intensity will stimulate retention, whereas a low usage rate may lead to disadoption (Lemon, White, and Winer 2002). While usage should generally have a positive impact on retention, we allow the two types of usage to have a differential effect. Compared to usage of the pay-per-use service, flat-rate usage is likely more consequential for customers' evaluation of the service subscription, because it is included in the fixed periodical fee (Bolton and Lemon, 1999).

Second, a consumer's retention decision is also influenced by marketing communication (e.g., Blattberg, Malthouse, and Neslin 2009). Specifically, direct marketing and advertising remind customers of the benefits of using the service or directly persuade them to retain it (Polo, Sese, and Verhoef 2011; Reinartz and Kumar 2003).

If consumers retain the service, they go through the same decision process in the following period. As indicated by the dashed lines, this repeated decision process drives customer lifetime value (CLV). In particular, the periodic retention decisions generate a stream of fixed subscription fees (which cover flat-rate usage) while usage of the pay-per-use service generates additional revenue for the firm.

\subsubsection{Differences between Free-Trial and Regular Customers}

Central to our study is the expectation that the decision process to use and retain the service differs between free-trial and regular customers. In Figure 2.1, this is represented by the thick lines originating from the acquisition-mode box. Our discussion focuses on the differences that are due to the effect of the acquisition mode.

For the development of our hypotheses, we draw from three theories. Importantly, these theories suggests that the effect of free-trial acquisition persists, even when the free trial period is over. First, we rely on principles of the psychological immune system. Similar to the biological immune system which fights diseases, consumers have a psychological immune system that protects them from any negative emotional consequences of suboptimal decisions (Gilbert and Ebert 2002). The psychological immune system makes a customer feel good, for example, about the decision to purchase a product or service (Gilbert and Ebert 2002; Gilbert 
et al. 1998; Vaillant 1993). However, in circumstances in which consumers receive the explicit opportunity to revise their decision, such as in a free-trial promotion, the psychological immune system is inhibited. That is, when consumers know an outcome is changeable, they tend to be more uncertain and pay more attention to the outcome's shortcomings than consumers who cannot revise their decision (Frey 1981; Frey and Rosch 1984; Gilbert and Ebert 2002; Lowe and Steiner 1968). This tendency persists also beyond the evaluation period (Gilbert and Ebert 2002; Gilbert et al. 1998): as Gilbert and Ebert (2002, pp. 504-505) put it, "even if the buyer does keep [the product], all of the critical thinking he or she did during the protracted evaluation period may leave him or her with the unshakable feeling that the [product's] good points just barely outweighed its bad, thus spoiling the fun forevermore."

Second, we also draw on buyer-seller relationship theory which posits that the strength of a customer franchise hinges on the nature of the relationship between customer and firm (Dwyer, Schurr, and Oh 1987; Johnson and Selnes 2004). Whereas subscription to a free trial resembles a discrete transaction which increases a consumer's awareness of the firm and facilitates relationship exploration, the anticipated longevity of a regular contract encourages customers to immediately expand the relationship and commit to the firm (Dwyer, Schurr, and Oh 1987). In other words, a free trial slows down the relationship formation process (Palmatier et al. 2013). As a result, the firm's relationship with free-trial customers may remain more fragile than that with regular customers.

Third, we build on attribution theory (Heider 1958). According to the self-perception principle of attribution theory, consumers try to give ex-post explanations for their own (purchase) behavior (e.g., Dhar and Wertenbroch 2012; Khan and Dhar 2006). Compared to regular customers, free-trial customers are more likely to attribute their subscription decision to external factors-in particular, the trial's zero price-and downplay the role of the service's intrinsic characteristics (Raghubir 2004). As a consequence, free-trial customers may question the service's quality and doubt its benefits. We now explain how these mechanisms influence the decision processes of free-trial and regular customers.

Baseline retention. On the basis of the principles discussed above, we expect free-trial customers to churn sooner than regular customers. Relative to regular customers, who subscribe to the service for a longer period, free-trial customers are less prone to the reassuring effects of the psychological immune system and may therefore remain insecure about their adoption decision, also after the free-trial period. Furthermore, their relationship development 
process may be delayed such that they may show a weaker commitment to the firm than regular customers. Finally, due to external attribution of their subscription decision, free-trial customers may have less trust in the service's intrinsic quality. Thus, we hypothesize that, even after the free-trial period has expired:

$\mathrm{H}_{1} \quad$ Free-trial customers have a lower retention rate than regular customers.

Impact of usage on retention. Because the psychological immune system of free-trial customers is inhibited, it provides little intrinsic justification and leaves them uncertain about whether or not to retain the service (Gilbert and Ebert 2002). Similarly, since free-trial customers are arguably in an earlier relationship stage than regular customers, they may be less sure about their level of commitment to the firm (Dwyer, Schurr, and Oh 1987). One major factor that informs consumers about the personal value of the service and thus helps to resolve their uncertainty is their own usage behavior (e.g., Bolton and Lemon 1999). A customer may wonder: Do I use the service enough to stay subscribed? We expect that, to overcome this uncertainty, free-trial customers are more inclined than regular customers to rely on their flat-rate and payper-use consumption:

$\mathrm{H}_{2 a} \quad$ The impact of usage of a flat-rate service on retention is greater for free-trial customers than for regular customers.

$\mathrm{H}_{2 \mathrm{~b}} \quad$ The impact of usage of a pay-per-use service on retention is greater for freetrial customers than for regular customers.

Impact of marketing communication on retention. In a similar vein, we argue that the firm's marketing communication, in the form of direct marketing and advertising, will be more informative to free-trial than to regular customers. Marketing communication provides freetrial customers with information that can compensate for their relatively high uncertainty (Mitchell and Olson 1981). Regular customers, in contrast, do not need to rely as much on these cues because the psychological immune system has increased their confidence about service adoption. In addition, regular customers' relationship with and commitment to the firm is likely stronger such that they are less susceptible to "outside" information. As a result, we expect that free-trial customers are more responsive to the firm's direct-marketing and advertising efforts:

$\mathrm{H}_{3 a} \quad$ The impact of direct marketing on retention is greater for free-trial customers than for regular customers.

$\mathrm{H}_{3 \mathrm{~b}} \quad$ The impact of advertising on retention is greater for free-trial customers than for regular customers. 
Baseline usage. Free-trial acquisition may also affect customers' usage intensity. On the one hand, free-trial customers may have a lower usage rate than regular customers because they are uncertain about their adoption decision, are less committed to the service, or doubt the service's quality. This mainly holds true for the flat-rate service, because consumers can try it out for free. On the other hand, free-trial customers may seek to promote comfort with their adoption decision and enhance the experienced service value (Gilbert and Ebert 2002; Gilbert et al. 1998) by using the flat-rate service more frequently (Bolton and Lemon 1999). In any case, the above (opposing) principles do not allow us to develop unidirectional expectations with regard to the impact of free-trial acquisition on usage of the flat-rate and pay-per-use services. We therefore leave this as an empirical question.

\subsection{Data}

\subsubsection{Study Context}

We test our hypotheses on the basis of a data set from a large European interactive TV (iTV) provider. iTV is a technology that enables customers to interact with their TV, for example, by browsing an electronic program guide or watching video-on-demand (VOD). Furthermore, iTV offers enhanced image quality over regular TV. To make use of the iTV service, customers need a broadband Internet connection from the same company and a set-top box which decodes the digital signal. Under regular (i.e., nonpromotional) conditions, customers formally commit to a 12-month subscription period. Nonetheless, they have the possibility to cancel the service earlier, in which case they pay a penalty ( $€ 50$, plus $€ 6$ for every remaining month until the end of the contractual period). After the first twelve months, the contract is automatically renewed but can be terminated on a monthly basis, without penalty. Customers are charged a one-time setup fee for hardware and activation (on average €16.24) and pay for service usage according to a two-part tariff structure (e.g., Ascarza, Lambrecht, and Vilcassim 2012; Iyengar et al. 2011). Specifically, the fixed monthly subscription fee of $€ 15.95$ covers unlimited usage of the basic iTV service (€9.95) and rent of the set-top box (€6). Additionally, customers can make use of a video-on-demand service, for which they are charged on a pay-per-use basis. They can select VODs from an electronic catalogue containing movies, live concerts, and soccer games. VOD rental for 24 hours costs around $€ 3$, with some limited variation in price due to differences in genre and length. 
The company's acquisition strategy offers a unique setting to study the impact of free-trial acquisition. For a period of 10 months (months 10 till 19 after the launch of the service), the company offered free trials parallel to its regular subscriptions. Adoption of the free trial (as opposed to the regular subscription) is largely driven by the consumer's awareness of the ongoing free-trial promotion, which was promoted via direct marketing. Moreover, the company's staff was encouraged to offer free trials to consumers who were doubtful of adopting the service while directly communicating with the firm over phone. Since not every new customer was aware of the free trial promotion or pushed for one, many ended up signing a regular contract.

Customers acquired with a free trial did not pay setup costs and were not charged monthly subscription fees for the usage of the flat-rate service during the three-month trial period. VOD usage, however, was not free of charge. Free-trial customers could revise their adoption decision by returning the set-top box to one of the company stores before the end of the trial period, without paying a penalty. If the product was not returned by the end of the free-trial period, the subscription was converted into a regular paid one.

\subsubsection{Data set}

From our initial sample of close to 21,000 customers who adopted the iTV service during the period in which both the free trial and regular subscription were available, we select a subset on the basis of several criteria. Specifically, we eliminate customers who had missing sociodemographics, were employees of the focal company, or did not speak the local language (and thus could not understand the advertising and direct marketing messages). We retain 16,512 customers of which 12,612 (76\%) were acquired with free trials, and 3,900 (24\%) with regular subscriptions. We observe their usage and retention behavior during the two years after launch of the service.

Our data set includes customers' monthly retention decisions. 6,079 (48\%) of the freetrial customers churn before the end of our observation period, while of the regular customers only 1,327 (34\%) do so. Further, we observe two types of usage: (1) flat-rate usage of the basic 
interactive TV service, which is measured by a customer's monthly number of channel zaps, ${ }^{3}$ and (2) usage of the VOD service, for which we use the monthly number of VODs the customer has watched. On average, customers zap 175 times and watch .69 on-demand videos per month. Compared to regular customers, free-trial customers have an average usage intensity that is $11 \%$ lower for the flat-rate service (169 versus 189 zaps per month), but $26 \%$ higher for the video-on-demand service (.73 versus .58 VODs per month). Usage at the beginning of a customer's tenure is, on average, lower than in the remaining months for both customer groups. However, these retention and usage measures are only indicative, because they do not account for selection effects or the impact of marketing activities.

The company uses two types of marketing communication: direct marketing and mass advertising. We operationalize direct marketing as the monthly number of direct-marketing contacts with a given customer (via phone, e-mail, or regular mail). On average, free-trial and regular customers are contacted .34 and .16 times per month, respectively. In addition, our data set includes a measure for the company's spending on mass advertising (via TV, printed media, radio, and the Internet). In particular, this variable quantifies the focal company's advertising spending for a given region in a given month, relative to the total advertising spending of the focal company and its main competitor for the same region and month. This share-of-voice advertising measure varies between 0 and 1 , and the average is .75. There is a small difference in the means for free-trial and regular customers (.74 and .79 , respectively). Table 2.2 lists summary statistics of the variables in the data set, for free-trial as well as regular customers, while Table 2.3 reports the correlations among our independent variables. We give more details on the control and socio-demographic variables when we discuss the model.

\footnotetext{
${ }^{3}$ By using monthly zaps, we are able to measure a customer's active use of the flat-rate service. We also have a measure of a customer's passive use. Specifically, the variable hours captures the monthly number of hours that the set-top box was switched on. However, this may not be an accurate indication of the number of hours that the customer actively watched TV. In fact, it was technically possible to switch off the TV while leaving the set-top box switched on, making this variable less than ideal. Moreover, this variable is only available for a period of 6 months. For the months in which we have both zaps and hours, we find a significant positive correlation of .66 $(p<.01)$.
} 
Table 2.2: Descriptive statistics for free-trial and regular customers

\begin{tabular}{|c|c|c|c|c|}
\hline & \multicolumn{2}{|c|}{ Free-Trial Customers } & \multicolumn{2}{|c|}{ Regular customers } \\
\hline & Mean & $(\mathrm{SD})$ & Mean & $(\mathrm{SD})$ \\
\hline \multicolumn{5}{|l|}{ Dependent variables } \\
\hline Retention probability & .93 & $(.25)$ & .96 & $(.19)$ \\
\hline Usage of flat-rate service (channel zaps) & 169.35 & (176.90) & 189.28 & (183.80) \\
\hline Usage of pay-per-use service (number of video-on-demands) & .73 & (2.19) & .58 & $(1.91)$ \\
\hline \multicolumn{5}{|l|}{ Marketing communication } \\
\hline Direct marketing (number of direct-marketing contacts) & .34 & $(.55)$ & .16 & $(.41)$ \\
\hline Advertising (share-of-voice) & .74 & $(.28)$ & .79 & $(.26)$ \\
\hline \multicolumn{5}{|l|}{ Customer-specific variables } \\
\hline Age (years) & 46.22 & $(12.64)$ & 44.89 & $(12.60)$ \\
\hline Household size & 2.98 & $(1.48)$ & 2.88 & $(1.53)$ \\
\hline Annual income (in $€ 10,000$ ) & 2.44 & $(.56)$ & 2.43 & $(.59)$ \\
\hline Time-to-adoption (in months following the launch of the service) & 13.14 & $(2.45)$ & 12.38 & $(2.20)$ \\
\hline \multicolumn{5}{|l|}{ Control variables } \\
\hline Monthly subscription fee (in $€$ ) & 9.66 & $(7.80)$ & 13.22 & $(4.85)$ \\
\hline Cancellation penalty (Fees - Future Fees, in $€$ ) & -59.80 & $(68.08)$ & -8.14 & $(25.02)$ \\
\hline Consumption credit for pay-per-use consumption (in $€$ ) & 5.50 & $(8.90)$ & 1.38 & $(5.08)$ \\
\hline Temperature $\left(\right.$ in $\left.{ }^{\circ} \mathrm{C}\right)$ & 12.82 & $(4.97)$ & 12.83 & (4.99) \\
\hline Time-since-adoption (in months) & 5.34 & $(3.52)$ & 5.95 & (3.68) \\
\hline Direct marketing prior to acquisition & .62 & $(.61)$ & .26 & $(.48)$ \\
\hline Advertising (share-of-voice) prior to acquisition & .73 & $(.27)$ & .76 & $(.27)$ \\
\hline Future subscription fees prior to acquisition (in $€$ ) & 193.83 & $(50.04)$ & 181.97 & (44.79) \\
\hline Number of customers & \multicolumn{2}{|c|}{12,612} & \multicolumn{2}{|c|}{3,900} \\
\hline
\end{tabular}

Table 2.3: Correlation matrix

\begin{tabular}{|c|c|c|c|c|c|c|c|c|c|c|c|}
\hline & 1 & 2 & 3 & 4 & 5 & 6 & 7 & 8 & 9 & 10 & 11 \\
\hline 1. Trial & & & & & & & & & & & \\
\hline 2. Direct marketing & 0.15 & & & & & & & & & & \\
\hline 3. Advertising & -0.08 & -0.04 & & & & & & & & & \\
\hline 4. Age & 0.05 & 0.03 & -0.09 & & & & & & & & \\
\hline 5. Household size & 0.03 & 0.02 & 0.00 & -0.10 & & & & & & & \\
\hline 6. Income & 0.01 & 0.04 & -0.24 & 0.11 & 0.04 & & & & & & \\
\hline 7. Time-to-adoption & 0.14 & 0.15 & 0.00 & 0.01 & 0.07 & 0.02 & & & & & \\
\hline 8. Subscription Fee & -0.22 & -0.09 & -0.03 & -0.02 & -0.03 & 0.00 & -0.14 & & & & \\
\hline 9. Cancellation penalty & -0.36 & -0.11 & 0.00 & -0.03 & -0.04 & -0.01 & -0.26 & 0.76 & & & \\
\hline 10. VOD credit & 0.22 & 0.07 & 0.02 & 0.00 & 0.04 & 0.00 & 0.27 & -0.70 & -0.62 & & \\
\hline 11. Temperature & 0.00 & 0.08 & 0.07 & 0.00 & -0.01 & -0.01 & -0.21 & -0.31 & -0.25 & 0.20 & \\
\hline 12. Time-since-adoption & -0.08 & -0.07 & -0.03 & -0.02 & -0.04 & -0.01 & -0.29 & 0.71 & 0.79 & -0.56 & -0.17 \\
\hline
\end{tabular}




\subsection{Model}

We need to address the interrelations between consumer's usage and retention decisions (e.g., Ascarza, Lambrecht, and Vilcassim 2012; Iyengar et al. 2011) and hence construct models for both retention and the two types of service usage (i.e., flat-rate and pay-per-use). Our model accounts for unobserved consumer heterogeneity, selection into the free trial or regular subscription, and the endogeneity of marketing communication activities.

\subsubsection{Retention}

The probability of retention is modeled with a binomial Probit model. We assume that customer $\mathrm{i}$ decides at the end of every month $\mathrm{t}$ after acquisition whether to retain the service $\left(r_{i t}=1\right)$ or disadopt $\left(r_{i t}=0\right)$. We write the utility $v_{i t}$ of retaining the service as follows:

(1) $v_{\text {it }}=\alpha_{0 i}+\alpha_{1 i}$ Trial $_{i}+\alpha_{2 i} U_{s a g e F R}+\alpha_{3 i} U_{\text {sagePPU }}+\alpha_{4 i} \mathrm{DM}_{i t}+\alpha_{5 i} A_{d v_{i t}}+$

$$
\begin{aligned}
& \alpha_{6 i} \text { UsageFR }_{i t} \times \text { Trial }_{i}+\alpha_{7 i} \text { UsagePPU }_{i t} \times \text { Trial }_{i}+\alpha_{8 i} \text { DM }_{i t} \times \text { Trial }_{i}+\alpha_{9 i} \text { Adv }_{\text {it }} \times \text { Trial }_{i}+ \\
& \alpha_{10, \text { Fee }_{i t}} \text { sub }+\alpha_{11, i} \text { Penalty }_{i t}+\alpha_{12, i} \text { Temp }_{i t}+\alpha_{13, i} \log \left(\text { Time }_{i t}\right)+\alpha_{14, i} \text { Initial }_{i t}+\xi_{\text {it }}
\end{aligned}
$$

Thus, the utility of retaining the service at the end of month $t$ is influenced by the dummy variable Trial $\mathrm{i}_{\mathrm{i}}(1$ if customer $\mathrm{i}$ was acquired with a free-trial; 0 otherwise), which allows us to test whether free-trial acquisition increases customers' churn rate $\left(\mathrm{H}_{1}\right)$. Other drivers include customer's monthly usage of the flat-rate (UsageFR $R_{i t}$ measured in monthly channel zaps divided by 100) and pay-per-use services (UsagePPU $\mathrm{it}_{\mathrm{it}}$ measured in number of VODs) for customer $\mathrm{i}$ in month $\mathrm{t}$. In addition, retention depends on the company's monthly directmarketing efforts $\left(\mathrm{DM}_{\mathrm{it}}\right)$ and advertising intensity for customer $\mathrm{i}\left(\mathrm{Adv}_{\mathrm{it}}\right.$, defined as share-ofvoice in customer i's region). ${ }^{4}$

We also include a set of control variables. $\mathrm{Fee}_{\mathrm{it}}{ }^{\text {sub }}$, the subscription fee for customer $\mathrm{i}$ in month $t$, captures the influence of price on a customer's retention decision (Ascarza, Lambrecht, and Vilcassim 2012). Variation in $\mathrm{Fee}_{i t}{ }^{\mathrm{sub}}$ is partly due to the zero-price in the beginning of a free-trial customer's tenure, and partly due to temporary price reductions. Our model accounts for a general pattern of high defection rates during the first four months of a customer's tenure by the dummy variable Initialit. On top of that, we include the variable Penalty $y_{\text {it }}$ to account for the fact that customers were able to cancel their 12-month subscription by paying an early-termination fee. We assume that customers trade off the termination fee

\footnotetext{
${ }^{4}$ We also estimate a model with lagged effects of direct marketing and advertising, but this leaves model fit virtually unaffected $(\triangle$ Hit probability $=-.0003, \triangle$ Hit rate $=-.0021)$. Therefore, we opted for our more parsimonious model.
} 
against future subscription fees within the current contractual period. Hence, Penaltyit equals to the termination fee for immediate disadoption minus the sum of all future subscription fees that would have to be paid during the remaining months of the contractual period. The higher Penalty $y_{i t}$, the more likely it is that a customer retains the service. We include the monthly average temperature (Temperature $e_{i t}$ ) to control for seasonality, ${ }^{5}$ and incorporate the log of time-since-adoption ( Time $_{i t}$ ) to accommodate changes in the baseline retention probability over a customer's lifetime (Prins, Verhoef, and Franses 2009).

The model coefficients $\alpha_{0 i}, \ldots, \alpha_{14, i}$ are customer-specific. Finally, the error term $\xi_{\text {it }}$ is normally distributed with a standard deviation set equal to 1 for reasons of identification of the Probit model.

\subsubsection{Usage of the Flat-Rate Service}

We model flat-rate usage (UsageFR $\mathrm{R}_{\mathrm{it}}$ ) as a log-log regression to account for the skewed nature of this variable (Iyengar et al. 2011):

$$
\begin{aligned}
\log \left(\text { UsageFR }_{i t}\right)= & \beta_{0 i}+\beta_{1 i} \text { Trial }_{i}+\beta_{2 i} \log \left(\text { UsageFR }_{i, t-1}\right)+\beta_{3 i} \log \left(\text { Fee }_{i t}^{\text {sub }}\right)+\beta_{4 i} \log \left(\text { Temp }_{i t}\right)+ \\
& \beta_{5 i} \log \left(\text { Time }_{i t}\right)+\theta_{i t}
\end{aligned}
$$

The free-trial acquisition dummy Trial $_{i}$ captures differences in flat-rate usage between free-trial and regular customers. Usage in the previous period (UsageFR $\mathrm{R}_{\mathrm{i},-1}$ ) accounts for persistence in usage behavior. We also include the control variables subscription fee, average temperature, and time-since-adoption. ${ }^{6}$ Before taking the logarithm, we add 1 to all variables for which zeros occur (e.g., Iyengar et al. 2011). The coefficients $\beta_{0 \mathrm{i}}, \ldots, \beta_{5 \mathrm{i}}$ are customer-specific. $\theta_{\mathrm{it}}$ is an error term following a normal distribution $\mathrm{N}\left(0, \sigma^{2}\right)$.

\subsubsection{Usage of the Pay-per-Use Service}

We model usage of the pay-per-use component, i.e., a consumer's monthly number of VODs, with a zero-inflated Poisson model, in which the zero inflation accommodates the spike at zero in our data (Greene 2003):

\footnotetext{
${ }^{5}$ To account for differences in the length of each month and the occurrence of holidays, we also estimate a model using monthly dummy variables. However, the results hardly change and model fit remains largely unaffected ( $\triangle \mathrm{Hit}$ probability $=.0016, \triangle$ Hit rate $=.0046, \Delta R^{2}$ Flat-rate $=.0366, \Delta R^{2}$ Pay-per-use $=-.0066$ ). In addition, the model becomes cumbersome to estimate with 66 parameters to capture seasonality (11 heterogeneous month coefficients in three equations). We therefore decide to stick to a more parsimonious model.

${ }^{6}$ We also estimate models in which we allow direct marketing and advertising to affect service usage. However, this does not lead to an improvement in model performance $\left(\triangle R^{2}\right.$ Flat-rate $=.0011, \triangle R^{2}$ Pay-per-use $\left.=-.0030\right)$.
} 


$$
\begin{aligned}
& \text { UsagePPU }{ }_{i t}=U_{s a g e P P U}{ }^{*} \sim \text { Poisson }\left(\lambda_{i t}\right) \quad \text { with probability } q_{i} \\
& \text { Usage } P P U_{\text {it }}=0 \\
& \text { with probability } 1 \text { - } q_{i}
\end{aligned}
$$

where $\mathrm{q}_{\mathrm{i}}$ is the probability that customer $\mathrm{i}$ is a potential user of the VOD service, modeled with a Probit structure with customer-specific normally distributed intercept $\delta_{0 ;} ; U_{s a g e P P U}{ }_{i t}$ is the number of VODs watched by customer i in period $t$, given that the customer is a VOD user. The expected number of VODs, $\lambda_{i t}$ is specified as an exponential function such that it is ensured to be positive:

$$
\begin{aligned}
\lambda_{i t}= & \exp \left(\gamma_{0 i}+\gamma_{1 i} \text { Trial }_{i}+\gamma_{2 i} \text { UsagePPU }_{i, t-1}+\gamma_{3 i} \text { Fee }_{i t}^{\text {sub }}+\gamma_{4 i} \text { Temp }_{i t}+\gamma_{5 i} \log \left(\text { Time }_{i t}\right)+\right. \\
& \left.\gamma_{6 i} \text { Creditit }_{i t}\right) .
\end{aligned}
$$

Similar to the model for flat-rate usage, the expected number of videos watched is a function of the mode of acquisition (Trial $\mathrm{i}_{\mathrm{i}}$ ), a customer's past usage (UsagePPU $\mathrm{U}_{\mathrm{i}, \mathrm{-}-\mathrm{1}}$ ), and the variables

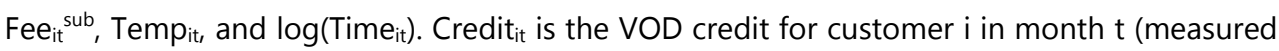
in $€)$. This VOD credit is granted by the company for a maximum period of four months to stimulate service usage. $\gamma_{0 i}, \ldots, \gamma_{6 i}$ are customer-specific coefficients.

\subsubsection{Customer Heterogeneity}

We include consumer heterogeneity by modeling all response parameters (intercepts and slope coefficients) as normally distributed across customers. To incorporate interdependence between the different model components, we allow for correlation between the intercepts. ${ }^{7}$ The expected values of the retention and usage intercepts $\alpha_{0 \mathrm{i}}, \beta_{0 \mathrm{i}}$, and $\gamma_{0 \mathrm{i}}$ are functions of the concomitant customer characteristics age, household size, income (e.g., Rust and Verhoef 2005), and time-to-adoption (Prins, Verhoef, and Franses 2009; Schweidel, Fader, and Bradlow 2008):

$$
\left(\begin{array}{l}
\mathrm{E}\left(\alpha_{0 \mathrm{i}}\right) \\
\mathrm{E}\left(\beta_{0 \mathrm{i}}\right) \\
\mathrm{E}\left(\gamma_{0 \mathrm{i}}\right)
\end{array}\right)=\left(\begin{array}{l}
\alpha_{0,0}+\alpha_{0,1} \text { Age }_{\mathrm{i}}+\alpha_{0,2} \text { Hhsize }_{i}+\alpha_{0,3} \text { Income }_{\mathrm{i}}+\alpha_{0,4} \text { Adopttime }_{\mathrm{i}} \\
\beta_{0,0}+\beta_{0,1} \text { Age }_{\mathrm{i}}+\beta_{0,2} \text { Hhsize }_{i}+\beta_{0,3} \text { Income }_{i}+\beta_{0,4} \text { Adopttime }_{\mathrm{i}} \\
\gamma_{0,0}+\gamma_{0,1} \text { Age }_{\mathrm{i}}+\gamma_{0,2} \text { Hhsize }_{\mathrm{i}}+\gamma_{0,3} \text { Income }_{\mathrm{i}}+\gamma_{0,4} \text { Adopttime }_{\mathrm{i}}
\end{array}\right)
$$

where $\mathrm{Age}_{\mathrm{i}}$, is the age of customer $\mathrm{i}$ (in years, shortly after service launch), Hhsize $\mathrm{e}_{\mathrm{i}}$ is the size of customer i's household (in number of persons), Income $e_{i}$ is the average income in the census block to which customer i belongs (in $€ 10,000$ ), and Adopttime $i$ is the time-to-adoption of

\footnotetext{
${ }^{7}$ To check whether we should structurally account for any correlation between the slope coefficients, we inspect the correlations between the consumer-specific posterior slope coefficients (Train 2009) and find the average absolute correlation to be very small (.0105). Furthermore, we computed the correlation between the residuals of the usage models. The low correlation coefficient $(\rho=.11)$ suggests that, after controlling for cross-sectional correlation, there is little interdependence between the error terms left.
} 
customer $\mathrm{i}$ (measured in months following the launch of the iTV service). $\alpha_{0, k,}, \beta_{0, k,} \gamma_{0, k}(k=0,1, \ldots$, 4) are coefficients to be estimated.

\subsubsection{Selection Model}

Because we are interested in the treatment effect of free-trial acquisition (i.e., of Triali $_{\mathrm{i}}$ ), we correct for the trial's selection effects (Thomas 2001; Villas-Boas and Winer 1999). We use a binary Probit structure to model whether a customer was acquired with a free-trial $\left(\operatorname{Trial}_{i}=1\right)$ or regular subscription $\left(\right.$ Trial $\left._{i}=0\right)$, and write the underlying latent variable as follows:

$$
\begin{aligned}
w_{i}= & \omega_{0}+\omega_{1} \text { Age }_{i}+\omega_{2} \text { Hhsize }_{i}+\omega_{3} \text { Income }_{i}+\omega_{4} \text { Adopttime }_{i}+\omega_{5} \text { DM }_{i}^{*}+\omega_{6} \text { Adv }_{i}^{*}+ \\
& \omega_{7} \text { Fee }_{i}^{*}+\zeta_{i}
\end{aligned}
$$

In addition to the customer characteristics age, household size, income, and time-to-adoption, we identify three possible drivers of free-trial acquisition. First, $\mathrm{DM}_{\mathrm{i}}^{*}$ represents the average number of direct-marketing contacts with customer $\mathrm{i}$ in the three months before signing up. Since the free-trial promotion was mentioned in direct-marketing contacts (e.g., in outbound telephone calls, to convince the customer), $\mathrm{DM}_{\mathrm{i}}{ }^{*}$ likely has a positive impact on consumers' awareness of the trial offer. Second, $A d v_{i}{ }^{*}$ is the average share-of-voice for customer $i$ in the three months before signing up. Because advertising usually promoted the regular offer, we expect $A d v_{i}^{*}$ to decrease the probability that a customer was acquired through a free trial. Third, $\mathrm{Fee}_{i}^{*}$ refers to the fees for a regular 12-month subscription at the time of customer i's signup. Higher fees for the regular subscription may lead consumers to search longer for a special deal (or push harder when in touch with a customer service agent), such that Fee ${ }_{i}^{*}$ should have a positive effect on the probability of free-trial acquisition. Finally, $\omega_{0}, \ldots, \omega_{7}$ are the to-beestimated coefficients and $\zeta_{i}$ is a standard-normal error term. To deal with selection effects, we allow for correlation between the error of the selection equation and the usage and retention intercept errors (Thomas 2001; Villas-Boas and Winer 1999).

\subsubsection{Endogeneity of Marketing Instruments}

We correct for the possible endogeneity of $\mathrm{DM}_{\mathrm{it}}$ and $A d v_{\text {it }}$ in the retention equation by using Gaussian copulas. Copulas are distribution functions describing the dependence structure between random variables (e.g., the "endogenous" part of a regressor), and the error term of the focal equation. While classical methods to correct for endogeneity require instrumental variables (IVs) to partial out the exogenous variation in the endogenous regressors, copulas do 
not require IVs and have recently been shown to be well-suited for endogeneity correction. In line with Park and Gupta (2012), we add two regressors, $\widetilde{\mathrm{DM}}_{\mathrm{it}}$ and $\widetilde{\mathrm{Adv}}_{\mathrm{it}}$, to Equation (1):

$$
\begin{aligned}
& \widetilde{\mathrm{DM}}_{\mathrm{it}}=\Phi^{-1}\left(\mathrm{H}_{\mathrm{DM}}\left(\mathrm{DM}_{\mathrm{it}}\right)\right) \\
& \widetilde{\mathrm{Adv}}_{\mathrm{it}}=\Phi^{-1}\left(\mathrm{H}_{\mathrm{Adv}}\left(\operatorname{Adv}_{\mathrm{it}}\right)\right),
\end{aligned}
$$

where $\mathrm{H}_{\mathrm{DM}}(\cdot)$ and $\mathrm{H}_{\mathrm{Adv}}(\cdot)$ are the empirical distribution functions of $\mathrm{DM}_{\mathrm{it}}$ and $\mathrm{Adv}_{\mathrm{it}}$, respectively, and $\Phi^{-1}$ is the inverse of the normal cumulative distribution function. ${ }^{8}$ For identification purposes, the endogenous regressors must be non-normally distributed (Park and Gupta 2012), which a Shapiro-Wilk test shows to be the case (Direct marketing: $W=.5811, p<.001$; Advertising: $\mathrm{W}=.7926, p<.001)$.

\subsection{Empirical Results}

We estimate the model using simulated maximum likelihood (Train 2009). Figure 2.2 shows averages of predicted versus observed values for the three dependent variables: retention, flat-rate usage, and usage of the pay-per-use service. Overall, the figures suggest that our model predictions fit the retention and usage data well for both free-trial and regular customers. Seemingly, the difference between average retention rates (Panel a) of free-trial and regular customers is small. However, the average values mask the substantial heterogeneity between customers, and differences in the importance of the drivers (usage and marketing) for the two customer groups. Our subsequent discussion sheds light on these aspects.

Table 2.4 reports in-sample and out-of-sample fit measures. To assess out-of-sample fit, we reestimate our model on a random draw of $70 \%$ of the customers, and predict usage and retention for the remaining $30 \%$. We use hit rate and hit probability as fit measures for retention (Allenby and Ginter 1995), and $R^{2}$ as a fit measure for usage of the flat-rate and payper-use services. Overall, the different measures suggest a good model fit.

\footnotetext{
${ }^{8}$ To keep the estimation tractable, we treat DM as a continuous variable. While semi-parametric methods usually require bootstrapping to obtain standard errors, we use regular standard errors which have been shown to be virtually the same (Park and Gupta 2012). We ran simulations and found that we can recover the parameters well.
} 
Table 2.4: Model fit

\begin{tabular}{|c|c|c|c|c|}
\hline & $\begin{array}{r}\text { Retention } \\
\text { (Hit rate) }\end{array}$ & $\begin{array}{r}\text { Retention } \\
\text { (Hit probability) }\end{array}$ & Flat-rate usage $\left(R^{2}\right)$ & Pay-per-use $\left(R^{2}\right)$ \\
\hline \multicolumn{5}{|l|}{ In-sample ${ }^{a}$} \\
\hline Free-trial & .8969 & .9202 & .6515 & .5810 \\
\hline Regular & .9147 & .9537 & .6541 & .5339 \\
\hline \multicolumn{5}{|c|}{ Out-of-sampleb } \\
\hline Free-trial & .8729 & .9123 & .6549 & .5334 \\
\hline Regular & .8936 & .9484 & .6580 & .4998 \\
\hline \multicolumn{5}{|c|}{$\begin{array}{l}\text { a Hit rates among non-churners (on average, } .9462) \text { are higher than hit rates among churners }(.2417) \text {. However, } \\
\text { these numbers still suggest a considerable improvement in fit compared to a naïve prediction based on observed } \\
\text { retention probabilities, especially among churners }(.9393 \text { for non-churners, and } .0607 \text { for churners). } \\
\text { b We reestimate the model on a random draw of } 70 \% \text { of the customers and compute model fit for the remaining } \\
30 \% \text {. }\end{array}$} \\
\hline
\end{tabular}

Figure 2.2: Model fit

\section{a) Retention}
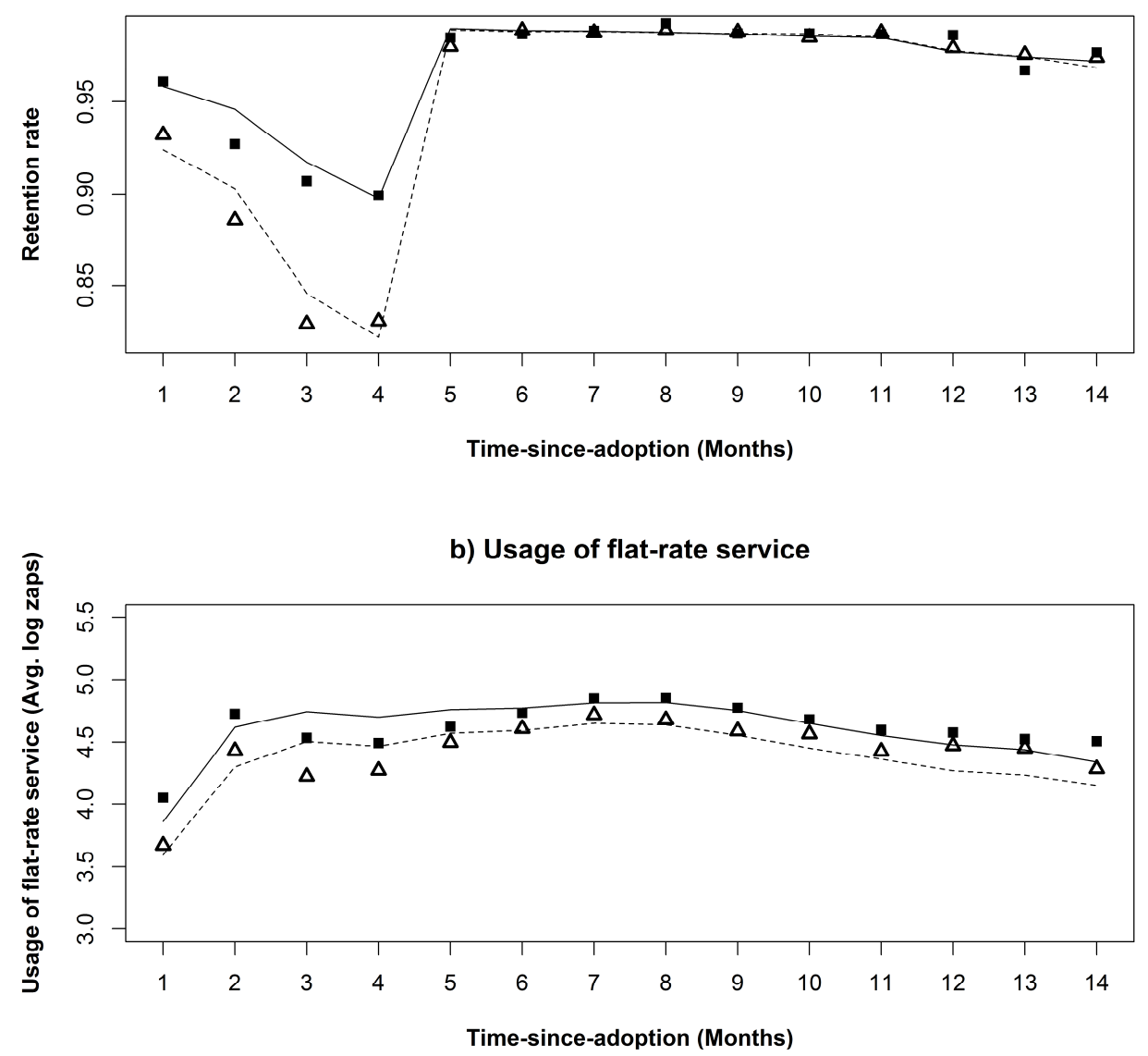
Figure 2.2: (continued)

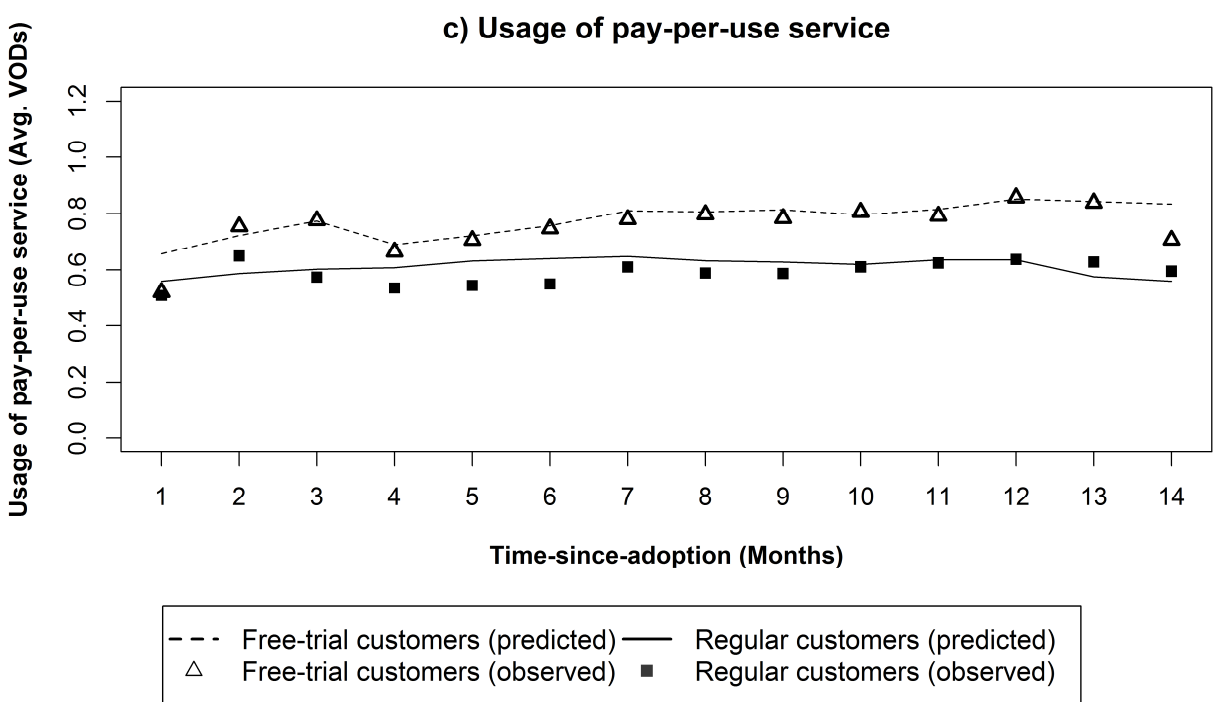

Table 2.5: Estimation results

\begin{tabular}{|c|c|c|c|c|}
\hline & \multicolumn{2}{|c|}{ Population Mean } & \multicolumn{2}{|c|}{ Standard Deviation } \\
\hline & Estimate & & Estimat & \\
\hline \multicolumn{5}{|l|}{ Retention } \\
\hline Intercept & 2.416 & $(.007)$ & .000 & $(.000)$ \\
\hline Age & -.002 & $(.000)$ & & \\
\hline Household size & -.054 & $(.002)$ & & \\
\hline Income & .070 & $(.003)$ & & \\
\hline Time-to-adoption & .004 & $(.001)$ & & \\
\hline Trial & -.066 & $(.008)$ & -.013 & $(.022)$ \\
\hline Flat-rate usage & .683 & $(.007)$ & .311 & $(.007)$ \\
\hline$\times$ Trial & .056 & $(.008)$ & .153 & $(.015)$ \\
\hline Pay-per-use usage & .045 & $(.005)$ & -.029 & $(.007)$ \\
\hline$\times$ Trial & .013 & $(.006)$ & .021 & $(.008)$ \\
\hline Direct marketing & .039 & $(.012)$ & .026 & $(.031)$ \\
\hline$\times$ Trial & .051 & $(.013)$ & -.055 & $(.035)$ \\
\hline Advertising & .272 & $(.009)$ & -.003 & $(.029)$ \\
\hline$\times$ Trial & .134 & $(.010)$ & .033 & $(.034)$ \\
\hline Copula correction term for DM & .022 & $(.004)$ & & \\
\hline Copula correction term for Adv. & .018 & $(.003)$ & & \\
\hline \multicolumn{5}{|l|}{ Control variables } \\
\hline Initial period & -1.253 & $(.008)$ & -.002 & $(.020)$ \\
\hline Monthly subscription fee & -.004 & $(.001)$ & .002 & $(.002)$ \\
\hline Cancellation penalty & .004 & $(.000)$ & .000 & $(.000)$ \\
\hline Temperature & .007 & $(.000)$ & -.001 & $(.001)$ \\
\hline log(Time-since-adoption) & -.516 & $(.005)$ & .010 & $(.014)$ \\
\hline
\end{tabular}


Table 2.5: (continued)

\begin{tabular}{|c|c|c|c|c|}
\hline & \multirow{2}{*}{\multicolumn{2}{|c|}{$\begin{array}{c}\text { Population Mean } \\
\text { Estimate (SE) }\end{array}$}} & \multirow{2}{*}{\multicolumn{2}{|c|}{$\begin{array}{c}\text { Standard Deviation } \\
\text { Estimate }(\mathrm{SE})\end{array}$}} \\
\hline & & & & \\
\hline \multicolumn{5}{|l|}{ Flat-rate usage (log zaps) } \\
\hline Intercept & 5.427 & $(.007)$ & .873 & $(.007)$ \\
\hline Age & .000 & $(.000)$ & & \\
\hline Household size & .043 & $(.002)$ & & \\
\hline Income & -.045 & $(.003)$ & & \\
\hline Time-to-adoption & -.039 & $(.001)$ & & \\
\hline Trial & -.300 & $(.008)$ & .010 & $(.015)$ \\
\hline \multicolumn{5}{|l|}{ Control variables } \\
\hline $\log ($ Monthly subscription fee) & -.022 & $(.003)$ & -.010 & $(.005)$ \\
\hline $\log (T e m p e r a t u r e)$ & -.393 & $(.003)$ & .008 & $(.005)$ \\
\hline log(Time-since-adoption) & -.313 & $(.004)$ & .347 & $(.005)$ \\
\hline lagged log(Flat-rate usage) & .240 & $(.001)$ & .009 & $(.003)$ \\
\hline $\log ($ sigma) & .014 & $(.002)$ & & \\
\hline \multicolumn{5}{|l|}{ Pay-per-use (VODs) } \\
\hline Intercept (incidence) & -.134 & $(.007)$ & 1.250 & $(.020)$ \\
\hline Intercept (amount) & -.610 & (.008) & 1.325 & $(.005)$ \\
\hline Age & -.005 & $(.000)$ & & \\
\hline Household size & .103 & $(.002)$ & & \\
\hline Income & .099 & (.003) & & \\
\hline Time-to-adoption & -.019 & $(.001)$ & & \\
\hline Trial & .049 & $(.009)$ & .084 & $(.009)$ \\
\hline \multicolumn{5}{|l|}{ Control variables } \\
\hline Monthly subscription fee & -.010 & $(.000)$ & .003 & $(.001)$ \\
\hline Consumption credit & .003 & $(.001)$ & -.003 & $(.002)$ \\
\hline Temperature & -.010 & $(.001)$ & .018 & $(.001)$ \\
\hline log(Time-since-adoption) & .042 & $(.004)$ & -.237 & $(.005)$ \\
\hline lagged Pay-per-use & .020 & $(.000)$ & .010 & $(.000)$ \\
\hline \multicolumn{5}{|l|}{ Selection (free-trial vs. regular) } \\
\hline Intercept & .315 & $(.011)$ & & \\
\hline Age & .005 & $(.000)$ & & \\
\hline Household size & .027 & $(.003)$ & & \\
\hline Income & -.072 & $(.004)$ & & \\
\hline Time-to-adoption & .009 & $(.001)$ & & \\
\hline Direct marketing & .649 & $(.017)$ & & \\
\hline Advertising & -.426 & (.014) & & \\
\hline Subscription fee & .001 & $(.000)$ & & \\
\hline
\end{tabular}

Log-likelihood: -212,586; N: 121,956; BIC: 426,272; AIC: 425,359

Note: Numbers in bold are significant at the $p<.05$ level (two-sided).

Table 2.5 presents the parameter estimates. We first discuss the relationships of our conceptual framework and then address the effects of the control variables. For the heterogeneous response parameters, we focus on the population means, which are all significant at the $p<.05$ level (two-tailed). For hypothesis testing, we use one-tailed tests. 


\subsubsection{Parameter Estimates for the Core Decision Process}

The results confirm our expectations for the core decision process (thin lines in Figure 2.1). The impact of both direct marketing $\left(\alpha_{4 i}=.039, p<.001\right)$ and advertising $\left(\alpha_{5 i}=.272, p<.001\right)$ on retention is positive, which is consistent with earlier findings that marketing communication creates interest in the service and increases retention (Polo, Sese, and Verhoef 2011; Reinartz and Kumar 2003). The significant coefficients of the copula correction terms (see Equations 7) suggest that correction for the endogeneity of marketing communication was indeed required $\left(\alpha_{15}=.018, p<.001 ; \alpha_{16}=.022, p<.001\right)$.

Furthermore, we find that retention is positively affected by flat-rate usage and usage of the pay-per-use service $\left(\alpha_{2 i}=.683, p<.001\right.$ and $\alpha_{3 i}=.045, p<.001$, respectively). Hence, a customer's own usage behavior is an indication of the personal value of the service and thus an important driver of retention (see also Lemon, White, and Winer 2002). In line with Bolton and Lemon (1999), changes in usage intensity of the pay-per-use service have weaker effects on retention, compared to changes in flat-rate usage (standardized $\alpha_{2 i}>$ standardized $\alpha_{3 i}$, $p<.001$ ). The pay-per-use service is less central to the digital TV service (i.e., most customers likely signed up to use the flat-rate service), and only increases utility at increased costs.

\subsubsection{Differences between Free-Trial and Regular Customers}

The selection equation (6) captures the process underlying consumers' selection into the freetrial or regular "regime." The parameter estimates are in line with our expectations. Direct marketing contacts, which made consumers aware of the free-trial promotion, increases the trial subscription probability $\left(\omega_{5}=.649, p<.001\right)$, as does a higher fee for the regular subscription $\left(\omega_{7}=.001, p<.001\right)$. In contrast, the more consumers are exposed to mass advertising (mainly featuring the regular offer), the less likely they are to sign up for a free trial $\left(\omega_{6}=-.426, p<.001\right)$. The significant correlations between the errors of the selection and main model equations suggest it is important to correct for selection (see Table 2.6).

Table 2.6: Estimated correlations

\begin{tabular}{|c|c|c|c|c|c|}
\hline & \multicolumn{5}{|c|}{ Correlation coefficient (SE) } \\
\hline & 1 & 2 & 3 & 4 & 5 \\
\hline 1. Selection & & & & & \\
\hline 2. Retention & $-.020(.024)$ & & & & \\
\hline 3. UsageFR & $.090(.012)$ & $.274(.104)$ & & & \\
\hline 4. UsagePPU & $.008(.019)$ & $.879(.052)$ & $.114(.012)$ & & \\
\hline 5. Zero-inflation of UsagePPU & $.116(.021)$ & $.087(.123)$ & $.222(.010)$ & $.452(.004)$ & \\
\hline
\end{tabular}


Baseline retention. In support of $\mathrm{H}_{1}$, acquisition via free trials has a direct negative impact on retention rates $\left(\alpha_{1 i}=-.066, p<.001\right)$, even after controlling for the higher defection of customers during the free-trial period. This is in line with the expectation that free-trial customers are less confident about retaining the service, either because their psychological immune system is inhibited (Gilbert and Ebert 2002; Gilbert et al. 1998) or because they attribute their subscription to the trial promotion and therefore doubt the service's quality (Heider 1958). In addition, free-trial customers may be in an earlier stage of their relationship with the firm, resulting in lower commitment (Dwyer, Schurr, and Oh 1987).

Impact of usage on retention. The positive interaction between the free-trial dummy and usage variables indicates that the usage effects are more prominent for free-trial than for regular customers, which confirms $\mathrm{H}_{2 a}$ and $\mathrm{H}_{2 b}\left(\alpha_{6 i}=.056, p<.001\right.$ for the flat-rate service and $\alpha_{7 \mathrm{i}}=.013, p=.012$ for the pay-per-use service). This suggests that free-trial customers tend to rely more on their usage behavior when making retention decisions, compensating for a higher level of uncertainty due to an inhibited psychological immune system or lower commitment to the firm (Bolton and Lemon 1999).

Impact of marketing communication on retention. In support of $\mathrm{H}_{3 a}$ and $\mathrm{H}_{3 \mathrm{~b}}$, free-trial customers are more responsive to marketing communication instruments than regular customers ( $\alpha_{8 \mathrm{i}}=.051, p<.001$ for direct marketing and $\alpha_{9 \mathrm{i}}=.134, p<.001$ for advertising). Similar to usage, advertising and direct marketing provide free-trial customers with cues that make them more secure about the service's value and assist them in their retention decision (Mitchell and Olson 1981).

Baseline usage. We find free-trial customers to use the flat-rate service less intensively than regular customers $\left(\beta_{1 \mathrm{i}}=-.300, p<.001\right)$. This is in line with free-trial customers being less certain of and less committed to the service. Interestingly, however, they use the pay-per-use service more intensively than regular customers $\left(\gamma_{1 i}=.049, p<.001\right)$. Because free-trial customers make less use of the flat-rate service, they may dedicate more time to exploring the paid add-on service (Schary 1971). ${ }^{9}$

\footnotetext{
${ }^{9}$ The fact free-trial customers use the paid component more intensively than regular customers cannot be picked up by correlated error terms, because we explicitly model this phenomenon with the trial dummy.
} 


\subsubsection{Control Variables}

The control variables have significant and face-valid effects. Usage drops in warmer months (when outdoor activities are an attractive alternative to watching TV), and available VOD credit increases usage of the VOD service. In addition, we find positive carry-over effects for both usage components (e.g., Bolton and Lemon 1999). ${ }^{10}$ Subscription fees lower consumers' propensity to retain and use the service (e.g., higher fees reduce consumers' budget and therefore decrease consumers' paid VOD consumption). The concomitant consumer characteristics also play a significant role. For example, all else equal, larger families are likely to use the service more intensively (both the flat-rate and pay-per-use component).

\subsection{Implications for Customer Lifetime Value}

We examine how the estimated effects manifest themselves in terms of CLV (see Figure 2.1). Therefore, we simulate and compare the CLV of free-trial and regular customers, and compute the elasticities of CLV with respect to changes in marketing communication efforts and customers' usage intensities. We first briefly explain how we derive CLV from customers' retention and usage behavior.

\subsubsection{Calculating Net CLV}

On the basis of the population parameter distributions, we derive customer-specific posterior distributions (Train 2009) and simulate customers' usage and retention behavior over a threeyear time horizon, in line with similar simulations for other high-tech products and services (Gupta and Lehmann 2003; Kumar et al. 2008; Rust, Kumar, and Venkatesan 2011). Our analysis is based on the same sample of customers used for model estimation.

We compute Net CLV as the total revenue stemming from a customer's consecutive retention and usage decisions less the costs to acquire and retain that customer. For a given month, revenue consists of the fixed subscription fee and the pay-per-use fees if the customer retains the iTV service, or the early-termination fee if the customer disadopts. On the cost side, we distinguish between direct marketing and advertising expenditures to acquire and retain

\footnotetext{
10 The carry-over coefficients for the two usage components are not directly comparable because we use a regression for flat-rate usage and a zero-inflated Poisson model for the pay-per-use service. Nonetheless, the relative magnitude of the coefficients suggests that the flat-rate service is characterized by higher state-dependence than the pay-per-use service. This is consistent with the idea that consumers get used to regularly watching the same television shows or series (flat-rate usage), as opposed to consuming possibly unrelated content from the video-on-demand service (pay-per-use).
} 
the customer. The Appendix to this study explains in detail how we calculate and allocate these marketing costs. Other costs are not directly related to the number of customers or their usage intensity (e.g., the network infrastructure which is owned by the company), or are zero (e.g., the marginal reproduction cost of a video-on-demand), and can thus be ignored in the computation of Net CLV. We use an annual discount rate of $15 \%$ to compute the present value of future cash flows (Kumar et al. 2008; Reinartz and Kumar 2003; Venkatesan and Kumar 2004). ${ }^{11}$ The Appendix provides the equations for the Net CLV calculations.

\subsubsection{Results}

Survival probabilities. As a first step towards calculating Net CLV, we investigate the survival probabilities for free-trial versus regular customers. Figure 2.3 shows, for each group, the average of the customer-specific survival probabilities over the simulation horizon of 36 months. The average survival probability is considerably lower for free-trial customers (dotted line) than for regular customers (solid line). Importantly, the survival probabilities are characterized by substantial consumer heterogeneity, for both free-trial and regular customers. We illustrate this by plotting the distribution of individual survival probabilities at six discrete points in time (in months $3,9,15,21,27$, and 33). On the basis of this graph, we can expect substantial differences in Net CLV between but also within the two customer groups.

Net CLV for free-trial and regular customers. The results of our Net CLV calculations are shown in Figure 2.4. Panel a presents average revenues, costs, and the resulting lifetime value for both customer groups. The major part of revenues comes from subscription fees. The payper-use service accounts for $15 \%$ (€39.96) of the total revenues from free-trial customers and $10 \%$ (€38.49) of the total revenues from regular customers. Regular customers, who do not have the possibility to cancel the service for free during a trial period, pay a relatively higher expected cancellation fee than free-trial customers ( $€ 23.46$ versus $€ 2.84$ ). The costs for acquisition ( $€ 170.30$ for free-trial and $€ 169.90$ for regular customers) and retention ( $€ 10.75$ for free-trial and $€ 11.28$ for regular customers) are very comparable. After taking into account all

\footnotetext{
11 Our relative results remain the same when we vary the simulation horizon or discount rate.
} 
revenues and costs, the resulting Net CLV is on average $55 \%$ lower for free-trial customers than for regular customers ( $€ 88$ versus $€ 196$ ). ${ }^{12}$

Figure 2.3: Survival distribution functions with customer heterogeneity

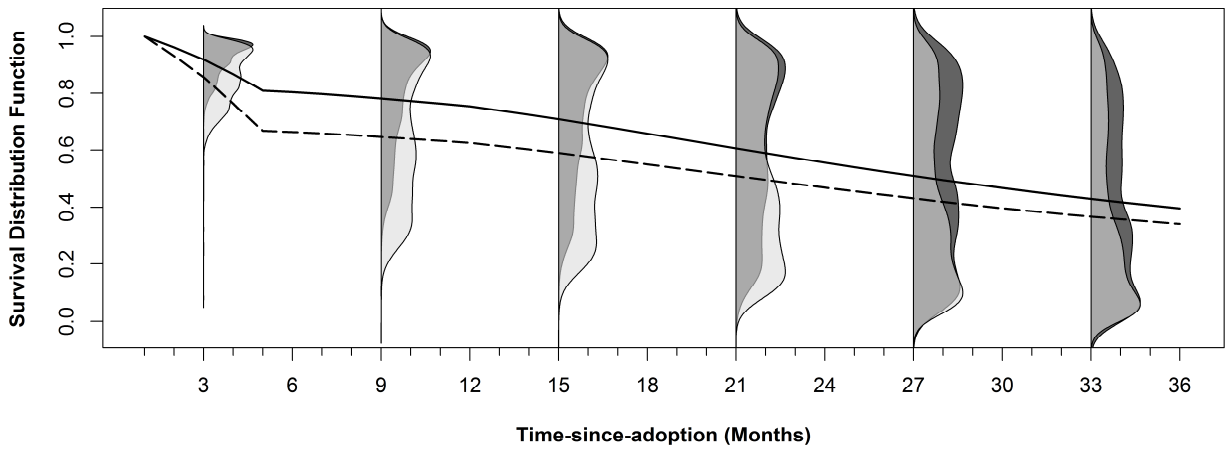

Free-trial customers Regular customers

----- Mean survival probability - Mean survival probability

Figure 2.4: Net customer lifetime value for free-trial and regular customers

a) Average Net CLV

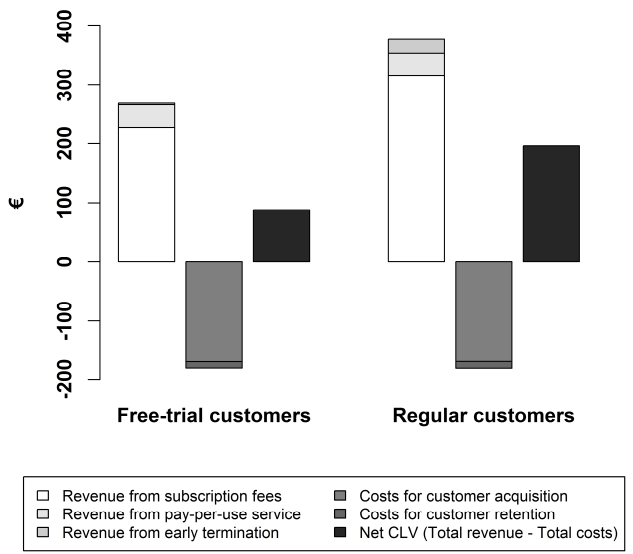

\section{b) Distribution of Net CLV}

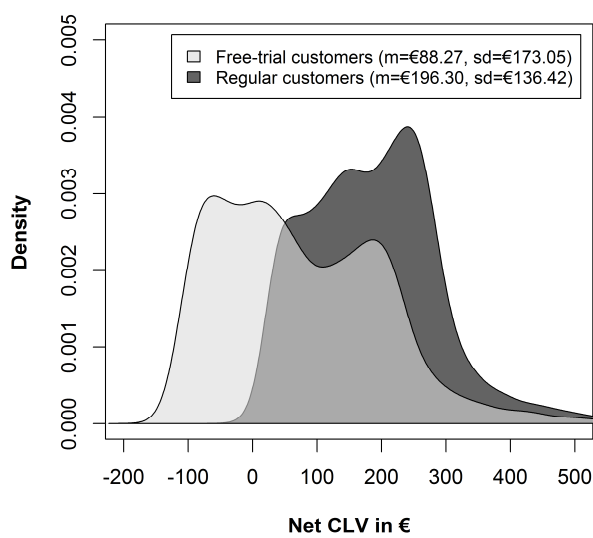

\footnotetext{
12 An alternative would be to consider the "free" months of free-trial customers as acquisition costs. To check for the robustness of our results, we also compare the Net CLV of free-trial customers after their free months with the Net CLV of regular customers. The difference in Net CLV remains substantial: Net $\mathrm{CLV}_{\text {Trial }}=€ 110.67$, Net $C L V_{\text {Regular }}=€ 196.30$ ( $\mathrm{t}=-31.07, \mathrm{df}=8915.06, p<.001$ using Welch's Two Sample $\mathrm{t}$-test).
} 
Panel b shows that free-trial customers are more heterogeneous in their Net CLV than regular customers. Indeed, although free-trial customers, on average, have a lower Net CLV, several of them generate a relatively high value, as becomes clear from the substantial overlap between the two distributions.

Marketing-communication and usage elasticities. The parameter estimates suggest that free-trial customers are significantly more responsive to changes in marketing communication and usage levels than regular customers. To quantify whether these differences are also managerially relevant, we calculate elasticities of Net CLV with respect to marketing communication and usage. We find that these elasticities are substantially higher for free-trial customers than for regular customers. As shown in Figure 2.5, the average advertising and direct-marketing elasticities of free-trial customers are .1135 and .0143 , respectively. For regular customers, however, we find average advertising and direct-marketing elasticities of only .0088 and .0002 , respectively. ${ }^{13}$

Figure 2.5: Responsiveness to marketing communication

a) Responsiveness to advertising

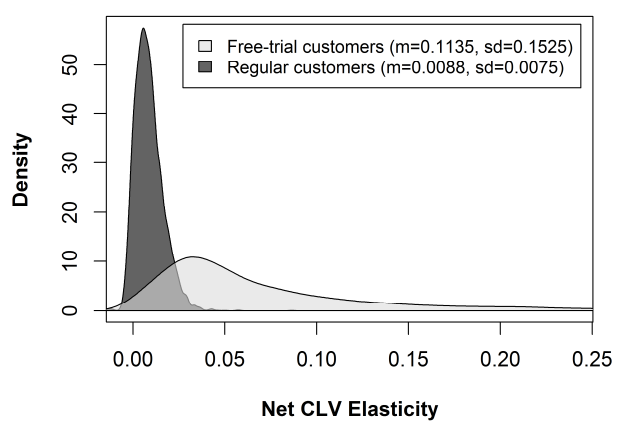

b) Responsiveness to direct marketing

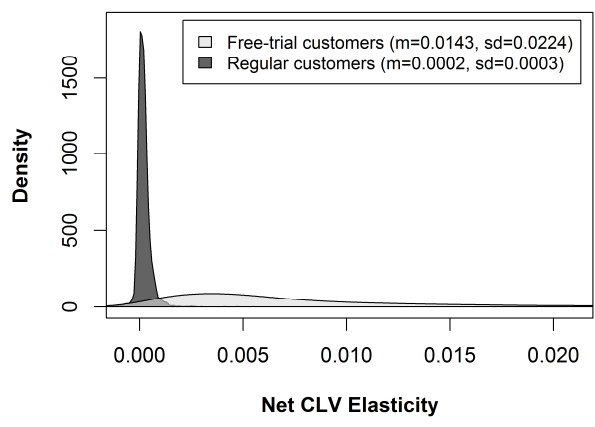

Notes: We compute arc elasticities for a $1 \%$ increase in advertising and direct marketing in the first period after acquiring the customer.

\footnotetext{
${ }^{13}$ We compute customer-specific arc elasticities for a $1 \%$ increase in the focal variable in the first period after acquiring the customer, and apply a 95\% Winsorization on estimated Net CLV elasticities to make sure that the summary statistics are not driven by outliers (Luo, Raithel, and Wiles 2013). Differences in elasticities between freetrial customers and regular customers are higher than what perhaps could be expected on the basis of the estimated coefficients (e.g., .272 for regular customers, and .272 + .134 for free-trial customers in the case of advertising). However, due to differences in the Net CLV base levels between the two customers groups, the same absolute lift in Net CLV represents a much higher percentage lift for a free-trial customer than for a regular customer. The higher response coefficients, combined with the lower Net CLV base levels, imply that the elasticities are considerably higher for free-trial customers than for regular customers.
} 
In a similar vein, we assess the extent to which Net CLV changes in response to an increase in usage (see Figure 2.6). For example, the iTV company could enhance usage by offering access to more channels (flat-rate service) or extending their VOD catalogue (pay-per-use service). We find that the average flat-rate usage elasticity equals .3235 for free-trial customers but only .0529 for regular customers. Likewise, the average pay-per-use elasticity is .0170 for free-trial customers, yet only .0028 for regular customers.

Figure 2.6: Responsiveness to usage

a) Responsiveness to shocks in flat-rate usage

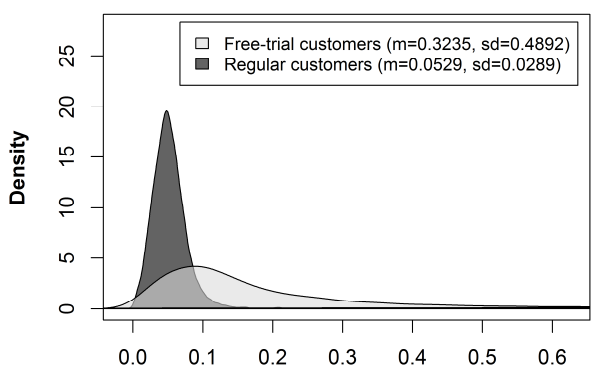

Net CLV Elasticity b) Responsiveness to shocks in PPU usage

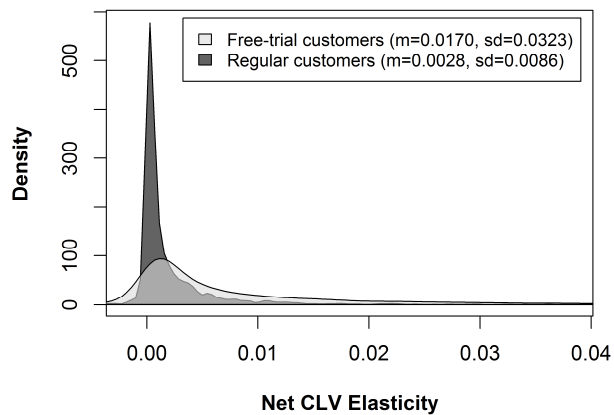

Notes: We compute arc elasticities for a $1 \%$ increase in usage levels in the first period after acquiring the customer.

\subsubsection{Improving Retention and Customer Equity}

An important finding of our study is that free-trial customers are more likely to churn, even after the free trial expires. While some managers may use this as a reason to invest less in subscribers that were attracted with free trials, these customers' high responsiveness to marketing communication actually suggests otherwise. Therefore, we recommend managers to pay specific attention to free-trial customers. To illustrate our recommendation, we simulate the impact of alternative targeting strategies on retention and Customer Equity (CE), i.e., the aggregated lifetime value of all customers (see Table 2.7). 
Table 2.7: Improving retention rates and customer equity

\begin{tabular}{|c|c|c|c|c|}
\hline \multirow[b]{3}{*}{ Increase direct marketing efforts for $20 \%$ of the customer } & \multicolumn{2}{|c|}{$\begin{array}{l}\text { Impact for } \\
\text { targeted customers (20\%) }\end{array}$} & \multicolumn{2}{|c|}{$\begin{array}{c}\text { Impact for } \\
\text { entire customer base (100\%) }\end{array}$} \\
\hline & $\begin{array}{l}\text { Impact on } \\
\text { retention }\end{array}$ & $\begin{array}{l}\text { Impact on } \\
\text { Net } C E^{\mathrm{b}}\end{array}$ & $\begin{array}{l}\text { Impact on } \\
\text { retentiona }\end{array}$ & $\begin{array}{l}\text { Impact on } \\
\text { Net } C E^{\mathrm{b}}\end{array}$ \\
\hline & & & & \\
\hline Scenario 1: No targeting (random) & $22.6 \%$ & $9.3 \%$ & $4.5 \%$ & $1.9 \%$ \\
\hline Scenario 2: Target free-trial customers (random) & $27.3 \%$ & $12.9 \%$ & $5.5 \%$ & $2.6 \%$ \\
\hline Scenario 3: Target regular customers (random) & $9.9 \%$ & $0.0 \%$ & $2.0 \%$ & $0.0 \%$ \\
\hline $\begin{array}{l}\text { Scenario 4: Target customers based on highest } \\
\text { individual-level response coefficients }\end{array}$ & $29.4 \%$ & $16.1 \%$ & $5.9 \%$ & $3.2 \%$ \\
\hline
\end{tabular}

Suppose a manager is provided with an additional monthly direct-marketing budget that enables her to increase direct-marketing efforts by $€ 1$ per customer for $20 \%$ of the customers. This corresponds to a substantial marketing investment of about $€ 1.2$ million given the company's total customer base of 160,000 customers at the end of our simulation period. The question then becomes how to select the $20 \%$ target customers. In scenario 1 , the manager simply selects customers from the company's database by chance, yielding an increase in retention (22.6\%) and Net CE (9.3\%) for the $20 \%$ targeted customers. The impact across the entire customer base is also substantial: $4.5 \%$ for retention, $1.9 \%$ for Net CE.

Alternatively, bearing in mind our finding that acquisition mode influences customers' response to marketing communication, a manager could follow scenario 2 and target only freetrial customers. Such a strategy would improve retention and Net CE of the selected customers even more (27.3\% for retention and $12.9 \%$ for Net CE). These returns stand in sharp contrast to scenario 3 in which the manger invests only in regular customers, leading to an increase of 9.9\% for retention and $0 \%$ for Net CE. Finally, a manager could opt for scenario 4 in which individual-level response coefficients are used to select customers with the highest responsiveness to direct-marketing. Such an optimal strategy would improve retention and Net CLV by $29.4 \%$ and $16.1 \%$ for targeted customers, and $5.9 \%$ and $3.2 \%$ for all customers. Notice that targeting free-trial customers (scenario 2) leads to results that come close to the optimal ones. 


\subsection{Conclusion}

\subsubsection{Discussion}

An emerging stream of research suggests that the way in which customers are acquired may have an enduring impact on their behavior, even long after adoption (Villanueva, Yoo, and Hanssens 2008). While some studies have found differences between customers attracted with sales promotions and regular customers (Anderson and Simester 2004; Lewis 2006), the consequences of recruiting customers through free-trial promotions are not well understood. Crucial questions have remained unanswered: What is the impact of free-trial acquisition on customer usage, retention, and lifetime value? Should free-trial customers be managed in a different way?

To answer these questions, we model a customer's decisions to use and retain the service-decisions that influence CLV-and examine how free-trial acquisition affects this decision process. Our model explicitly accounts for selection effects (i.e., customers attracted with free trials may differ intrinsically from other customers) and for the endogeneity of marketing communication. We estimate our model on a unique panel data set, covering monthly usage (of flat-rate and pay-per-use services) and retention decisions for 16,512 customers of an interactive digital TV service provider. We then use our model estimates to simulate CLV and quantify its sensitivity to changes in marketing communication and usage rates.

Throughout our analyses, we find strong evidence for systematic differences between free-trial and regular customers. We show that free-trial promotions are associated with higher defection rates, also beyond the free-trial period. This effect is consistent with principles from psychology and buyer-seller relationship theory which suggest that free-trial customers doubt the service's quality, are insecure about their adoption decision (Gilbert and Ebert 2002), and show weaker commitment than regular customers (Palmatier et al. 2013).

Our study further adds to the growing understanding that acquisition mode may also impact consumers' usage behavior. A consumer's usage intensity is of key importance to understand his or her retention decisions, because usage influences costumers' valuation of the service (Bolton and Lemon 1999). For example, Iyengar et al. (2011) show that pricing conditions under which a customer is acquired affect usage behavior. We, in turn, show that free-trial promotions affect consumers' usage behavior for two types of services. While free- 
trial customers use a flat-rate service less intensively than regular customers, they make more intensive use of a pay-per-use service, which directly generates revenue.

The higher churn rate makes free-trial customers worth considerably less than regular customers in terms of Net CLV. Managers and business analysts may have to temper profit expectations if the customer base includes a substantial share of free-trial subscribers. At the same time, we find free-trial customers to be more "malleable" than regular customers. They are more responsive to marketing communication and rely more on their usage behavior when deciding whether or not to retain the service. As a result, investments in direct marketing or efforts to lift usage intensity are more effective when targeted to free-trial as opposed to regular customers. In settings in which free-trial customers seek even more "external confirmation" (e.g., more expensive services), targeting free-trial customers may compensate for their initially lower retention levels and potentially lift their lifetime value above that of regular customers.

\subsubsection{Future Research}

The limitations of our work open opportunities for future research. First, because our study investigates the effects of free-trial acquisition with data from only one company in one particular industry, future research could focus on different industries using multiple data sets. For example, the value of regular and free-trial customers may diverge even more if the free trial lasts longer than three months, as is common for Internet companies using the so-called "freemium" model (Pauwels and Weiss 2008). Under this scenario, customers can chose between the free-trial (the "free service") and only pay for enhanced features or functionality (the "premium service"). For example, the cloud storage provider Dropbox allows customers to store and share files online, free of charge. However, customers need to pay a monthly subscription fee for the "premium" version of the service, which allows for much higher storage volume and extended backup features. The flexibility to switch between the premium service and the free limited service offers potential for extra research. Do customers acquired with the free service switch between these modes more frequently than customers who directly adopt the paid service? Second, future research may give a more complete account of the profitability implications of free-trial and regular acquisition. For example, for a news site, usage may be a source of advertising revenues (e.g., the number of page views may determine the income from advertising). Furthermore, it may be worthwhile to incorporate other value-creating behaviors 
as well (e.g., Kumar et al. 2010; Verhoef, Reinartz, and Krafft 2010). In particular, one could examine whether free-trial and regular customers differ in the extent to which they engage in word-of-mouth communication.

In summary, this paper sheds light on the implications of free-trial acquisition on customer usage, retention, and CLV. We show how service usage and marketing activities drive consumers' retention decisions and CLV, and how free-trial acquisition interferes with these relationships. Our findings offer managers new insights on how to improve the value of their customer base. 


\subsection{Appendix}

We compute Net CLV of a customer as the discounted value of the expected future profits minus the costs to acquire that customer:

(8) Net $\operatorname{CLV}_{\mathrm{i}}=\sum_{\mathrm{t}=1}^{36} \frac{\mathrm{S}_{\mathrm{it}} \times \mathrm{m}_{\mathrm{it}}+\left(1-\mathrm{S}_{\mathrm{it}}\right) \times \mathrm{P}_{\mathrm{it}}}{(1+\mathrm{d})^{\mathrm{t}}}-\mathrm{AC}_{\mathrm{i}}$,

where $S_{i t}$ is the survival probability of customer $i$ in month $t$ after acquisition, $m_{i t}$ is the customer's expected profit if he or she retains the service in month $t, P_{i t}$ is the penalty (in $€$ ) the customer has to pay when he or she terminates the contract in month $\mathrm{t}$ (zero during a trial and from month 12 onward), $A C_{i}$ are the customer's acquisition costs, and $d$ is the monthly discount factor $(.0125$, which corresponds to an annual rate of $15 \%$, see Kumar et al. 2008; Reinartz and Kumar 2003; Venkatesan and Kumar 2004).

Notice that the survival probability $S_{\text {it }}$ in month $t$ is based on the customer's retention decisions in the preceding months: $\mathrm{S}_{\mathrm{it}}=\operatorname{Prob}\left(\mathrm{r}_{\mathrm{i}, 0}, \ldots, \mathrm{r}_{\mathrm{i}, \mathrm{t}-1}=1\right)$. Furthermore, the expected margin $m_{i t}$ in a given month equals the revenue generated by the customer, less the costs to retain the customer (Reinartz, Thomas, and Kumar 2005):

$$
\mathrm{m}_{\mathrm{it}}=\underbrace{\mathrm{Fee}_{\mathrm{it}}^{\mathrm{sub}}+\overline{\mathrm{Fee}^{\mathrm{PPU}}} \times \mathrm{UsagePPU}_{\mathrm{it}}}_{\text {Revenue }}-\underbrace{\mathrm{DM}_{\mathrm{it}} \times \overline{\text { Costs }^{\mathrm{DM}}}-\overline{\text { Costs }^{\mathrm{Adv}}}}_{\text {Costs }},
$$

where Fee $_{i t}^{\text {sub }}$ is the monthly subscription fee of $€ 15.95$ that customer $i$ has to pay in month $t$ (zero during a free-trial period), $\overline{\text { Fee }^{\mathrm{PPU}}}$ is the per-unit fee for the pay-per-use service (set to $€ 3$ throughout the simulation period), UsagePPU $U_{\text {it }}$ refers to the customer's expected consumption amount (in units) of the pay-per-use service in month $t, \mathrm{DM}_{\mathrm{it}}$ is the number of direct marketing contacts with the customer in month $t, \overline{\operatorname{Costs}^{\mathrm{DM}}}$ is the average cost for a single marketing contact, and $\overline{\operatorname{Costs}^{\mathrm{Adv}}}$ is the average monthly advertising cost.

To determine $\mathrm{AC}_{\mathrm{i}}, \overline{\text { Costs }^{\mathrm{DM}}}$, and $\overline{\text { Costs }^{\mathrm{Adv}}}$, we need to allocate the observed marketing efforts between acquisition and retention (Gupta, Lehmann, and Stuart 2004). Because we observe consumer-specific direct marketing efforts before and after the acquisition of a given customer, we can readily compute the direct marketing (acquisition and retention) costs for that customer by multiplying the relevant number of direct marketing contacts by the average 
delivery cost of $€ 0.37 .{ }^{14}$ Notice that the average observed monthly number of marketing contacts for customer acquisition is .62 for free-trial, and .26 for regular customers. The company uses direct marketing less often for customer retention: once acquired, free-trial and regular customers are contacted on average .34 and .16 times per month, respectively. In line with Gupta, Lehmann, and Stuart (2004), we use these average retention efforts when simulating future behavior beyond our observation period.

We also need to split the expenditures on mass advertising into retention and acquisition costs. We allocate the monthly total advertising budget to retention and acquisition proportionally to the numbers of iTV adopters and non-adopters in the company's total customer base (see Gupta, Lehmann, and Stuart 2004). On average, the company spends $€ 169.61$ on advertising to acquire a new customer. ${ }^{15}$ This number is close to the US\$181.8 reported in Libai, Muller, and Peres (2009) for another telecommunication provider in the same geographical region. The monthly advertising cost for retaining a customer is $€ 0.51$, and thus substantially lower than the acquisition cost (Thomas 2001). ${ }^{16}$

Other fixed costs are not directly related to the number of customers or their usage intensity (e.g., the network infrastructure which is owned by the company), or are zero (e.g., the marginal reproduction cost of a video-on-demand), and hence can be ignored in the computation of Net CLV.

\footnotetext{
${ }^{14}$ The number of iTV customers was small relative to the company's entire customer base, so that we can safely assume that the already existing service employees handled iTV customers as well. As a result, direct marketing costs correspond to the actual delivery costs of the messages. There are three media for direct marketing in our data set: postal mail, outbound calls, and e-mail. We take actual postal fees of the National Post in 2004 ( $€ 0.44$ for non-priority delivery), contact time of the average phone call (6.39 minutes for non-technical inquiries; Sun and Li 2011) multiplied by the per-minute call fee of the national carrier in 2004 ( $€ 0.051)$, and a nominal amount of $€ 0.01$ to reflect the small delivery costs of emails (Danaher and Dagger 2013). Finally, we weigh the delivery costs by the relative occurrence of the respective media in the data set and arrive at an average direct marketing cost of $€ 0.37$ per contact.

${ }^{15}$ We compute the quarterly share of iTV adopters versus all potential adopters (i.e., all customers with a fixed telephone line), and use these weights to allocate mass advertising spending to acquisition and retention. On average, the company spends $98 \%$ of their mass advertising budget to acquire new customers. In total, $€ 18.7 \mathrm{~m}$ spent on acquiring 110,000 customers (leading to acquisition costs of $€ 169.61$ per person). The company spends $€ 800,000$ on customer retention.

${ }^{16}$ We divide advertising spending on retention ( $€ 800,000$, see Footnote 15$)$ by the total number of customers retained in every month during the observation period. Similarly, Thomas (2001) reports retention costs (US\$2.15) that are substantially lower than the acquisition costs (US\$26.94).
} 


\section{Chapter 3}

\section{Usage Rates, Facebook Likes, and Online Piracy: Using Big Data to Manage Entertainment Products*}

\subsection{Introduction}

Global consumer spending on entertainment goods (e.g., video games, home videos, music albums) surpassed US $\$ 240$ billion in 2012 and appears poised to grow even further. The main driver of the industry's growth is the increasing offer of digitized content, for which the current market share of $35 \%$ is expected to rise to $47 \%$ in 2017 (PricewaterhouseCoopers 2013b). However, two main challenges related to the ongoing digitization create concern about companies' prospects for continued revenue growth (PricewaterhouseCoopers 2013a). First, digitization has cluttered the market, such that it is both dominated by a few popular names and flooded by numerous small players who use digital channels to reach their audiences directly (Bhattacharjee et al. 2011). Marketing instruments that should help brands (e.g., music artists) to get noticed in this competitive landscape are losing effectiveness, making managers look for ideas to boost the "bang for their marketing buck" (Sethuraman, Tellis, and Briesch 2011). Second, digitization facilitates online piracy, a serious threat to the entertainment

\footnotetext{
* The article presented in this chapter is based on Hannes Datta, Bram Foubert, and Dominik Papies (2013), "Usage Rates, Facebook Likes, and Online Piracy: Using Big Data to Manage Entertainment Products." The authors are grateful to Harald J. van Heerde for his excellent feedback. Further, they acknowledge Aurélie Lemmens and Johannes Boegershausen for helpful comments and suggestions. They thank Musicmetric, Last.fm, and Musicbrainz for generously providing access to the data used in this study. This work was carried out on the Dutch national einfrastructure with the support of the SURF Foundation.
} 
industry (Liebowitz 2008). For example, an estimated $63 \%$ of music acquired by U.S. consumers in 2009 was not paid for (RIAA 2013). As a result, managers seek new strategies to curb the effects of unauthorized sharing.

Simultaneously, digitization in the entertainment industry offers new opportunities. As smart devices gain popularity, consumers increasingly leave digital footprints that reveal how they engage with brands after purchase (Belk 2013). Recent research emphasizes the implications of these engagement behaviors for the generation of firm value (e.g., Van Doorn et al. 2010; Verhoef, Reinartz, and Krafft 2010). Two particular types of brand engagement that prior to the big data era were largely unobservable are becoming visible to firms: First, consumer brand usage ( $\mathrm{CBU}$ ) refers to the actual consumption of a given brand (e.g., listening to an artist's music) and can be assessed on the basis of consumers' digital usage rates (e.g., song plays). Second, consumer brand endorsement (CBE) reflects public approval or support of consumers (e.g., openly idolizing an artist) and can be measured by consumers' expressions of appreciation in public fora (e.g., an artist's Facebook Likes). The availability of CBU and CBE information is particularly critical in the entertainment industry, where products continue being consumed and buzzed about long after they are sold, and sales do not reliably reflect current brand engagement. A consumer base with high CBU and CBE levels may be highly receptive to a brand's marketing efforts, so companies could enhance their marketing effectiveness by accounting for engagement levels when allocating their marketing budget across brands. Information on $\mathrm{CBU}$ and $\mathrm{CBE}$ also can shed light on the implications of piracy: If piracy leads to a more engaged consumer base, it might generate new sales, which would partly offset its cannibalization effect.

Against this background, we develop a conceptual framework to study the consequences of $C B U$ and $C B E$ for the impact of marketing activities and piracy. Because CBU and $C B E$ differ fundamentally in their nature and purpose, it is essential to distinguish between them. CBE enables consumers to connect themselves publicly to a brand and therefore hinges on social cues (e.g., Aaker 1999; Hollenbeck and Kaikati 2012). In contrast, CBU refers to the, typically private, consumption of a brand's products and is therefore less prone to social influence. As a result, CBU and CBE may reflect consumers' preferences differently (Ratner and Kahn 2002). We investigate how these two distinct brand engagement behaviors moderate the sales impact of marketing activities, such as promotion or new product releases, as well as how they mediate the relationship between piracy and sales. 
We apply our framework to the U.S. music industry and build a system of equations to model the interrelationships among an artist's weekly album sales, CBU and CBE, marketing efforts, and piracy. We calibrate our model with rank data from Billboard album charts (sales), aggregate play counts (CBU), Facebook Likes (CBE), radio promotion and album releases (marketing), and illegal downloads (piracy) for 569 artists over 66 weeks. To construct these variables, we develop code (in Python and R) that crawls websites, accesses online databases using Application Protocol Interfaces (APIs), and extracts manageable data sets from the terabytes of relevant data. The results show that CBU and CBE not only enhance marketing effectiveness but also positively mediate the impact of piracy, offsetting its cannibalization effect by $55 \%$. Interestingly, CBU exerts a substantially greater influence in these relationships than $\mathrm{CBE}$. Against the social media hype, this finding corroborates the growing awareness among managers that CBE may not be the best criterion for marketing investment decisions (e.g., The Economist 2011a).

In what follows, we first explain how our research contributes to the extant literature. Next, we introduce our conceptual framework and develop hypotheses. We then outline our data and model, present the estimation results, and illustrate the relevance of our findings with simulations. Finally, we discuss the academic and managerial implications of our work and point out some limitations and directions for further research.

\subsection{Contribution to the Literature}

Fueled by the explosion of detailed consumer data, growing interest has focused on the role of brand engagement, which refers to the behaviors of consumers towards a brand beyond purchase (e.g., Van Doorn et al. 2010; Verhoef, Reinartz, and Krafft 2010). According to extant research, consumers' brand usage drives perceived value and, as a result, increases retention rates and sales performance (e.g., Bolton and Lemon 1999; Iyengar, Ansari, and Gupta 2007). However, we know little about brand endorsement, or consumers' public expression of liking for a brand (e.g., Hennig-Thurau et al. 2010; Onishi and Manchanda 2012; Stephen and Galak 2012). Research has identified the motivations underlying brand endorsement; for example, Hollenbeck and Kaikati (2012) show that consumers endorse brands (e.g., through Facebook Likes) to express their ideal rather than actual selves. Similarly, Ratner and Kahn (2002) show that consumers who express an opinion in public may deviate from their true opinions in order to be evaluated positively by others. However, these studies do not spell out how brand 
endorsement interferes in the sales generation process or how its role differs from that of brand usage. Brand usage arguably offers a more authentic reflection of consumers' preferences, because it is less prone to social pressure (Ratner and Kahn 2002). Therefore, as a first contribution, we use brand engagement behaviors that are becoming increasingly observable by tracking consumer behavior on smart devices and social media platforms to explicitly quantify and compare the effects of CBU and CBE on a brand's sales performance.

Furthermore, we examine how $\mathrm{CBU}$ and $\mathrm{CBE}$ moderate the impact of marketing activities. Existing research has documented the importance of marketing activities like promotions and new product releases, but ignores the role of brand engagement (e.g., Lee, Boatwright, and Kamakura 2003; Luan and Sudhir 2010). However, marketing actions may be more effective when they fall on the fertile ground of an engaged consumer base. Specifically, we investigate how $\mathrm{CBU}$ and $\mathrm{CBE}$ influence the effectiveness of new product introductions and promotion. Indeed, because brands in the entertainment industry typically earn most of their revenue shortly after the release of a new product, managing new product introductions (e.g., new music albums) is crucial (Luan and Sudhir 2010). Other research underscores the importance of promotion and shows that promoting music albums through radio airplay increases album sales (Lee, Boatwright, and Kamakura 2003). If CBU and CBE indeed moderate the sales impact of new product releases and promotion, then managers can use these engagement measures to improve the allocation of their marketing budget.

By studying $\mathrm{CBU}$ and $\mathrm{CBE}$, we also contribute to the ongoing debate about the impact of piracy on sales of entertainment products (e.g., Bhattacharjee et al. 2007; Liebowitz 2008; Oberholzer-Gee and Strumpf 2007). No studies to date have investigated whether piracy solely cannibalizes legal sales or also encourages $\mathrm{CBU}$ and $\mathrm{CBE}$, and thereby triggers an indirect, positive sales effect. Extant piracy literature often speculates about such positive mediation effects but has not provided empirical evidence of their existence (Gopal, Bhattacharjee, and Sanders 2006; Peitz and Waelbroeck 2006). By explicitly investigating the impact of piracy on $\mathrm{CBU}$ and $\mathrm{CBE}$, we are the first to test the existence and assess the relative size of the CBU- and CBE-mediated effects of piracy. If these effects exist, and, as argued before, $C B U$ and $C B E$ interact with marketing instruments, marketers may be able to reduce the detrimental impact of piracy. Specifically, they can enhance their marketing efforts to reinforce the positive mediation effects. 
Finally, considering the pivotal role of $\mathrm{CBU}$ and $\mathrm{CBE}$, it is vital to understand how they can be managed. Therefore, we examine how marketing activities drive CBU and CBE. Previous research has considered antecedents of usage that are, at least to some degree, under managerial control, such as price level and price structure (Ascarza, Lambrecht, and Vilcassim 2012; Danaher 2002), customer satisfaction (Bolton and Lemon 1999), and adoption timing in the product life cycle (Prins, Verhoef, and Franses 2009). Other studies investigate how marketing communication drives consumers' public product or service evaluations on blogs and fora (e.g., Onishi and Manchanda 2012; Stephen and Galak 2012). To the best of our knowledge though, no research has assessed or compared the effects of promotion and new product launch on CBU and CBE. Another reason to study how managers can mold CBU and $\mathrm{CBE}$ is that these measures increasingly serve as focal business metrics. For example, $\mathrm{CBU}$ determines the royalties paid for music on streaming services such as Pandora or Spotify, and CBE often serves as a measure to evaluate the popularity of ad campaigns.

In summary, $\mathrm{CBU}$ and $\mathrm{CBE}$ are forms of engagement that are becoming increasingly observable on smart devices and social media platforms. We use these data to assess (1) the direct effects of $C B U$ and $C B E$ on brand sales, (2) the moderating impact of $C B U$ and $C B E$ on the sales effects of promotion and new product launch, (3) the extent to which CBU and CBE positively mediate the impact of piracy, and (4) the effects of promotion and new product launch on CBU and $\mathrm{CBE}$. In all four relationships, we explicitly compare the roles of $\mathrm{CBU}$ and $\mathrm{CBE}$.

\subsection{Conceptual Framework and Hypotheses}

Figure 3.1 presents the conceptual framework for our research. Central to our framework are $\mathrm{CBU}$ and $\mathrm{CBE}$, and their relationships with marketing, piracy, and brand sales. We develop hypotheses with regard to the direction of these relationships and the differences in magnitude of effects between CBU and CBE. To facilitate the comparison of effects, we use elasticities, which are independent of the variables' measurement units.

The relationships indicated by the thin arrows in Figure 3.1 are not the subject of formal hypotheses, because they follow from previous work. For example, we expect marketing activities to have a positive effect, and piracy to have a negative effect on sales (e.g., Liebowitz 2008). Also, we include feedback effects from sales to CBU and CBE: Increased sales should lead to a wider availability of the brand's products and enhance the opportunity for consumers to engage with it. 
Figure 3.1: Conceptual framework

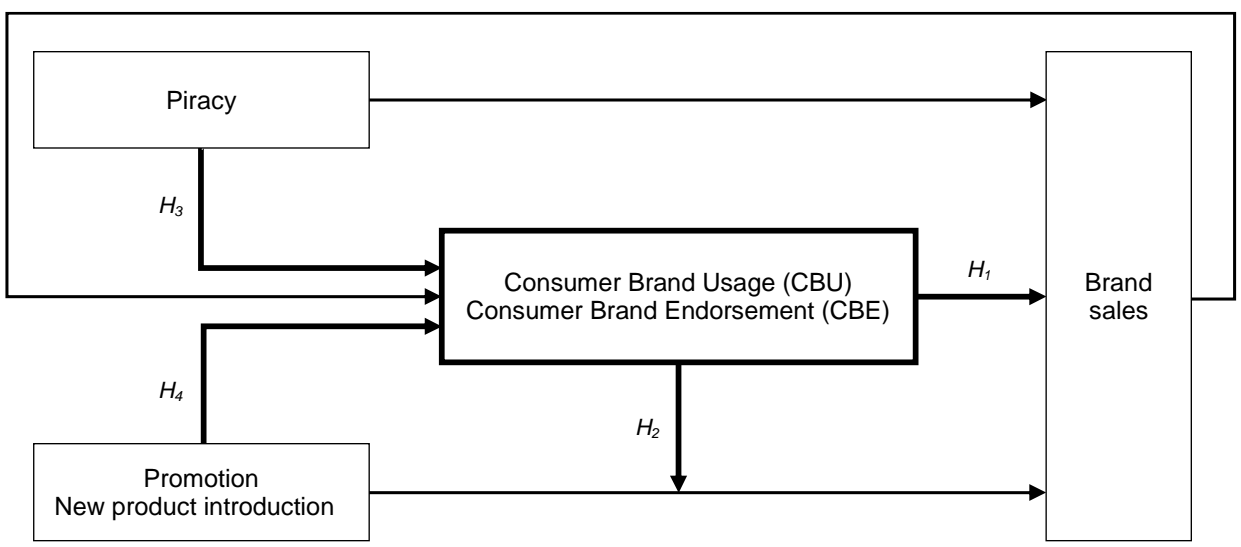

\subsubsection{Effects of CBU and CBE on Brand Sales}

The key to understanding why $\mathrm{CBU}$ and $\mathrm{CBE}$ generate future sales is the role that consumer engagement plays in expanding consumers' brand relationships (e.g., Van Doorn et al. 2010). Engagement requires consumer-brand interactions, whether through consumption (use of the brand's products) or communication (e.g., endorsement). During these interactions, consumers establish cognitive and emotional connections with the brand (Park et al. 2010). Especially in a hedonic context, such as the entertainment industry, these connections even may become profound (Hirschman and Holbrook 1982) and lead consumers to grow attached to the brand (Park et al. 2010). Because brand attachment increases consumers' willingness to pay (Thomson, MacInnis, and Park 2005), highly engaged consumers likely buy more of the brand's products (e.g., additional albums by a favored artist). Consequently, we expect $C B U$ and $C B E$, which are common forms of consumer engagement, to drive brand sales.

However, their effects on sales likely differ. First, compared with $\mathrm{CBE}, \mathrm{CBU}$ involves consumer-brand interactions that require more time, effort, and attention (Belk 1988). In turn, CBU should generate stronger brand emotions, cognitions, and attachment (Park et al. 2010). Second, unlike CBU, CBE occurs in a public space; others observe the brands that consumers endorse (Hennig-Thurau et al. 2010). Previous research has established that consumers in public spaces deviate from an option they would privately favor, to comply with social cues, 
such as the expectations or behaviors of others (Aaker 1999; Ratner and Kahn 2002). It then follows that the brands consumers publicly endorse are not necessarily those they prefer intrinsically (Hollenbeck and Kaikati 2012). The fact that CBE is extrinsically motivated may hinder the formation of genuine brand attachment and weaken the relationship between CBE and sales (e.g., Dholakia 2006). Thus, we expect CBU to have a stronger effect on sales than CBE and hypothesize:

$\mathrm{H}_{1 \mathrm{a}} \quad \mathrm{CBU}$ and $\mathrm{CBE}$ increase brand sales.

$\mathrm{H}_{1 \mathrm{~b}} \quad \mathrm{CBU}$ has a stronger sales effect than $\mathrm{CBE}$.

\subsubsection{Effects of CBU and CBE on Marketing Effectiveness}

Beyond their direct effect on sales, $C B U$ and $C B E$ may influence consumers' responses to marketing activities (i.e., new product releases and promotions). First, a highly engaged consumer base likely devotes considerable attention to the focal brand and related marketing initiatives (Van Doorn et al. 2010). Consumers more easily process information related to their own interests (Greenwald and Leavitt 1984), so pertinent marketing activities should become more salient and yield a greater impact on sales when consumers engage with the brand. Second, strong emotions inherent to engagement behaviors may lead to a confirmation mindset, preventing the generation of counterarguments (Batra and Stayman 1990). Therefore, promotion and the buzz around new product introductions may be more persuasive among brands with engaged consumers than among brands with less devoted consumers. These arguments imply that $\mathrm{CBU}$ and $\mathrm{CBE}$ both reinforce the impact of marketing activities on sales.

However, the strength of this moderation effect should depend on the type of brand engagement. As we argued, in comparison with $\mathrm{CBE}, \mathrm{CBU}$ is more likely to align with consumers' intrinsic brand preferences, which may make consumers more susceptible to the brand's promotion efforts and new product introductions (Ratner and Kahn 2002). We hypothesize accordingly:

$\mathrm{H}_{2 a} \quad \mathrm{CBU}$ and $\mathrm{CBE}$ strengthen the sales effects of marketing activities.

$\mathrm{H}_{2 b} \quad \mathrm{CBU}$ has a more positive impact on the sales effects of marketing activities than CBE. 


\subsubsection{Effects of Piracy on CBU and CBE}

Piracy also may lead consumers to engage with a brand. All else being equal, piracy contributes to the diffusion of the brand's products, such that more consumers get to know and use the brand and publicly express their appreciation. Such increased engagement then may translate into a positive effect on brand sales. Several studies recognize this mechanism, though empirical support is lacking (e.g., Gopal, Bhattacharjee, and Sanders 2006; Peitz and Waelbroeck 2006). We already formalized our expectations with regard to the effects of CBU and $\mathrm{CBE}$ on sales in $\mathrm{H}_{1 a}$ and $\mathrm{H}_{1 \mathrm{~b}}$, so here we focus on the relationship between piracy and the two engagement behaviors.

We again expect different roles for $\mathrm{CBU}$ and $\mathrm{CBE}$. The impact of piracy on $\mathrm{CBU}$ is likely to be greater than the impact on $\mathrm{CBE}$, because access to a brand's products is a prerequisite only for CBU: Whereas CBU involves the brand's products, consumers can endorse a brand through the mere usage of its symbols, such as its name or logo (Belk 1988). Therefore,

$$
\begin{aligned}
& \mathrm{H}_{3 a} \quad \text { Piracy increases } \mathrm{CBU} \text { and } \mathrm{CBE} \text {. } \\
& \mathrm{H}_{3 \mathrm{~b}} \quad \text { Piracy has a stronger effect on } \mathrm{CBU} \text { than on CBE. }
\end{aligned}
$$

\subsubsection{Effects of Marketing Activities on CBU and CBE}

We expect that marketing activities, such as new product launches and promotions, not only boost sales but also increase CBU and CBE. New products and promotions increase a brand's salience and reactivate consumers' feelings and thoughts connected to the brand. As a result, consumers may want to engage with the brand to revive their emotional bond, obtained through previous engagement (Russell and Levy 2012). However, we argue that CBU and CBE respond differently to marketing activities. Compared with $\mathrm{CBE}, \mathrm{CBU}$ is more likely to be driven by consumers' internal belief structure, which is subject to marketing efforts (e.g., Holbrook 1978). In contrast, CBE depends more on social cues, such as the opinions of others, which may attenuate the effects of marketing (e.g., Aaker 1999; Hollenbeck and Kaikati 2012). Therefore, the impact of marketing activities should be stronger on CBU than on CBE.

$\mathrm{H}_{4 \mathrm{a}} \quad$ New product releases and promotion increase $\mathrm{CBU}$ and $\mathrm{CBE}$.

$\mathrm{H}_{4 \mathrm{~b}} \quad$ New product releases and promotion have a stronger effect on CBU than on CBE. 


\subsection{Data}

\subsubsection{Study Context}

We test our conceptual framework in the context of the U.S. music industry, which generated revenues of US $\$ 4.48$ billion in 2012 and thus constitutes an important part of the entertainment industry (Billboard 2013). Moreover, it has received substantial academic interest (e.g., Bhattacharjee et al. 2007; Dewan and Ramaprasad 2012; Elberse 2010).

The purposes of this study require us to measure consumer engagement that was largely unobservable in the past. To this end, we collected weekly data at the brand (i.e., artists) level from various websites and online databases using SQL, web scraping, and APIs. Unlike web scraping, which extracts semi-structured data from websites, APIs offer direct access to a company's databases using standardized and authenticated web requests (Toubia and Stephen 2013). We collected these data for the period January 2012-May 2013.

\subsubsection{Data Collection}

Sales rank data. To measure sales in the United States, we obtain weekly chart placements for all 979 popular music artists that appeared on the Billboard 200 album charts in $2012 .{ }^{17}$ Billboard reports weekly ranks of the 200 best-selling albums and EPs, according to physical and digital sales numbers collected by Nielsen SoundScan (e.g., Bhattacharjee et al. 2007; Elberse 2010). Sales rank data has been used widely in extant research, relates strongly to actual sales (e.g., Chevalier and Goolsbee 2003; Chevalier and Mayzlin 2006), and are particularly useful when actual sales data are hard or too expensive to obtain, such as when thousands of observations are required on many brands over a long period (e.g., Chevalier and Mayzlin 2006; Danaher et al. 2010; Dewan and Ramaprasad 2012). We programmed a web scraper to collect the charts data from the Ultimate Music Database (umdmusic.com), a website that has been gathering historical charts starting in $1989 .^{18}$

\footnotetext{
17 This selection from among best-selling albums may suggest a focus on successful artists only, but it actually features many new artists too: $33 \%$ of the artists in our sample never appeared on the Billboard album charts between 1991 (the first year of observations available) and the beginning of our calibration period.

${ }^{18}$ Although the sales rank data are censored, we capture substantial album sales, because the vast majority of sales can be accounted for by the top chart positions (i.e., top 200; see Bhattacharjee et al. 2007). In rare cases in which an artist has multiple albums on the charts at the same time, we integrate their chart positions, relying on a linear sales-to-rank transformation rule.
} 
Consumer brand usage (CBU). Whereas previously $\mathrm{CBU}$ has been hard to track, digital footprints left by consumers using smart devices and online services make this type of engagement visible. We gathered data on the artists' weekly number of song plays from Last.fm, a popular music website (e.g., Garg, Smith, and Telang 2011; Goldenberg, Oestreicher-Singer, and Reichman 2012; Oestreicher-Singer and Zalmanson 2013). At the core of Last.fm's service is a small piece of software that runs on virtually any device or music player and automatically tracks the listening behavior of Last.fm's 40 million users. Consumers can use this software, for example, to view recently played tracks or receive information on artists. Importantly, it also registers consumers' listening behavior on computers (e.g., through Windows Media Player) or mobile devices (e.g., smart phone, mobile MP3 player), irrespective of the music's origin (i.e., downloaded online or ripped from a $C D$, legal or illegal). Computers or devices do not require a constant Internet connection to record song plays but instead can submit in batches when a connection becomes available. In 2011, Last.fm tracked 11 billion plays (Last.fm 2011).

We used the service's API (see lastfm.com/api) to extract data on the weekly listening behavior of close to 9,000 randomly chosen, U.S.-based Last.fm users and linked this information to the artists in our data set. Although Last.fm attracts users who exhibit more average daily music consumption than the general population, the relative song play frequencies for artists in a given music genre should be generally representative of music consumption in the United States. ${ }^{19}$ Thus, digital song play frequencies are used by leading music rights management organizations to determine royalties and by market research firms to compile popularity charts.

Consumer brand endorsement (CBE). We used the weekly number of incremental Likes on an artist's Facebook page to measure CBE (Dhar and Chang 2009). Consumers can endorse an artist by clicking the Like button on the artist's Facebook page (Hollenbeck and Kaikati 2012). The artist's name then appears on these consumers' personal Facebook pages and contributes to their online profile (Belk 2013). Using an API, we extracted Likes data from the database of Musicmetric (see developer.musicmetric.com), a marketing research company that tracks

\footnotetext{
${ }^{19}$ Average daily music consumption is 1.5 hours for Last.fm users (assuming a song length of 4 minutes, Twardos 2011) but only .5 hours for the average U.S. citizen (self-reported, see Veronis Suhler Stevenson 2010). The difference is not surprising; Last.fm's user base consists of consumers interested in listening to music, whereas the U.S. average also includes consumers who do not listen to music at all.
} 
various online measures in the music industry. Because Facebook does not disclose Likes at the country level, our CBE metric is a global measure.

Piracy. To quantify piracy, we used the weekly number of illegal music downloads through the BitTorrent file sharing protocol (Danaher et al. 2010), which is currently the most widely used system for distributing data over the Internet, accounting for $62 \%$ of total file sharing activity in the Americas and Canada (Palo Alto Networks 2013). Most research on the impact of piracy uses downloading behavior by small samples (e.g., a limited number of file sharers, Oberholzer-Gee and Strumpf 2007; or limited longitudinal coverage, Bhattacharjee et al. 2007) or relies on proxies (e.g., Internet penetration rate; Liebowitz 2008). Yet advances in tracking and storage technologies enable firms to monitor the entire BitTorrent network, so it is possible to obtain accurate information on artist-specific numbers of illegal downloads in the United States. Musicmetric collects these data using proprietary scraping technology, and we extract the data using their API.

Marketing activities. We investigate two types of marketing activities: promotion and new album releases. Because record labels deem radio airplay vital and pay radio stations to increase the exposure of their artists, it is the key measure to stimulate demand (Lee, Boatwright, and Kamakura 2003; Nielsen 2012). We measure an artist's promotional intensity by radio airplay rank, using the artist's position in the weekly top 200 of most popular songs, ranked by radio airplay counts at 305 U.S. radio stations. ${ }^{20}$ We used web scraping technology to collect these data from charly1300.com, a website that provides U.S. airplay charts starting in 2008. Next, we collected data on artists' album releases from the MusicBrainz database (MusicBrainz.org) and Ultimate Music Database (umdmusic.com), two large databases of information about the music industry. Finally, we used various online databases (see Table 3.2) to obtain auxiliary information (e.g., genres, record labels).

\subsubsection{Sample Description}

We dropped all artists for which we did not have at least six consecutive months of observations, due to missing or inaccurate data about CBU, CBE, piracy, or marketing. This step reduced the number of artists to 569; for each artist on average, we had 66 weeks of complete data.

\footnotetext{
${ }^{20}$ In line with our sales rank metric, we combined airplay ranks in the few cases in which an artist appeared multiple times in the airplay charts.
} 
Artists appearing in the album charts ranked, on average, in position 86 . Of the 569 artists, 286 artists (50\%) made it to the top 40. An average artist was listened to 66 times per week for every 1,000 users of Last.fm and received about 23,000 new Facebook Likes per week. Every week on average, 9 artists $(.016 \times 569$ artists) released a new album. They appear on the radio airplay charts for $17 \%$ of the weeks in our sample, in position 82 on average. The piracy data reveal substantial illegal downloading activity. On a weekly basis, a given artist's products are downloaded an average of 2,640 times. We provide the correlations among our dependent and independent variables in Table 3.1, and report descriptive statistics in Table 3.2.

Table 3.1: Correlations among the dependent and independent variables

\begin{tabular}{|c|c|c|c|c|c|c|c|c|c|c|}
\hline & & 1 & 2 & 3 & 4 & 5 & 6 & 7 & 8 & 9 \\
\hline 1. & Sales rank & & & & & & & & & \\
\hline 2. & Consumer brand usage (CBU) & 0.26 & & & & & & & & \\
\hline 3. & Consumer brand endorsement (CBE) & 0.25 & 0.29 & & & & & & & \\
\hline 4. & New product introduction & 0.19 & 0.11 & 0.02 & & & & & & \\
\hline 5. & Promotion & 0.22 & 0.18 & 0.33 & 0.02 & & & & & \\
\hline 6. & Piracy & 0.23 & 0.34 & 0.51 & 0.05 & 0.37 & & & & \\
\hline 7. & Major label & 0.01 & 0.14 & 0.14 & 0.01 & 0.05 & 0.14 & & & \\
\hline 8. & Superstar & 0.05 & 0.11 & 0.22 & 0.00 & 0.02 & 0.12 & 0.20 & & \\
\hline 9. & Release of a new single & 0.03 & 0.08 & 0.07 & 0.05 & 0.06 & 0.14 & 0.05 & 0.02 & \\
\hline 10. & Weeks since last album release & -0.05 & -0.08 & -0.07 & 0.02 & -0.04 & -0.05 & -0.04 & 0.03 & -0.01 \\
\hline
\end{tabular}




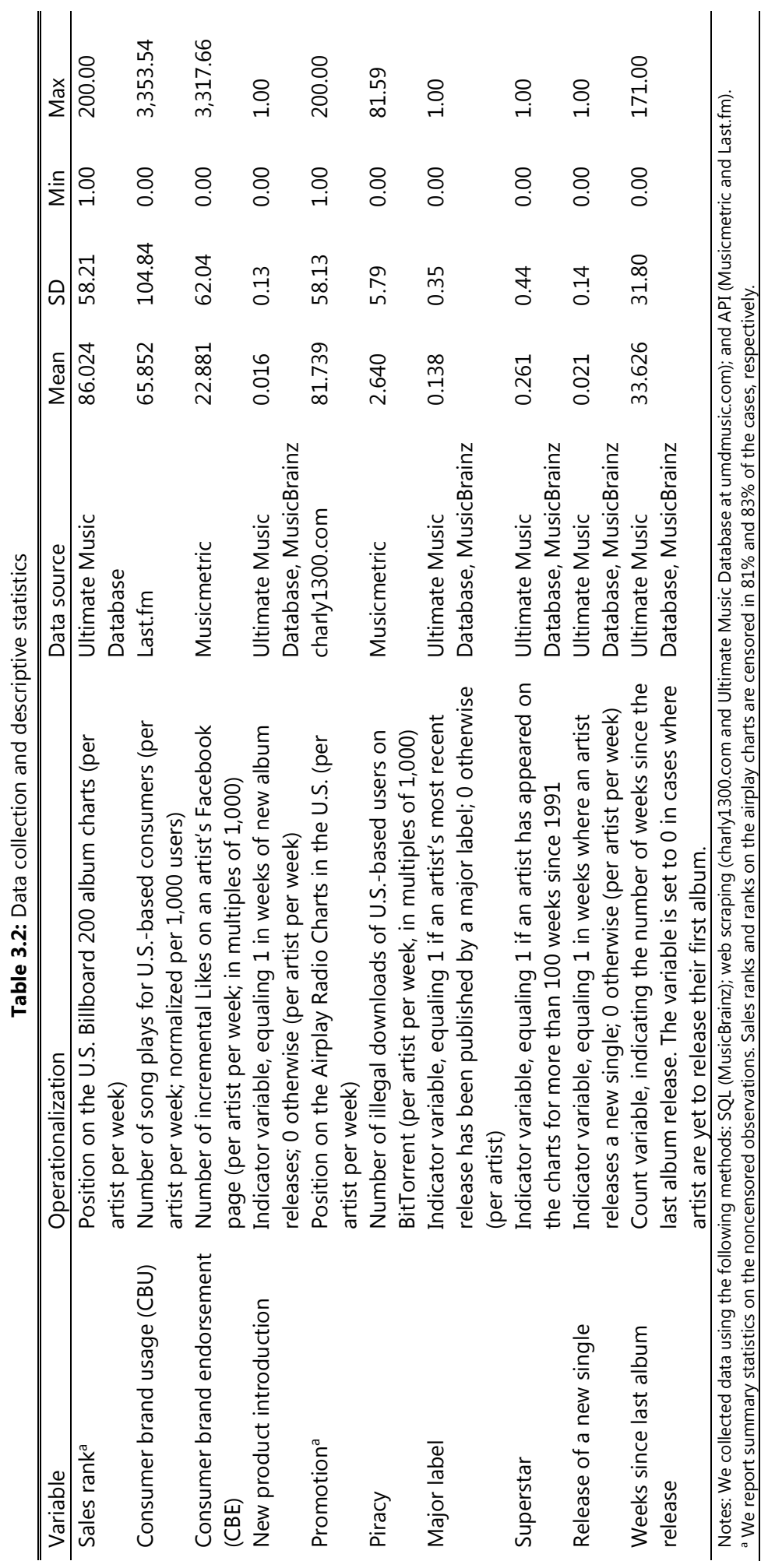




\subsection{Model}

To test the hypothesized relationships, we build a system of three interdependent equations for sales ranks, $\mathrm{CBU}$, and $\mathrm{CBE}$.

\subsubsection{Sales Ranks}

In line with extant research that models sales using rank data, we opt for a log-log regression structure (e.g., Chevalier and Mayzlin 2006; Ghose and Sundararajan 2006). ${ }^{21}$ In these models, the coefficients (of non-dummy variables) represent elasticities, which facilitates the comparison of effects across independent variables. Moreover, a log-log regression model accounts for the distribution of the underlying sales data: The difference in sales for artists ranked at the top of the charts (e.g., position 1 versus 2 ) is much greater than the difference in sales for low-selling artists (e.g., position 199 versus 200, Chevalier and Goolsbee 2003).

Because any rank below 200 remains unobserved in the chart data, we specify a Tobit 1 model that accounts for censoring if the artist's sales rank is greater than 200. In the noncensored case, we use the following expression:

(1) InSalesRank $_{i t}=\alpha_{0 \mathrm{i}}+\alpha_{1}$ Album $_{\mathrm{it}}+\alpha_{2} \ln _{\text {Promotion }}$ it $+\alpha_{3} \operatorname{lnCBU} \mathrm{U}_{\mathrm{i}, \mathrm{t}-1}+\alpha_{4} \operatorname{lnCBE} E_{\mathrm{i}, \mathrm{t}-1}+$

$$
\begin{aligned}
& \alpha_{5} \text { Album }_{i t} \times \operatorname{lnCBU}_{\mathrm{i}, \mathrm{t}-1}+\alpha_{6} \text { Album }_{\mathrm{it}} \times \operatorname{lnCBE_{i,t-1}+} \\
& \alpha_{7} \ln \text { Promotion }_{\text {it }} \times \operatorname{InCBU}_{\mathrm{i}, \mathrm{t}-1}+\alpha_{8} \ln \text { Promotion }_{\mathrm{it}} \times \operatorname{InCBE}_{\mathrm{i}, \mathrm{t}-1}+ \\
& \alpha_{9} \ln \text { SalesRank }_{i, t-1}+\alpha_{10} \ln \text { Piracy }_{i t}+\alpha_{11}{ }^{\prime} X_{i t}+\varepsilon_{i t,}
\end{aligned}
$$

where InSalesRank $k_{\text {it }}$ represents the natural logarithm of the sales rank of artist $\mathrm{i}$ in week $\mathrm{t}$. We

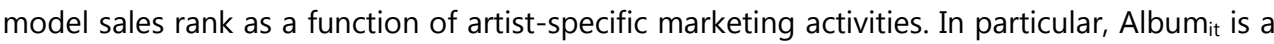
dummy variable equaling 1 when artist i releases a new album in week t ( 0 otherwise); InPromotion ${ }_{i t}$ refers to (the natural logarithm of) the artist's radio airplay chart rank in week $\mathrm{t}^{22}$ We include lagged values for consumer brand usage ( $\operatorname{lnCBU}_{i, t-1}$, number of song plays for the

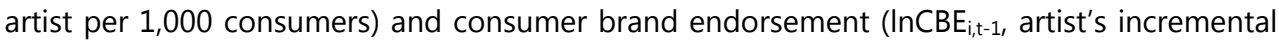
number of Facebook Likes, in multiples of 1,000 ) to test the effect of consumer engagement on sales of the artist's album portfolio $\left(\mathrm{H}_{1 \mathrm{a}}\right.$ and $\left.\mathrm{H}_{1 b}\right)$. To test the moderating impact of $\mathrm{CBU}$ and $\mathrm{CBE}$ on the relationship between marketing and sales $\left(\mathrm{H}_{2 \mathrm{a}}\right.$ and $\left.\mathrm{H}_{2 \mathrm{~b}}\right)$, we let $\ln C B \mathrm{U}_{\mathrm{i}, t-1}$ and $\operatorname{lnCBE} \mathrm{E}_{\mathrm{i},-1}$

\footnotetext{
${ }^{21}$ We also estimated a linear model, leading to similar conclusions about the role of CBU and CBE.

22 We replaced all censored observations by $200+1$, because artists that do not appear in the airplay charts are promoted to similar (i.e., limited) extents.
} 
(grand-mean centered) interact with the marketing variables. The coefficients of the interaction terms should be interpreted as changes in the effect of the marketing variable (e.g., changes in promotion elasticity) as a result of a $1 \%$ increase in CBU or CBE. To capture the cannibalization effect of piracy, we add InPiracy $\mathrm{it}_{\text {, }}$ which represents (the natural logarithm of) the number of illegal music downloads for the given artist in the United States. Next, $X_{i t}$ is a vector of artist- and time-specific control variables; the lagged dependent variable InSalesRank $k_{i, t-1}$ allows for carryover effects (Elberse 2010). ${ }^{23}$ Finally, $\varepsilon_{i t}$ is a normally distributed error term.

\subsubsection{Consumer Brand Usage (CBU) and Consumer Brand Endorsement (CBE)}

In line with Equation 1, we model CBU and CBE with log-log regressions:

(2) $\operatorname{lnCBU} U_{\text {it }}=$

$$
\begin{aligned}
& \beta_{0 i}+\beta_{1} \text { Album }_{i t}+\beta_{2} \ln \text { Promotion }_{i t}+\beta_{3} \operatorname{lnCBU} U_{i, t-1}+\beta_{4} \operatorname{lnCBE}_{i, t-1}+ \\
& \beta_{5} \ln \text { SalesRank }_{i, t-1}+\beta_{6} \ln \text { Piracy }_{i, t-1}+\beta_{7} Z_{i t}+U_{i t} \text { and }
\end{aligned}
$$

(3) $\ln \mathrm{CBE}_{\text {it }}=$

$$
\begin{aligned}
& \gamma_{0 i}+\gamma_{1} \text { Album }_{i t}+\gamma_{2} \ln \text { Promotion }_{i t}+\gamma_{3} \ln C B U_{i, t-1}+\gamma_{4} \operatorname{lnCBE}_{i, t-1}+ \\
& \gamma_{5} \ln \text { InalesRank }_{i, t-1}+\gamma_{6} \ln \text { Piracy }_{i, t-1}+\gamma_{7}{ }^{\prime} Z_{i t}+\xi_{i t} .
\end{aligned}
$$

Both $\mathrm{CBU}$ and $\mathrm{CBE}$ for artist $\mathrm{i}$ in week $\mathrm{t}$ can be influenced by the release of new albums (Album $\mathrm{it}_{\mathrm{t}}$ ) and the intensity of radio promotion (InPromotion ${ }_{i t}$ ). With the coefficients of these variables, we test $\mathrm{H}_{4 a}$ and $\mathrm{H}_{4 \mathrm{~b}}$. We add $\operatorname{lnCBU}_{\mathrm{i}, \mathrm{t}-1}$ and $\operatorname{lnCBE}_{\mathrm{i}, \mathrm{t}-1}$ such that changes in usage and endorsement in one period may carry over to the next periods, and the two types of engagement behaviors may reinforce each other (e.g., actual consumption leads consumers to publicly endorse the artist). Furthermore, we include lagged legal sales (InSalesRank $k_{i, t-1}$ ) and illegal downloads in the past period (InPiracyi,t-1): When more people have obtained (legal or illegal) access to an artist's music, usage and endorsement for this artist increase. The coefficients of InPiracyit,-1 enable us to test $\mathrm{H}_{3 a}$ and $\mathrm{H}_{3 \mathrm{~b}}$. Finally, $\mathrm{Z}_{\mathrm{it}}$ refers to artist- and timespecific control variables, and $U_{i t}$ and $\xi_{i t}$ are normally distributed error terms.

\subsubsection{Artist Heterogeneity, Error Correlation, and Endogeneity}

We include unobserved artist heterogeneity by modeling the intercepts of the equations as normally distributed across artists. We do not explicitly account for slope heterogeneity, because estimated coefficients represent the effects relative to artist-specific baselines, due to

\footnotetext{
${ }^{23}$ In cases where SalesRank $k_{i,-1}$ is censored (i.e., sales rank > 200), we set this variable to $200+1$, consistent with the notion that artists not appearing in the charts have similarly low sales levels.
} 
the multiplicative structure of our models. Because an artist's popularity may drive sales, $C B U$, and $\mathrm{CBE}$, we estimate the correlations between their intercepts. Furthermore, we accommodate contemporaneous correlation between the error terms of the sales rank, $\mathrm{CBU}$, and $\mathrm{CBE}$ equations, to allow for unobserved common shocks over time.

To account for the possible endogeneity of promotion and piracy but also avoid the (notoriously difficult) task of finding appropriate instrumental variables, we rely on an instrument-free method, which has recently been shown to perform very well (Park and Gupta 2012). In particular, we use Gaussian copulas to model the correlation between the endogenous explanatory variables and the error term of the sales equation. In line with Park and Gupta (2012), we add two regressors to Equation 1, Piracy ${ }^{*}{ }_{\text {it }}$ and Promotion ${ }^{*}$ it:

(4) Piracy $^{*}$ it $\quad=\Phi^{-1}\left(H_{\text {Piracy }}\left(\right.\right.$ InPiracy $\left.\left.y_{i t}\right)\right)$, and

Promotion $_{i \mathrm{it}}^{*}=\Phi^{-1}\left(\mathrm{H}_{\text {Promotion }}\left(\right.\right.$ InPromotion $\left.\left._{\mathrm{it}}\right)\right)$,

where $\Phi^{-1}$ is the inverse of the normal cumulative distribution function, and $H_{\text {piracy }}(\cdot)$ and $\mathrm{H}_{\text {promotion }}(\cdot)$ are the empirical distribution functions of InPiracy ${ }_{\text {it }}$ and InPromotion ${ }_{\text {it, }}$, respectively. ${ }^{24}$ For identification, the regressors InPiracyit and InPromotion ${ }_{\text {it }}$ must be non-normally distributed, which a Shapiro-Wilk test confirms $\left(\mathrm{W}_{\text {Piracy }}=.9926, p<.001 ; \mathrm{W}_{\text {Promotion }}=.3991, p<.001\right) .{ }^{25}$

\subsubsection{Control Variables}

To all three equations, we add MajorLabel $_{i}$, a dummy variable equaling 1 if an artist's most recent album or single release was featured by a major label. ${ }^{26}$ We add Superstar ${ }_{i}$, a dummy variable equaling 1 if an artist had appeared on the album charts for more than 100 weeks between 1991, which marks our earliest chart observations, and 2012, the start of our calibration period (Bhattacharjee et al. 2007). In addition, we use genre-specific dummy variables to accommodate fluctuations in sales, $C B U$, and $C B E$ across genres and monthspecific dummy variables to take seasonal effects into account. We add the dummy variable Single $_{\text {it }}$ to capture the impact of the release of a single on (album) sales, CBU, and CBE. Finally, in the sales rank equation, we include InTimeSinceLastRelease $e_{i t}$ measuring (the natural

\footnotetext{
${ }^{24}$ While semi-parametric methods usually require bootstrapping to obtain standard errors, we use regular standard errors which have been shown to be virtually the same (Park and Gupta 2012).

${ }^{25}$ We tested if promotion was endogenous in the CBU and CBE models; it was not (Promotion ${ }^{*}$ it was insignificant).

${ }^{26}$ In line with Bhattacharjee et al. (2007), we classify four record labels as major: Sony Music Entertainment, Warner Music Group, Universal Music Group, and EMI.
} 
logarithm of) the time since the artist's last album release to capture any remaining cross-time effects of album releases.

\subsection{Empirical Results}

We estimated the model using simulated maximum likelihood; in Table 3.3 we report the inand out-of-sample fit for sales ranks, CBU, and CBE. We use Adj. $\mathrm{R}^{2}$ and mean absolute percentage error as fit measures. To assess out-of-sample fit, we reestimated our model with a random draw of $70 \%$ of the artists and predicted sales ranks, $C B U$, and $C B E$ for the remaining 30\%. In Figure 3.2, we illustrate model fit for artist Adele. Overall, these figures suggest decent model fit.

Table 3.4 contains the parameter estimates. To facilitate interpretation of the coefficients of the rank variables InSalesRank $\mathrm{it}_{\mathrm{t}}$ and InPromotion $\mathrm{it}_{\mathrm{i}}$, we multiplied them by -1 . Because lowest ranks correspond to the highest (sales or promotional) levels, our transformation ensures that all coefficients can be interpreted intuitively as an increase in one variable (e.g., sales rank) in response to an increase of another (e.g., promotion). Furthermore, the coefficients can be directly compared, because with the exception of the dummy variables, they all represent (shifts in) elasticities. Finally, we corrected the promotion and piracy effects on sales performance for endogeneity. As Table 3.4 shows, the coefficients of the correction terms are positive and significant $\left(\alpha_{\text {Piracy }_{\mathrm{it}}^{*}}=.356\right.$ and $\left.\alpha_{\text {Promotion }_{\mathrm{it}}^{*}}=.116, p<.001\right)$, suggesting that the endogeneity correction is warranted (Park and Gupta 2012). Next, we discuss the focal relationships in our conceptual framework, then address the remaining effects and artist heterogeneity.

Table 3.3: Model fit

\begin{tabular}{lccccc}
\hline \hline & \multicolumn{2}{c}{ In-sample fit } & & \multicolumn{2}{c}{ Out-of-sample fit $^{\mathrm{a}}$} \\
\cline { 2 - 3 } \cline { 5 - 6 } Sales rank & Adj. R & MAPE & & Adj. R ${ }^{2}$ & MAPE \\
Consumer Brand Usage (CBU) & $65.84 \%$ & $7.52 \%$ & & $60.64 \%$ & $14.05 \%$ \\
Consumer Brand Endorsement (CBE) & $92.40 \%$ & $12.80 \%$ & & $91.58 \%$ & $13.05 \%$ \\
\hline a We reestimated the model on a random draw of 70\% of the artists and computed model fit for the remaining 30\%.
\end{tabular}


Figure 3.2: Model fit for Adele

a) Sales ranks

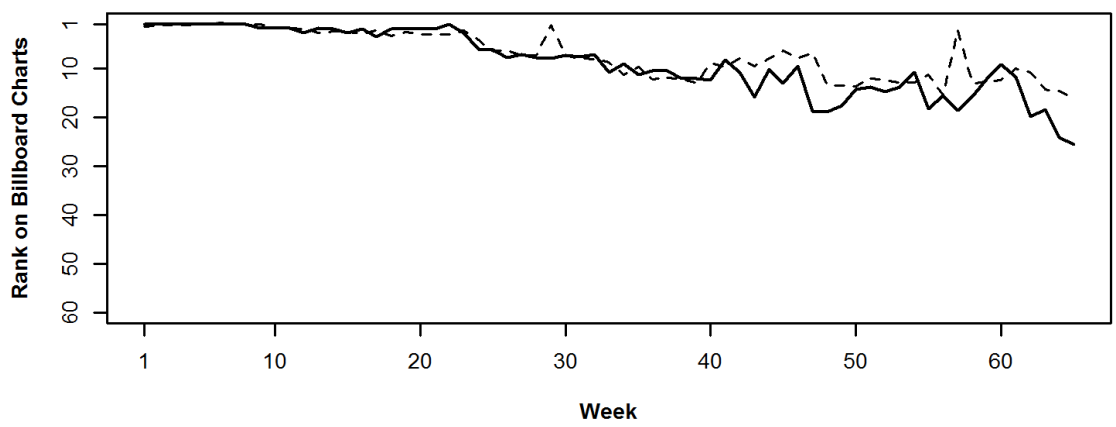

b) Consumer brand usage (CBU)

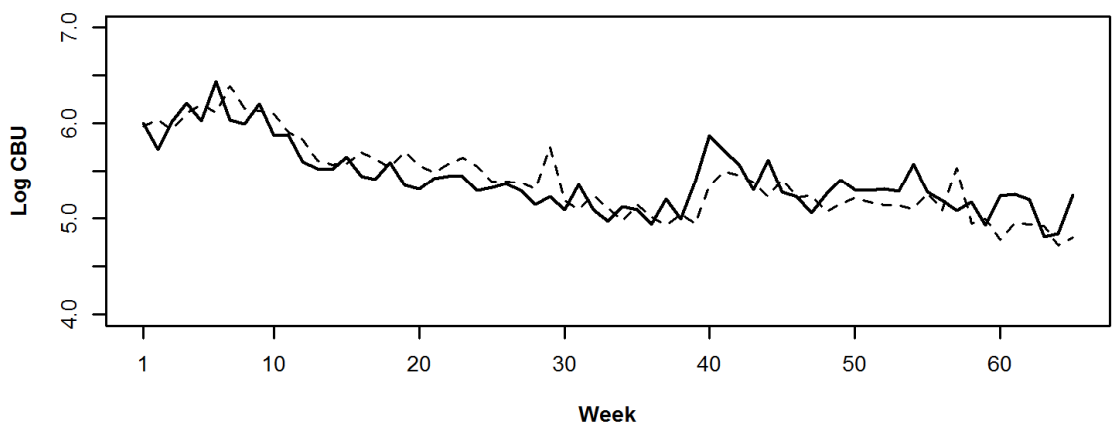

c) Consumer brand endorsement (CBE)

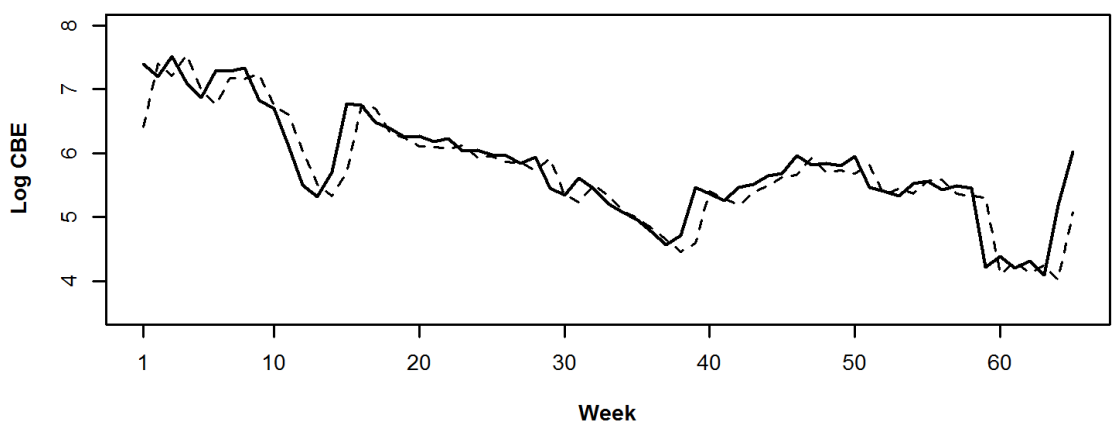

- Actual ------- Fitted 
Table 3.4: Estimation results

\begin{tabular}{|c|c|c|c|c|c|c|}
\hline & \multicolumn{2}{|c|}{ Sales Rank } & \multicolumn{2}{|c|}{$\begin{array}{c}\text { Consumer } \\
\text { Brand Usage (CBU) } \\
\end{array}$} & \multicolumn{2}{|c|}{$\begin{array}{c}\text { Consumer Brand } \\
\text { Endorsement (CBE) }\end{array}$} \\
\hline & Coeff. & SE & Coeff. & SE & Coeff. & SE \\
\hline New product release & 1.714 & .030 & .506 & .016 & .079 & .010 \\
\hline x Lag CBU & .104 & .019 & & & & \\
\hline$x$ Lag CBE & .004 & .018 & & & & \\
\hline Promotion & .002 & .006 & .052 & .001 & .015 & .000 \\
\hline x Lag CBU & .026 & .003 & & & & \\
\hline$x$ Lag CBE & .007 & .002 & & & & \\
\hline Lag CBU & .062 & .006 & .464 & .001 & .011 & .000 \\
\hline Lag CBE & .040 & .005 & .087 & .002 & .962 & .001 \\
\hline Lag Sales & .495 & .003 & .070 & .001 & -.006 & .000 \\
\hline (Lag) Piracy & -.050 & .001 & .078 & .001 & .013 & .000 \\
\hline \multicolumn{7}{|l|}{ Individual-level intercept } \\
\hline Mean & -2.249 & .011 & 1.812 & .005 & .109 & .001 \\
\hline Standard Deviation & .375 & .010 & .529 & .004 & .015 & .001 \\
\hline \multicolumn{7}{|l|}{ Control variables } \\
\hline Major label dummy & -.048 & .024 & .184 & .011 & .003 & .003 \\
\hline Superstar dummy & .058 & .018 & .237 & .010 & .031 & .003 \\
\hline Release of a new single & .101 & .034 & & & & \\
\hline Time since last album release & -.086 & .004 & & & & \\
\hline \multicolumn{7}{|l|}{$\begin{array}{l}\text { Endogeneity corrections using } \\
\text { copulas }\end{array}$} \\
\hline Piracy & .356 & .008 & & & & \\
\hline Promotion & .116 & .007 & & & & \\
\hline \multicolumn{7}{|c|}{$\begin{array}{l}\text { Log-likelihood: }-26,766 ; \mathrm{BIC}: 54,615 ; \text { AIC: } 53,737 ; \mathrm{N}: 37,362, \text { Number of artists: } 569 \text {. } \\
\text { Note: Numbers in bold are significant at the } p<.05 \text { level (two-sided). We also include month and genre dummies to control for } \\
\text { seasonality and genre-specific characteristics, but do not report these coefficients in the interest of space. } \\
\text { a We lag piracy in the CBU and CBE equations, but take current-period piracy in the sales rank equation to estimate the extent } \\
\text { of cannibalization between piracy and legal sales. We control for the endogeneity of current-period piracy using Gaussian } \\
\text { copulas (Park and Gupta 2012). }\end{array}$} \\
\hline
\end{tabular}

\subsubsection{CBU and CBE as Drivers of Sales Performance}

In line with $\mathrm{H}_{1 \mathrm{a}}, \mathrm{CBU}$ and $\mathrm{CBE}$ significantly drive sales performance $\left(\alpha_{3}=.062\right.$ and $\alpha_{4}=.040$, $p$ <.001). Brand usage and endorsement foster brand attachment (Park et al. 2010), leading consumers to expand their relationship and buy more of the brand's products (Van Doorn et al. 2010). To verify whether the difference in magnitude of the estimated coefficients is significant, we use two-tailed t-tests, taking into account the coefficients' covariance. In support of $\mathrm{H}_{1 \mathrm{~b}}, \mathrm{CBU}$ is a stronger driver of sales than $\mathrm{CBE}\left(\alpha_{3}>\alpha_{4}, \mathrm{t}=2.385, p=.017\right)$. Because CBU involves a substantially higher investment of attention and is less likely to be governed by social 
cues than CBE (Aaker 1999; Belk 2013), the resulting brand attachment is stronger, leading to a higher sales effect.

\subsubsection{CBU and CBE as Moderators of Marketing Effectiveness}

The results largely confirm our expectations in $\mathrm{H}_{2 a}$ regarding the moderating impact of $\mathrm{CBU}$ and $\mathrm{CBE}$ on the sales effects of marketing activities. Although promotion does not have a significant main effect $\left(\alpha_{2}=.002, p=.718\right)$, its impact significantly increases at higher levels of CBU and CBE $\left(\alpha_{7}=.026\right.$ and $\left.\alpha_{8}=.007, p<.001\right)$. Furthermore, new product releases exert a significant main effect $\left(\alpha_{1}=1.714, p<.001\right)$, reinforced significantly by CBU $\left(\alpha_{5}=.104, p<.001\right)$. The moderating impact of CBE is not significant though ( $\left.\alpha_{6}=.004, p=.844\right)$, suggesting that CBE does not provide a strong indicator of consumers' engagement prior to the release of a new product. Still, the results support the notion that a more engaged consumer base devotes more attention to the focal brand and related communication, thereby increasing the salience of marketing activities. In support of $\mathrm{H}_{2 \mathrm{~b}}$, the moderating impact of $\mathrm{CBE}$ is much smaller than that of $C B U$, and this difference is significant for both new product introductions $\left(\alpha_{5}>\alpha_{6}\right.$, $\mathrm{t}=3.388, p<.001)$ and promotion $\left(\alpha_{7}>\alpha_{8,} \mathrm{t}=4.077, p<.001\right)$. Consumers' public endorsement of an artist does not necessarily reveal their intrinsic preferences (Ratner and Kahn 2002); as a result, relative to $\mathrm{CBU}, \mathrm{CBE}$ does not drive consumers' responsiveness to an artist's marketing as strongly.

\subsubsection{CBU and CBE as Mediators of Piracy}

Piracy has a negative, direct effect on sales performance $\left(\alpha_{10}=-.050, p<.001\right.$; Liebowitz 2008). However, in line with our expectations, it also triggers a positive, indirect effect, mediated by $\mathrm{CBU}$ and $\mathrm{CBE}$. Consistent with $\mathrm{H}_{3 \mathrm{a}}$, piracy increases $\mathrm{CBU}$ and $\mathrm{CBE}\left(\beta_{6}=.078\right.$ and $\gamma_{6}=.013$, $p$ <.001). In support of $\mathrm{H}_{3 \mathrm{~b}}$, the impact of piracy on $\mathrm{CBU}$ is greater than its impact on $\mathrm{CBE}$ $\left(\beta_{6}>\gamma_{6}, t=85.990, p<.001\right)$. Thus, piracy increases engagement, especially in terms of CBU, because usage requires access to the brand's products.

To demonstrate the significance of the CBU- and CBE-mediated effects of piracy on sales, we conduct a moderated multiple mediation test (Preacher and Hayes 2008; Preacher, Rucker, and Hayes 2007). Specifically, we compute Sobel's $z$ with the product-of-coefficients approach, take into account the interactions between marketing activities and $C B U$ and $C B E$, 
and use the delta method to obtain standard errors. ${ }^{27}$ Our analysis confirms that piracy has a statistically significant, indirect effect on sales performance through CBU and CBE. We use simulations to assess the extent to which this positive mediation effect offsets the negative direct impact of piracy, as we detail in the managerial section.

\subsubsection{Marketing Drivers of CBU and CBE}

In line with $\mathrm{H}_{4 a}, \mathrm{CBU}$ and $\mathrm{CBE}$ increase significantly in response to new product releases $\left(\beta_{1}=.506\right.$ for $\mathrm{CBU}$ and $\gamma_{1}=.079$ for $\left.\mathrm{CBE}, p<.001\right)$ and promotion $\left(\beta_{2}=.052\right.$ for CBU and $\gamma_{2}=.015$ for $\left.\mathrm{CBE}_{1} p<.001\right)$. Furthermore, in support of $\mathrm{H}_{4 \mathrm{~b}}$, marketing effects on $\mathrm{CBU}$ are significantly greater than those on CBE $\left(\beta_{1}>\gamma_{1}, t=23.210\right.$ for new products; $\beta_{2}>\gamma_{2}, t=33.976$ for promotions; $p<.001)$. Compared with $\mathrm{CBE}, \mathrm{CBU}$ is more likely to depend on consumers' internal beliefs, which are influenced by a brand's marketing activities (Holbrook 1978). A test for moderated multiple mediation shows that new products and promotion significantly increase sales performance through their effects on $\mathrm{CBU}$ and $\mathrm{CBE} .^{28}$

In summary, the results fully support our hypotheses with regard to the impact of CBU and $\mathrm{CBE}$ on sales performance $\left(\mathrm{H}_{1 \mathrm{a}}\right)$ and the effects of piracy and marketing activities on $\mathrm{CBU}$ and $\mathrm{CBE}\left(\mathrm{H}_{3 a}\right.$ and $\mathrm{H}_{4 a}$, respectively). Furthermore, they largely confirm the role of $\mathrm{CBU}$ and $\mathrm{CBE}$ as moderators of marketing efforts $\left(\mathrm{H}_{2 \mathrm{a}}\right)$. In all relationships, the role of $\mathrm{CBU}$ is consistently more important than that of $\mathrm{CBE}\left(\mathrm{H}_{1 b}-\mathrm{H}_{4 b}\right)$.

\subsubsection{Remaining Effects, Artist Heterogeneity, and Error Correlation}

The remaining variables generally have significant and face-valid effects. For example, superstar brands, all else being equal, get used and endorsed more often and sell more than other artists. Introducing a new single positively affects (album) sales by bolstering consumers' interest in the artist. The carryover coefficients in the three equations indicate that shocks in one period persist in future periods. For example, the release of a new album generates additional sales, not only in the current week but also in subsequent periods. For $C B U$ and $C B E$,

\footnotetext{
${ }^{27}$ We compute the test statistics for all observed values of the marketing variables because the mediated effect of piracy through $\mathrm{CBU}$ and $\mathrm{CBE}$ on sales depends on the moderating role of the marketing variables. The Sobel $z$ statistics vary between 8.179 and 10.830 and are all significant at $p<.001$. Bootstrapping is not required because of the large sample size $(\mathrm{N}=37,362)$, ensuring that the test statistics are normally distributed (Preacher, Rucker, and Hayes 2007).

${ }^{28}$ In line with footnote 27, we compute Sobel's $z$ for all observed values of the new product and promotion variables, because the significance of the indirect effect depends on the chosen values for the marketing variables (Preacher, Rucker, and Hayes 2007). The $z$ statistics vary between 6.569 and 11.740 and are all significant at $p<.001$.
} 
the carryover effects indicate that each type of engagement reinforces the other, and that engagement persists over time (e.g., because seeing other consumers engage with artists enhances consumers' own engagement). ${ }^{29}$

The significant standard deviations for the sales, $C B U$, and $C B E$ intercepts reveal the presence of substantial unobserved artist heterogeneity. The intercept correlations in Table 3.5 show that, conditional on the independent variables, artists that sell more are also endorsed more. In contrast, random shifts in sales performance do not automatically correspond to similar shifts in brand usage, which makes the differential natures of CBU and CBE apparent again. Finally, as indicated by the significantly positive contemporaneous correlation coefficients in Table 3.5, the three dependent variables share time-specific, unobservable shocks.

Table 3.5: Estimated correlations

\begin{tabular}{lcc}
\hline Heterogeneous intercept & & \\
$\rho_{\text {Sales, CBU }}$ & -.018 & $(.011)$ \\
$\rho_{\text {Sales, CBE }}$ & .398 & $(.005)$ \\
$\rho_{\mathrm{CBU}, \mathrm{CBE}}$ & -.921 & $(.003)$ \\
Contemporaneous correlation & & \\
$\eta_{\text {Sales, CBU }}$ & .259 & $(.006)$ \\
$\eta_{\text {Sale, CBE }}$ & $\mathbf{. 0 2 6}$ & $(.004)$ \\
$\eta_{\text {CBU, CBE }}$ & .055 & $(.003)$ \\
\hline Note: Numbers in bold are significant at the $p<.05$ level (two-sided).
\end{tabular}

\subsection{Managerial Implications}

Both $\mathrm{CBU}$ and $\mathrm{CBE}$-forms of engagement that are becoming increasingly observable by tracking consumer behavior on smart devices and social media platforms-have important consequences for the sales performance of entertainment products. In particular, they moderate the effects of marketing activities and mitigate the negative impact of piracy. We illustrate how these insights can help managers boost their marketing effectiveness and combat the detrimental effects of piracy.

\footnotetext{
${ }^{29}$ In the sales equation, the coefficient of the major label dummy variable is negative. Because major labels regularly launch new albums and have many superstars, both of which have significantly positive effects on sales performance, the negative "rest effect" may be due to the fact that some consumers have an explicit preference for indie music. Furthermore, our results show that lagged sales performance positively affects CBU. The low coefficient (.07) is not surprising, because CBU contains listening counts for all songs ever released by an artist; also, sales effects take some time to unfold. Lagged sales performance negatively affects CBE. Although the overall correlation between sales performance and endorsement may be positive (due to common drivers), improving sales performance apparently lowers an artist's value for self-expression, thereby decreasing endorsement.
} 


\subsubsection{Improving Marketing Effectiveness}

Because $\mathrm{CBU}$ and $\mathrm{CBE}$ tend to reinforce the sales impact of marketing, managers can increase marketing effectiveness by focusing on brands with high engagement levels. To illustrate this principle, we use our estimated model to simulate the sales effects of marketing efforts for artists with different engagement levels. ${ }^{30}$ Simulation is preferable to inspecting the estimated response elasticities, because the total sales effect of a marketing effort involves multiple coefficients and manifests itself over multiple periods. First, we calculate the impact of an album release and a permanent $20 \%$ increase in average promotional intensity on expected unit sales over a six-month period for two well-known artists, Adele and Rihanna. Whereas Rihanna has a much higher CBU level than Adele (25,327 versus 16,438 plays), her CBE level is much lower (22.6 versus 31.7 million incremental Likes). Our simulations show that Rihanna, with a higher CBU but lower CBE level, performs considerably better, with sales growths of $2.15 \%$ after the promotion increase (cf. $1.8 \%$ for Adele) and $31.12 \%$ after the album release (cf. $29.48 \%$ for Adele). Because CBU is a stronger moderator of marketing effectiveness than $\mathrm{CBE}$, it offers a better indicator of expected sales increases. To generalize this notion, we extend our simulation to all 569 artists in our data set. In Figure 3.3, we plot artists (grey dots) on the basis of their expected percentage sales increase ( $\mathrm{Y}$-axis) and their baseline usage and endorsement levels (X-axis). Panel a contains the expected sales effects of the $20 \%$ promotion increase and new product launch, both as a function of artists' CBU baseline levels; Panel b displays the same expected sales effects as a function of artists' CBE baseline levels.

As we learn from Figure 3.3, Panel a, there is a strong relationship between CBU and the expected marketing impact. For example, in the switch from the average to the highest CBU level, the sales impact of the lift in airplay increases from $1.0 \%$ to $2.9 \%$, and the impact of the album release grows from $29 \%$ to $32.8 \%$. For a given level of CBU, the uncertainty around the expected sales effect is very small, as the limited spread in sales effects reveals. Thus, CBU forms a reliable indication of marketing effectiveness that can help managers make marketing budget allocation decisions. Alternatively, a manager may rely on a measure of CBE (e.g.,

\footnotetext{
30 Following extant research, we predict unit sales from sales ranks by calibrating the relationship $\ln (\mathrm{sales})=\mathrm{c}-$ $\theta \ln ($ rank) with an additional data set that includes both ranks and unit sales (52 weeks, January-December 2009) (e.g., Chevalier and Goolsbee 2003; Chevalier and Mayzlin 2006; Ghose and Sundararajan 2006). We obtain the following estimates: $c=11.48$ and $\theta=.601$. Our substantive conclusions do not change when we vary $c$ or $\theta$. To initialize the dependent variables in the first period of our simulation, we use artist-specific posterior intercepts and means for (lagged) sales, CBU, CBE, and piracy. All other variables are set to their global mean (e.g., time since last release) or 0 (dummy variables for February-December).
} 
Facebook Likes) to improve marketing spending. Panel b reveals a positive relationship between $\mathrm{CBE}$ and the expected sales effects of the promotion increase or new product launch. However, the slopes of the relationships are lower than those in Panel a. Furthermore, for a given level of $\mathrm{CBE}$, the uncertainty around the expected sales effect is much higher than for a given level of $\mathrm{CBU}$. These insights corroborate recent managerial intuition that CBE may not be the best criterion for marketing investment decisions (The Economist 2011a).

Figure 3.3: Marketing effectiveness as a function of $C B U$ and $C B E$

a) Marketing effectiveness by consumer brand usage (CBU)

Impact of Promotions

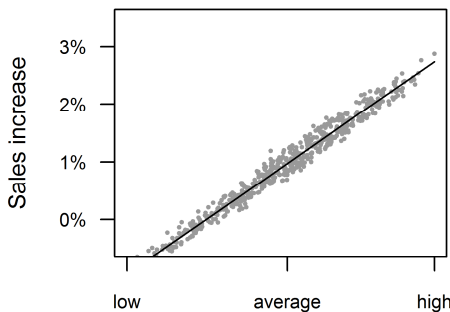

Baseline CBU
Impact of New products

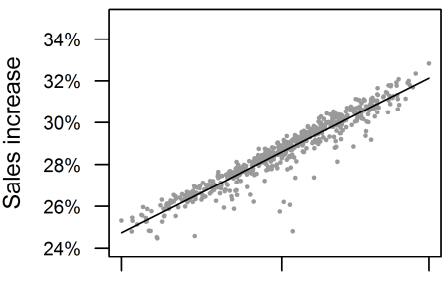

low

average

high

Baseline CBU

b) Marketing effectiveness by consumer brand endorsement (CBE)
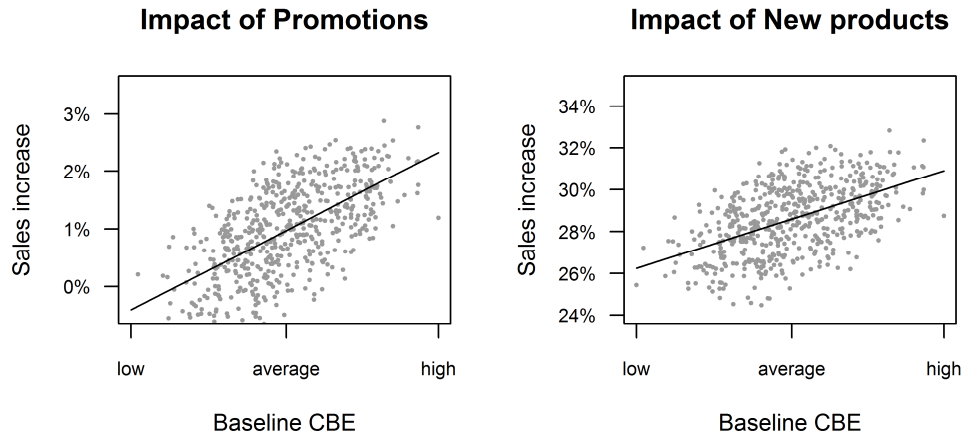

Notes: We calculate the impacts of a $20 \%$ permanent increase in promotions and the release of a new album on subsequent sales during a six-month (26-week) period. 


\subsubsection{Reducing the Negative Effect of Piracy}

To illustrate ways to reduce the negative effect of piracy, we first simulate the sales effects of a permanent $20 \%$ increase in piracy and decompose this impact into a direct negative effect and a positive indirect effect, mediated by CBU and CBE. As shown in Figure 3.4, Panel a, for an average artist, a $20 \%$ increase in piracy triggers a direct sales decrease of approximately $1.1 \%$. However, brands that experience a piracy shock also can benefit from greater engagement, which may generate sales in future periods. These CBU- and CBE-mediated effects are remarkably strong (+0.6\%) and offset the direct impact by $55 \%$ (from $-1.1 \%$ to $-0.5 \%$ ).

Because engagement and marketing reinforce each other's sales effects $\left(\mathrm{H}_{2 \mathrm{a}}\right)$, managers could use promotions to strengthen the positive CBU- and CBE-mediated piracy impact. To illustrate this finding, we repeat the previous simulation but vary promotion intensity throughout the simulation period (from $20 \%$ to $200 \%$ of the current average promotion intensity). Figure 3.4, Panel $b$, shows that the negative effect of piracy ranges from $-0.74 \%$ to $-0.37 \%$, depending on the level of promotion intensity. Although the total effect of piracy remains negative (Liebowitz 2008), marketing activities, such as promotion, can reduce its harm.

Figure 3.4: Sales impact of piracy

\section{a) Decomposition of the negative sales impact of piracy}

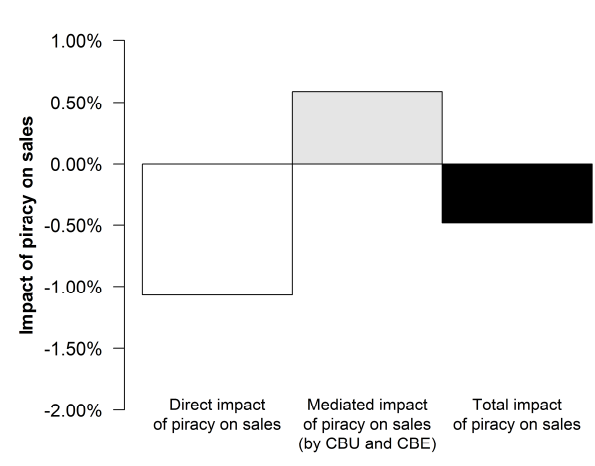

b) Mitigating the negative sales impact of piracy using promotion

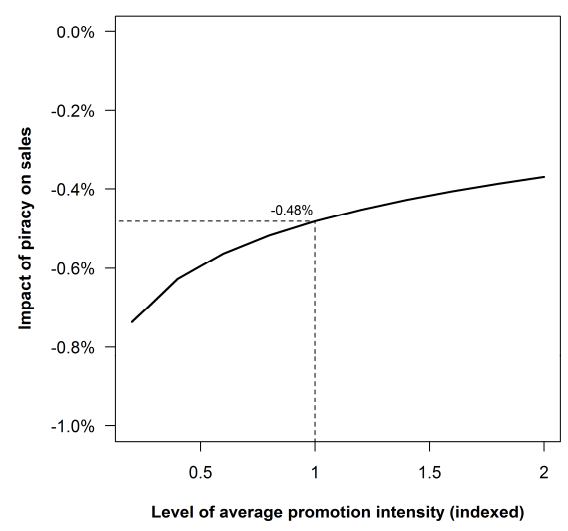

Notes: We report percentage changes in sales due to a $20 \%$ increase in piracy during a six-month (26-week) period. 


\subsection{Discussion and Conclusion}

\subsubsection{Summary of Main Findings}

Concerned with revenue growth (PricewaterhouseCoopers 2013a), managers in the entertainment industry face two crucial questions: How can they enhance the effectiveness of their marketing activities to ensure their brands get noticed in an environment in which many brands vie for consumers' attention and marketing effectiveness is on the decline? And which strategies can they follow to curb the impact of piracy?

To answer these questions, we wrote web scraping software and API mining scripts to tap into the big data sources of websites and social media platforms. Specifically, we collected data about consumers' engagement with brands in the U.S. music industry-information that only very recently became available as customers increasingly started sharing their personal data on public fora through the Internet. We used these data in a systematic comparison of the implications of customer engagement measures for a brand's sales performance. For all hypothesized relationships, we have demonstrated that the role of $\mathrm{CBU}$ is more important than CBE. Not only do $C B U$ and $C B E$ drive sales, but they also moderate the sales impact of marketing activities (i.e., promotion and new product introductions). The importance of $\mathrm{CBU}$ and $\mathrm{CBE}$ is reflected in their role as mediators between piracy and sales. Our contribution to the ongoing debate about the effects of piracy on sales is novel (e.g., Gopal, Bhattacharjee, and Sanders 2006; Oberholzer-Gee and Strumpf 2007; Peitz and Waelbroeck 2006), in that we provide the first empirical evidence that piracy affects $C B U$ and $C B E$, which in turn increase sales. The negative impact of piracy can be reduced even more with the help of marketing activities. In addition, our results imply that managers can influence CBU and CBE using marketing (e.g., promotions, new products). This finding has particular significance, because brands increasingly generate revenue on a per use basis, such as streaming services for which royalties are commensurate with usage (e.g., number of song plays). Similarly, consumers' brand endorsement (e.g., via Facebook Likes) increasingly serves as a focal business metric.

\subsubsection{Discussion}

These results have several implications for our understanding of consumers and markets. First, even when managers observe little or no sales activity, consumers actively use or endorse products. These behaviors remained invisible to managers prior to the big data era, forcing them to rely on market performance metrics or surveys to assess how consumers valued the 
firm's products. Instead, our research shows that it is vital to examine these data and understand how consumers use and endorse products, because CBU and CBE influence brand performance and determine marketing effectiveness. This influence may be particularly relevant in industries in which managers cannot rely on the market to learn how much value consumers attach to their product. In the music industry for example, sales rapidly decline after the release of a new product, impeding managers to assess how engaged consumers are with a brand. In such situations, CBU and CBE can provide valuable information that is well grounded in theory and, as we show, empirically meaningful.

Second, we analyze two measures that managers can use to assess brand engagement. Whereas digitization provides the opportunity to observe both measures, they differ in their level of accessibility. By definition CBE is a public activity and therefore easy to measure; CBU is not a public activity and may be less straightforward to track. Our research raises awareness about the opportunities that lie in $\mathrm{CBU}$, as well as the feasibility of measuring it. In contrast, CBE- even though publicly visible and easy to obtain-is less informative about sales and marketing effectiveness. Managers thus should strive to obtain a measure of $\mathrm{CBU}$, rather than settling for prominently displayed CBE measures, which offer inferior and less accurate predictions of sales or marketing effectiveness. Apparently, CBE relates to how consumers want to be seen by their social environment (e.g., Aaker 1999; Ratner and Kahn 2002) rather than how they actually behave.

We have studied the relevance of $\mathrm{CBU}$ and $\mathrm{CBE}$ for the music industry but believe our findings generalize beyond this context. Many consumers leave online traces of how they engage with brands. For example, the rise of electronic books enables firms to determine which books consumers read repeatedly or never finish. A similar case can be made for PC or console games or other product categories in which consumers decide about their own usage intensity. Even beyond the entertainment industry, firms that market products such as digital cameras might consider monitoring users' engagement behaviors. For example, they could obtain measures of $\mathrm{CBU}$ or CBE from photo-sharing websites such as Flickr, to help them improve the effectiveness of their marketing activities. 


\subsubsection{Future Research}

The limitations of our study suggest several opportunities for future research. Our data only allow us to study these phenomena on the brand level; others studies might explore consumerlevel purchase, $\mathrm{CBU}, \mathrm{CBE}$, and piracy data. For example, researchers could analyze the extent to which users' online streaming activity (e.g., subscription to Pandora or Spotify) changes their music consumption behavior (e.g., variety seeking). The amount of streaming through paid subscription services in our observation period is relatively limited, but this channel could mature into a viable alternative for buying music (similar to movies; e.g., Netflix). Consumerlevel data might account more explicitly for word-of-mouth effects, because CBE could affect other people. We implicitly allow for social contagion effects (carryover of $\mathrm{CBE}$ ), but the aggregation level of our data keeps us from explicitly modeling the underlying mechanisms.

Our analysis also is based on sales ranks. We use appropriate econometric techniques to account for the characteristics of the rank data (e.g., Chevalier and Mayzlin 2006), but actual sales data would grant further insights into absolute effects. For example, the size of the music market fluctuates over the year; releases in one month (e.g., around Christmas) may be more successful than in others. Sales rank data only reflect a brand's performance relative to other brands, without accounting for market expansion or contraction. We control for seasonality, but sales data might reveal a more fine-grained picture.

Finally, studies could analyze the importance of $C B U$ and $C B E$ across countries. Most literature, especially that pertaining to piracy, uses U.S. data. However, $C B U, C B E$, and piracy levels vary significantly across countries (The Economist 2011b). It may be interesting for artists to determine the countries in which the positive spillovers on sales, through the CBU- and CBEmediated impact of piracy, are highest (and thus identify where not to fight piracy).

In summary, we develop a detailed account of how big data describing consumers' engagement with brands (i.e., $\mathrm{CBU}$ and $\mathrm{CBE}$ ) can enhance marketing effectiveness and mitigate the negative impact of piracy. In addition, we investigated the impact of two specific marketing activities (promotions and new product introductions) on $\mathrm{CBU}$ and $\mathrm{CBE}$. Equally important, we find that the role of $\mathrm{CBU}$ is consistently more important than the role of $\mathrm{CBE}$. Our findings offer new insights with value to managers, even beyond the context of the entertainment industry. 


\section{Chapter 4}

\section{Conclusion}

This dissertation consists of two studies on the role of consumers' usage behavior in improving retention and lifetime value for customers acquired with free trials (chapter 2), and in managing marketing investments and piracy for entertainment goods (chapter 3). Below, we discuss the main contributions of these studies, and suggest potential avenues for further research. In the last section, we end with some final conclusions.

\subsection{Contributions of this Research}

\subsubsection{Theoretical contributions}

Our research findings shed light on the multiple roles that consumers' usage behavior fulfills in understanding consumption behavior.

First, both studies consider the consequences of consumers' usage behavior. These consequences have received some consideration by research in service settings (e.g., how usage drives retention, Prins, Verhoef, and Franses 2009). In study 1, we build on this stream of research and extend the concept of usage to a setting in which consumers make use of different types of service components that may drive sales differently. For example, consumers' usage 
of the pay-per-use service increases retention less than consumers' usage of the flat-rate service. However, using the pay-per-use service generates additional revenue, beyond recurring subscription fees. Study 2 advances our understanding of usage to entertainment products which are typically bought once but used long after adoption (e.g., music albums). In this setting, usage occurs at zero marginal cost, is non-depleting, and is not limited in time. In other words, abstracting from their physical quality, products can be used as much and as long as desired at no charge. We show that in such a setting, usage is a way for consumers to develop brand attachment, which ultimately affects a brand's sales performance (Park et al. 2010).

Second, both studies deal with the drivers of consumers' usage behavior. These drivers are worth studying, because usage has important revenue implications. In study 1 , we show that free-trial acquisition influences consumers' usage and retention behavior, and thereby directly affects the lifetime value of customers. In study 2, we investigate whether two commonly used marketing instruments, namely promotion and new product introductions, drive consumers' usage behavior. As we show, marketing instruments affect consumers' usage behavior beyond the initial purchase transaction.

Third, we illustrate that usage is an important mediator in customer-product interactions. In study 1 , customer acquisition via free trials affects retention through its effect on usage. Not only do free-trial customers churn earlier, but they also use the flat-rate component of the service less, thereby further decreasing their propensity to retain the service. In study 2 , we make the role of usage as a mediator even more prominent. Specifically, we conceive usage to mediate the relationships between piracy and sales, and marketing activities and sales. While we show that piracy reduces sales, we also empirically demonstrate that a positive, usagemediated effect mitigates the negative sales effect. Thus, pending on usage behavior, piracy can be considered an indirect antecedent of sales so far neglected in marketing research. Similarly, marketing activities stimulate consumers' usage behavior, which increases sales in subsequent periods.

Fourth, we investigate the merits of usage as a moderator in customer-product interactions. Prior research has not attended to the role of usage to enhance or attenuate the sales impact of other variables. In study 2 , we therefore allow usage to govern the effectiveness of marketing activities. As we find, usage moderates the sales effects of marketing activities 
and offers ways to improve marketing effectiveness (e.g., by targeting based on consumers' usage behavior).

\subsubsection{Managerial contributions}

This dissertation contributes to the ongoing debate on how companies can benefit from massive amounts of usage data to improve business decisions.

First, our results suggest that managers should carefully monitor consumers' usage behavior because of its direct and indirect revenue implications. In study 1, we analyze usage behavior of consumers of a contractual service. Because low usage levels signal defection, managers can react upon this information by targeting retention-enhancing marketing communication towards these customers. From study 2, it becomes evident that usage is a more viable indicator of sales performance than relatively easily accessible measures of brand endorsement (e.g., Facebook Likes). It is therefore of tremendous importance to further advance (online) tracking methods of consumers' usage behavior, while at the same time respecting consumers' privacy.

Next, managers should realize that their decisions have implications far beyond consumer-firm transactions. As a matter of fact, usage behavior, which normally is completely within the discretion of consumers, is influenced by marketing activities such as new products or promotions. Similarly, managers should be aware that the mode of acquisition may persistently influence consumer behavior. As we find, free-trial customers use the flat-rate component systematically less than regular customers, but use more of the pay-per-use service and are more sensitive to their own usage behavior when making retention decisions.

In addition, we suggest managers to nourish an active user base, because committed users eventually monetize. For example, music brands (e.g., artists) are frequently plagued by piracy which decreases immediate sales, but piracy also builds a more engaged fan base. With the industry adopting more and more usage-based revenue models, artists that suffered from high levels of piracy could now generate a larger number of song plays, and therefore get more royalties from music subscription services. Also, as we show in study 2 , brand usage is the missing link between piracy and sales: while indeed piracy decreases legal sales, it has an indirect positive effect on consumers' usage behavior, and leads to a positive sales effect. In other words, brands with higher levels of piracy may not only be listened to more often, but 
may also generate higher sales of their products (e.g., music albums) through increased brand attachment and relationship expansion (e.g., Park et al. 2010).

\subsection{Future Research}

Notwithstanding its limitations, the research presented in this dissertation provides insights into the various roles consumers' usage behavior takes on in our understanding of how consumers interact with products and services. In this section, we outline ideas for future work.

First, it would be worthwhile to investigate the implications of new (usage-based) business models for the sales performance of brands. Because businesses increasingly generate revenue through usage instead of product sales, consumers will gradually stop owning products, which may change their valuations for products and possibly their consumption behavior (e.g., Dommer and Swaminathan 2013). For example, it may be interesting to reveal whether consumers' usage behavior (e.g., variety seeking) changes in response to not owning music albums. Such a finding may also have implications on how brands should best generate revenue from usage-based royalty distribution systems. One can also imagine that usagebased models will gain popularity for high-value products such as cars, which could change consumers' price sensitivity and potentially erode brand sales.

A second avenue for future research arises from the limitations of the research design used in the two studies. Both make use of data which was not "deliberately engineered" to answer our research questions, but rather "made appropriate" by a set of econometric methods. For example, so-called endogeneity concerns arise if a factor unobserved to the researcher influences both the explaining variable (e.g., free-trial acquisition, piracy), as well as the explained variable (e.g., sales). While econometric methods exist to control for possibly confounding effects, the researcher can never be sure to have completely controlled for it. A possible remedy are data from field experiments, which are by construction free of endogeneity concerns. At the same time, field experiments in our research context are difficult to conduct. For example, to replicate the findings of study 1 , we would have to randomly assign customers to a free trial or not, while at the same time making sure that neither group of customers knows about the existence of the other. Similarly, it may be difficult to engineer an event causing piracy in study 2 to be meaningfully increased for some random artists, while left unchanged for others. 
Next, in both studies, we have only focused on the intensity of usage (i.e., a continuum from low to high usage). However, it may also be appealing to study consumers' usage variance. For instance, a more uncertain usage behavior may lead to different conclusions than a more stable usage behavior. In addition, it may be worthwhile to augment usage data with a geographical dimension, for example, using location data collected on smartphones. Also, the type of device (e.g., mobile device versus desktop computer) could play a role. For example, consumers' usage behavior may differ, depending on where (geographically) and how (e.g., type of device) a product or service is used. A closer look on these dimensions could enable managers to learn about the right moment to target consumers with ads on mobile devices, or decide about the complexity of information that is being displayed (e.g., depending on whether a consumer is stationary or moving).

Another extension arises from the way we link usage to sales in both studies. For example, the level on which usage occurs (e.g., daily), may not match the level in which retention decisions are made (e.g., monthly, or quarterly). In other words, usage "runs on a different clock" than consumers' retention decisions and brand sales (Ascarza and Hardie 2013). To cope with this challenge, we aggregate consumers' usage behavior to a common level. Because data on different aggregation levels is ubiquitous and aggregation leads to a loss of information, it may be worthwhile to further explore new models of linking consumers' usage behavior to sales.

Last, future research questions emerge which exceed the context of this dissertation. To this extent, we have focused on solving problems whose existence dates back to the pre-big data era. Specifically, we study the effectiveness of acquisition modes in study 1 , and investigate how to manage entertainment products in study 2. However, new problems arise from the mere availability of big data. Certainly, processing of large databases in an automatic fashion, as well as mining of relatively unstructured data sources, is an opportunity for future research. 


\subsection{Final Conclusion}

In this dissertation, we have focused on consumers' usage behavior of products and services. Specifically, we have illustrated the managerial, theoretical, and methodological value of analyzing consumers' usage behavior (chapter 1 ). To this extent, we embed the concept of analyzing usage data in the broad trend of extracting information from big data sets. Next, we demonstrate the role of consumers' usage behavior in analyzing the effectiveness of free-trial acquisition (chapter 2) and in managing entertainment goods (chapter 3 ). In combining the research findings of chapter 2 and 3, we have derived some general contributions of our work, and present avenues for further research (chapter 4). To conclude, we show that exciting conceptual and substantive insights can be gained from analyzing usage data, but recognize that there are ample opportunities for further research. 


\section{References}

Aaker, Jennifer L. (1999), "The Malleable Self: The Role of Self-Expression in Persuasion," Journal of Marketing Research, 36 (1), 45-57.

Alba, Joseph W. and J. Wesley Hutchinson (1987), "Dimensions of Consumer Expertise," Journal of Consumer Research, 13 (4), 411-454.

Albuquerque, Paulo and Yulia Nevskaya (2012), "The Impact of Innovation on Product Usage: A Dynamic Model with Progression in Content Consumption." Working Paper.

Allenby, Greg M. and James L. Ginter (1995), "The Effects of In-Store Displays and Feature Advertising on Consideration Sets," International Journal of Research in Marketing, 12 (1), 67-80.

Anderson, Eric. T. and Duncan I. Simester (2004), "Long-Run Effects of Promotion Depth on New Versus Established Customers: Three Field Studies," Marketing Science, 23 (1), 420.

Aral, Sinan, Anand Bodapati, Eric Bradlow, Theodoros Evgeniou, David Godes, Dan Goldstein, PK Kannan, Peter Lenk, Rob McCulloch, and Carl Mela (2013), "Call for PapersMarketing Science Special Issue on Big Data: Integrating Marketing, Statistics, and Computer Science," Marketing Science, 32 (4), 678-678.

Ascarza, Eva and Bruce G.S. Hardie (2013), "A Joint Model of Usage and Churn in Contractual Settings," Marketing Science, 32 (4), 570-590.

Ascarza, Eva, Anja Lambrecht and Naufel Vilcassim (2012), "When Talk Is "Free": The Effect of Tariff Structure on Usage Under Two- and Three-Part Tariffs," Journal of Marketing Research, 49 (6), 882-899. 
Batra, Rajeev and Douglas M. Stayman (1990), "The Role of Mood in Advertising Effectiveness," Journal of Consumer Research, 17 (2), 203-214.

Bawa, Kapil and Robert Shoemaker (2004), "The Effects of Free Sample Promotions on Incremental Brand Sales," Marketing Science, 23 (3), 345-363.

Belk, Russell W. (1988), "Possessions and the Extended Self," Journal of Consumer Research, 15 (2), 139-168.

(2013), "Extended Self in a Digital World," Journal of Consumer Research, 40 (3), 477-500.

Bhattacharjee, Sudip, Ram D. Gopal, Kaveepan Lertwachara, James R. Marsden, and Rahul Telang (2007), "The Effect of Digital Sharing Technologies on Music Markets: A Survival Analysis of Albums on Ranking Charts," Management Science, 53 (9), 1359-1374.

Bhattacharjee, Sudip, Ram D. Gopal, James R. Marsden, and Ramesh Sankaranarayanan (2011), "Digital Goods and Markets: Emerging Issues and Challenges," ACM Transactions on Management Information Systems, 2 (2).

Billboard (2013), "IFPI 2013 Recording Industry in Numbers: Global Revenue, Emerging Markets Rise; U.S., U.K., Germany Drop," (accessed 3 December, 2013), http://www.billboard.com /biz/articles/news/digital-and-mobile/1556590/ifpi-2013-recording-industry-innumbers-global-revenue.

Blattberg, Robert C., Edward C. Malthouse and Scott A. Neslin (2009), "Customer Lifetime Value: Empirical Generalizations and Some Conceptual Questions," Journal of Interactive Marketing, 23 (2), 157-168.

Blau, Max (2013), "How Spotify Engineered the New Music Economy," (accessed 9 October, 2013), http://mashable.com/2013/10/06/spotify-music-economy/.

BMI (2013), "BMI-About," (accessed 13 October, 2013), http://www.bmi.com/about.

Bolton, Ruth N. and Katherine N. Lemon (1999), "A Dynamic Model of Customers' Usage of Services: Usage as an Antecedent and Consequence of Satisfaction," Journal of Marketing Research, 36 (2), 171-186.

Bolton, Ruth N., Katherine N. Lemon and Peter C. Verhoef (2004), "The Theoretical Underpinnings of Customer Asset Management: A Framework and Propositions for Future Research," Journal of the Academy of Marketing Science, 32 (3), 271-292.

Bulygo, Zach (2013), "How Netflix Uses Analytics to Select Movies, Create Content, and Make Multimillion Dollar Decisions," (accessed 21 October, 2013), http://blog.kissmetrics.com /how-netflix-uses-analytics/.

Chan, Tat Y., Chunhua Wu and Ying Xie (2011), "Measuring the Lifetime Value of Customers Acquired from Google Search Advertising," Marketing Science, 30 (5), 837-850.

Chevalier, Judith A. and Austan Goolsbee (2003), "Measuring Prices and Price Competition Online: Amazon.com and BarnesandNoble.com," Quantitative Marketing and Economics, 1 (2), 203-222.

Chevalier, Judith A. and Dina Mayzlin (2006), "The Effect of Word of Mouth on Sales: Online Book Reviews," Journal of Marketing Research, 43 (3), 345-354.

Danaher, Brett, Samita Dhanasobhon, Michael D. Smith, and Rahul Telang (2010), "Converting Pirates Without Cannibalizing Purchasers: The Impact of Digital Distribution on Physical Sales and Internet Piracy," Marketing Science, 29 (6), 1138-1151. 
Danaher, Brett, Michael Smith, Rahul Telang, and Siwen Chen (2013), "The Effect of Graduated Response Anti-Piracy Laws on Music Sales: Evidence from an Event Study in France," Journal of Industrial Economics, forthcoming.

Danaher, Peter J. (2002), "Optimal Pricing of New Subscription Services: Analysis of a Market Experiment," Marketing Science, 21 (2), 119-138.

Dewan, Sanjeev and Jui Ramaprasad (2012), "Research Note-Music Blogging, Online Sampling, and the Long Tail," Information Systems Research, 23 (3-Part-2), 1056-1067.

Dhar, Ravi and Klaus Wertenbroch (2012), "Self-Signaling and the Costs and Benefits of Temptation in Consumer Choice," Journal of Marketing Research, 49 (1), 15-25.

Dhar, Vasant and Elaine A. Chang (2009), "Does Chatter Matter? The Impact of User-Generated Content on Music Sales," Journal of Interactive Marketing, 23 (4), 300-307.

Dholakia, Utpal M. (2006), "How Customer Self-Determination Influences Relational Marketing Outcomes: Evidence from Longitudinal Field Studies," Journal of Marketing Research, 43 (1), 109-120.

Dommer, Sara Loughran and Vanitha Swaminathan (2013), "Explaining the Endowment Effect through Ownership: The Role of Identity, Gender, and Self-Threat," Journal of Consumer Research, 39 (5), 1034-1050.

Dwyer, F. Robert, Paul H. Schurr and Sejo Oh (1987), "Developing Buyer-Seller Relationships," Journal of Marketing, 51 (2), 11-27.

Ebbes, Peter, Zan Huang and Arvind Rangaswamy (2012), "Subgraph Sampling Methods for Social Networks: The Good, the Bad, and the Ugly." Working Paper.

Elberse, Anita (2010), "Bye-Bye Bundles: The Unbundling of Music in Digital Channels," Journal of Marketing, 74 (3), 107-123.

Erdem, Tülin and Michael P. Keane (1996), "Decision-Making Under Uncertainty: Capturing Dynamic Brand Choice Processes in Turbulent Consumer Goods Markets," Marketing Science, 15 (1), 1-20.

Frey, Dieter (1981), "Reversible and Irreversible Decisions," Personality and Social Psychology Bulletin, 7 (4), 621-626.

Frey, Dieter and Marita Rosch (1984), "Information Seeking after Decisions," Personality and Social Psychology Bulletin, 10 (1), 91-98.

Garg, Rajiv, Michael D. Smith and Rahul Telang (2011), "Measuring Information Diffusion in an Online Community," Journal of Management Information Systems, 28 (2), 11-38.

Garrett, Jason and Srinath Gopalakrishna (2010), "Customer Value Impact of Sales Contests," Journal of the Academy of Marketing Science, 38 (6), 775-786.

Gartner, Inc. (2013), "Gartner Survey Reveals That 64 Percent of Organizations Have Invested or Plan to Invest in Big Data in 2013," (accessed December 10, 2013), http://www.gartner.com/newsroom/id/2593815.

Gedenk, Karen and Scott A. Neslin (1999), "The Role of Retail Promotion in Determining Future Brand Loyalty: Its Effect on Purchase Event Feedback," Journal of Retailing, 75 (4), 433459. 
Gensler, Sonja, Peter Leeflang and Bernd Skiera (2012), "Impact of Online Channel Use on Customer Revenues and Costs to Serve: Considering Product Portfolios and SelfSelection," International Journal of Research in Marketing, 29 (2), 192-201.

Ghose, Anindya and Sang Pil Han (2011), "An Empirical Analysis of User Content Generation and Usage Behavior on the Mobile Internet," Management Science, 57 (9), 1671-1691.

Ghose, Anindya and Arun Sundararajan (2006), "Evaluating Pricing Strategy Using E-Commerce Data: Evidence and Estimation Challenges," Statistical Science, 21 (2), 131-142.

Gilbert, Daniel T., Timothy D. Wilson, Elizabeth C. Pinel, Stephen J. Blumberg, and Thalia P. Wheatley (1998), "Immune Neglect: A Source of Durability Bias in Affective Forecasting," Journal of Personality and Social Psychology, 75 (3), 617-638.

Gilbert, Daniel. T. and Jane E. J. Ebert (2002), "Decisions and Revisions: The Affective Forecasting of Changeable Outcomes," Journal of Personality and Social Psychology, 82 (4), 503-514.

Goettler, Ronald L. and Karen Clay (2011), "Tariff Choice with Consumer Learning and Switching Costs," Journal of Marketing Research, 48 (4), 633-652.

Goldenberg, Jacob, Gal Oestreicher-Singer and Shachar Reichman (2012), "The Quest for Content: How User-Generated Links Can Facilitate Online Exploration," Journal of Marketing Research, 49 (4), 452-468.

Gopal, Ram D., Sudip Bhattacharjee and G. Lawrence Sanders (2006), "Do Artists Benefit from Online Music Sharing?," The Journal of Business, 79 (3), 1503-1533.

Greene, William H. (2003), Econometric Analysis (5th ed.). Upper Saddle River, N.J.: Prentice Hall.

Greenwald, Anthony G. and Clark Leavitt (1984), "Audience Involvement in Advertising: Four Levels," Journal of Consumer Research, 11 (1), 581-592.

Gupta, Sunil and Donald R. Lehmann (2003), "Customers as Assets," Journal of Interactive Marketing, 17 (1), 9-24.

Hair, Joseph F., William C. Black, Barry J. Babin, and Rolph E. Anderson (2010), Multivariate Data Analysis (7th ed.). Upper Saddle River, New Jersey: Pearson.

Heider, Fritz (1958), The Psychology of Interpersonal Relations: Psychology Press.

Heilman, Carrie, Kyryl Lakishyk and Sonja Radas (2011), "An Empirical Investigation of In-Store Sampling Promotions," British Food Journal, 113 (10), 1252-1266.

Heiman, Amir, Bruce McWilliams, Zhihua Shen, and David Zilberman (2001), "Learning and Forgetting: Modeling Optimal Product Sampling over Time," Management Science, 47 (4), 532-546.

Hennig-Thurau, Thorsten, Edward C. Malthouse, Christian Friege, Sonja Gensler, Lara Lobschat, Arvind Rangaswamy, and Bernd Skiera (2010), "The Impact of New Media on Customer Relationships," Journal of Service Research, 13 (3), 311-330.

Hirschman, Elizabeth C. and Morris B. Holbrook (1982), "Hedonic Consumption: Emerging Concepts, Methods and Propositions," Journal of Marketing, 46 (3), 92-101.

Holbrook, Morris B. (1978), "Beyond Attitude Structure: Toward the Informational Determinants of Attitude," Journal of Marketing Research, 15 (4), 545-556. 
Holbrook, Morris B. and Elizabeth C. Hirschman (1982), "The Experiential Aspects of Consumption: Consumer Fantasies, Feelings, and Fun," Journal of Consumer Research, 9 (2), 132-140.

Hollenbeck, Candice R. and Andrew M. Kaikati (2012), "Consumers' Use of Brands to Reflect Their Actual and Ideal Selves on Facebook," International Journal of Research in Marketing, 29 (4), 395-405.

Holt, Douglas B. (1995), "How Consumers Consume: A Typology of Consumption Practices," Journal of Consumer Research, 22 (1), 1-16.

Hutchinson, Wesley J. and Eric M. Eisenstein (2008), Consumer Learning and Expertise. Handbook of Consumer Psychology.

Iyengar, Raghuram, Asim Ansari and Sunil Gupta (2007), "A Model of Consumer Learning for Service Quality and Usage," Journal of Marketing Research, 44 (4), 529-544.

Iyengar, Raghuram, Kamel Jedidi, Skander Essegaier, and Peter J. Danaher (2011), "The Impact of Tariff Structure on Customer Retention, Usage, and Profitability of Access Services," Marketing Science, 30 (5), 820-836.

Jain, Dipak, Vijay Mahajan and Eitan Muller (1995), "An Approach for Determining Optimal Product Sampling for the Diffusion of a New Product," Journal of Product Innovation Management, 12 (2), 124-135.

Johnson, Eric J. and J. Edward Russo (1984), "Product Familiarity and Learning New Information," Journal of Consumer Research, 11 (1), 542-550.

Johnson, Michael D. and Fred Selnes (2004), "Customer Portfolio Management: Toward a Dynamic Theory of Exchange Relationships," Journal of Marketing, 68 (2), 1-17.

Kannan, P. K., Barbara Kline Pope and Sanjay Jain (2009), "Pricing Digital Content Product Lines: A Model and Application for the National Academies Press," Marketing Science, 28 (4), 620-636.

Khan, Uzma and Ravi Dhar (2006), "Licensing Effect in Consumer Choice," Journal of Marketing Research, 43 (2), 259-266.

Kumar, V., Lerzan Aksoy, Bas Donkers, Rajkumar Venkatesan, Thorsten Wiesel, and Sebastian Tillmanns (2010), "Undervalued or Overvalued Customers: Capturing Total Customer Engagement Value," Journal of Service Research, 13 (3), 297-310.

Kumar, V. and Denish Shah (2009), "Expanding the Role of Marketing: From Customer Equity to Market Capitalization," Journal of Marketing, 73 (6), 119-136.

Kumar, V., Rajkumar Venkatesan, Tim Bohling, and Denise Beckmann (2008), "Practice Prize Report-The Power of CLV: Managing Customer Lifetime Value at IBM," Marketing Science, 27 (4), 585-599.

Lakshmanan, Arun and H. Shanker Krishnan (2011), "The Aha! Experience: Insight and Discontinuous Learning in Product Usage," Journal of Marketing, 75 (6), 105-123.

Lambrecht, Anja, Katja Seim and Bernd Skiera (2007), "Does Uncertainty Matter? Consumer Behavior under Three-Part Tariffs," Marketing Science, 26 (5), 698-710.

Lambrecht, Anja, Katja Seim and Catherine Tucker (2011), "Stuck in the Adoption Funnel: The Effect of Interruptions in the Adoption Process on Usage," Marketing Science, 30 (2), 355-367. 
Lambrecht, Anja and Bernd Skiera (2006), "Paying Too Much and Being Happy About It: Existence, Causes and Consequences of Tariff-Choice Biases," Journal of Marketing Research, 43 (2), 212-223.

Lammers, H. Bruce (1991), "The Effect of Free Samples on Immediate Consumer Purchase," The Journal of Consumer Marketing, 8 (2), 31-37.

Last.fm (2011), "Best of 2011," (accessed 25 August, 2013), http://www.lastfm.de/bestof/2011/ yearinmusic.

Lee, Jonathan, Peter Boatwright and Wagner A. Kamakura (2003), "A Bayesian Model for Prelaunch Sales Forecasting of Recorded Music," Management Science, 49 (2), 179-196.

Lemon, Katherine N., Tiffany Barnett White and Russell S. Winer (2002), "Dynamic Customer Relationship Management: Incorporating Future Considerations into the Service Retention Decision," Journal of Marketing, 66 (1), 1-14.

Lewis, Michael (2006), "Customer Acquisition Promotions and Customer Asset Value," Journal of Marketing Research, 43 (2), 195-203.

Liebowitz, Stan J. (2008), "Testing File-Sharing's Impact by Examining Record Sales in Cities," Management Science, 54 (4), 852-859.

Lowe, Rosemary H. and Ivan D. Steiner (1968), "Some Effects of the Reversibility and Consequences of Decisions on Postdecision Information Preferences," Journal of Personality and Social Psychology, 8 (2), 172-179.

Luan, Y. Jackie and K. Sudhir (2010), "Forecasting Marketing-Mix Responsiveness for New Products," Journal of Marketing Research, 47 (3), 444-457.

Lund, Susan, James Manyika, Scott Nyquist, Lenny Mendonca, and Sreenivas Ramaswamy (2013), "Game Changers: Five Opportunities for US Growth and Renewal." McKinsey Global Institute.

Luo, Xueming, Sascha Raithel and Michael A Wiles (2013), "The Impact of Brand Rating Dispersion on Firm Value," Journal of Marketing Research, 50 (3), 399-415.

McAfee, Andrew and Erik Brynjolfsson (2012), "Big Data: The Management Revolution," Harvard Business Review, 90 (10), 60-66.

McKinsey (2013), "Big Data, Big Profits," (accessed 10 December, 2013), http://mckinseyon marketingandsales.com/infographic-big-data-big-profits.

Mela, Carl F. (2011), "Structural Workshop Paper-Data Selection and Procurement," Marketing Science, 30 (6), 965-976.

Mitchell, Andrew A. and Jerry C. Olson (1981), "Are Product Attribute Beliefs the Only Mediator of Advertising Effects on Brand Attitude?," Journal of Marketing Research, 18 (3), 318332.

MSI (2012), "MSI Research Priorities 2012-2014." Cambridge, MA, USA: Marketing Science Institute.

Neslin, Scott A. and Robert W. Shoemaker (1989), "An Alternative Explanation for Lower Repeat Rates after Promotion Purchases," Journal of Marketing Research, 26 (2), 205-213.

Nielsen (2012), "Music 360." New York. 
Oberholzer-Gee, Felix and Koleman Strumpf (2007), "The Effect of File Sharing on Record Sales: An Empirical Analysis," Journal of Political Economy, 115 (1), 1-42.

Oestreicher-Singer, Gal and Lior Zalmanson (2013), "Content or Community? A Digital Business Strategy for Content Providers in the Social Age," Management Information Systems Quarterly, 37 (2), 591-616.

Onishi, Hiroshi and Puneet Manchanda (2012), "Marketing Activity, Blogging and Sales," International Journal of Research in Marketing, 29 (3), 221-234.

Osborne, Matthew (2011), "Consumer Learning, Switching Costs, and Heterogeneity: A Structural Examination," Quantitative Marketing and Economics, 9 (1), 25-70.

Palmatier, Robert W., Mark B. Houston, Rajiv P. Dant, and Dhruv Grewal (2013), "Relationship Velocity: Toward a Theory of Relationship Dynamics," Journal of Marketing, 77 (1), 1330 .

Palo Alto Networks (2013), "Application Usage \& Threat Report," (accessed 4 August, 2013), http://researchcenter.paloaltonetworks.com/app-usage-risk-report-visualization.

Park, C. Whan, Deborah J. MacInnis, Joseph R. Priester, Andreas B. Eisingerich, and Dawn Iacobucci (2010), "Brand Attachment and Brand Attitude Strength: Conceptual and Empirical Differentiation of Two Critical Brand Equity Drivers," Journal of Marketing, 74 (6), 1-17.

Park, Sungho and Sachin Gupta (2012), "Handling Endogenous Regressors by Joint Estimation Using Copulas," Marketing Science, 31 (4), 567-586.

Pauwels, Koen and Allen Weiss (2008), "Moving from Free to Fee: How Online Firms Market to Change Their Business Model Successfully," Journal of Marketing, 72 (3), 14-31.

Peitz, Martin and Patrick Waelbroeck (2006), "Why the Music Industry May Gain From Free Downloading-The Role of Sampling," International Journal of Industrial Organization, 24 (5), 907-913.

Polo, Yolanda, F. Javier Sese and Peter C. Verhoef (2011), "The Effect of Pricing and Advertising on Customer Retention in a Liberalizing Market," Journal of Interactive Marketing, 25 (4), 201-214.

Preacher, Kristopher J. and Andrew F. Hayes (2008), "Asymptotic and Resampling Strategies for Assessing and Comparing Indirect Effects in Multiple Mediator Models," Behavior Research Methods, 40 (3), 879-891.

Preacher, Kristopher J., Derek D. Rucker and Andrew F. Hayes (2007), "Addressing Moderated Mediation Hypotheses: Theory, Methods, and Prescriptions," Multivariate Behavioral Research, 42 (1), 185-227.

PricewaterhouseCoopers (2013a), "16th Annual Global CEO Survey." (2013b), "Global Entertainment and Media Outlook 2013-2017."

Prins, Remco, Peter C. Verhoef and Philip Hans Franses (2009), "The Impact of Adoption Timing on New Service Usage and Early Disadoption," International Journal of Research in Marketing, 26 (4), 304-313.

Raghubir, Priya (2004), "Free Gift with Purchase: Promoting or Discounting the Brand?," Journal of Consumer Psychology, 14 (1-2), 181-186. 
Ratner, Rebecca K. and Barbara E. Kahn (2002), "The Impact of Private versus Public Consumption on Variety-Seeking Behavior," Journal of Consumer Research, 29 (2), 246257.

Reinartz, Werner J. and V. Kumar (2003), "The Impact of Customer Relationship Characteristics on Profitable Lifetime Duration," Journal of Marketing, 67 (1), 77-99.

Reinartz, Werner J., J. S. Thomas and V. Kumar (2005), "Balancing Acquisition and Retention Resources to Maximize Customer Profitability," Journal of Marketing, 69 (1), 63-79.

RIAA (2013), "Piracy Online-Scope of the Problem," (accessed 30 August, 2013), http://www.riaa.com/physicalpiracy.php?content_selector=piracy-online-scope-ofthe-problem.

Rogers, Everett M. and Floyd F. Shoemaker (1971), Communication of Innovations: A CrossCultural Approach. New York: The Free Press.

Russell, Cristel Antonia and Sidney J. Levy (2012), "The Temporal and Focal Dynamics of Volitional Reconsumption: A Phenomenological Investigation of Repeated Hedonic Experiences," Journal of Consumer Research, 39 (2), 341-359.

Rust, Roland T., V. Kumar and Rajkumar Venkatesan (2011), "Will the Frog Change into a Prince? Predicting Future Customer Profitability," International Journal of Research in Marketing, 28 (4), 281-294.

Rust, Roland T. and Peter C. Verhoef (2005), "Optimizing the Marketing Interventions Mix in Intermediate-Term CRM," Marketing Science, 24 (3), 477-489.

Schary, Philip B. (1971), "Consumption and the Problem of Time," Journal of Marketing, 35 (2), 50-55.

Schmitt, Philipp, Bernd Skiera and Christophe Van den Bulte (2011), "Referral Programs and Customer Value," Journal of Marketing, 75 (1), 46-59.

Schweidel, David A., Peter S. Fader and Eric T. Bradlow (2008), "Understanding Service Retention Within and Across Cohorts Using Limited Information," Journal of Marketing, 72 (1), 82 94.

Scott, Carol A. (1976), "The Effects of Trial and Incentives on Repeat Purchase Behavior," Journal of Marketing Research, 13 (3), 263-269.

Sethuraman, Raj, Gerard J. Tellis and Richard A. Briesch (2011), "How Well Does Advertising Work? Generalizations from Meta-Analysis of Brand Advertising Elasticities," Journal of Marketing Research, 48 (3), 457-471.

Shankar, Venkatesh, Amy K. Smith and Arvind Rangaswamy (2003), "Customer Satisfaction and Loyalty in Online and Offline Environments," International Journal of Research in Marketing, 20 (2), 153-175.

Steffes, Erin M., B.P.S. Murthi and Ram C. Rao (2011), "Why are some Modes of Acquisition more Profitable: A Study of the Credit Card Industry," Journal of Financial Services Marketing, 16 (2), 90-100.

Stephen, Andrew T. and Jeff Galak (2012), "The Effects of Traditional and Social Earned Media on Sales: A Study of a Microlending Marketplace," Journal of Marketing Research, 49 (5), 624-639. 
Szymanowski, Maciej and Els Gijsbrechts (2012), "Consumption-Based Cross-Brand Learning: Are Private Labels Really Private?," Journal of Marketing Research, 49 (2), 231-246.

The Economist (2011a), "A New, Improved Hit Machine," (October 22, 2011).

The Economist (2011b), "Spotting the Pirates," (August 20, 2011).

Thomas, Jacquelyn S. (2001), "A Methodology for Linking Customer Acquisition to Customer Retention," Journal of Marketing Research, 38 (2), 262-268.

Thomson, Matthew, Deborah J. MacInnis and C. Whan Park (2005), "The Ties That Bind: Measuring the Strength of Consumers' Emotional Attachments to Brands," Journal of Consumer Psychology, 15 (1), 77-91.

Toubia, Olivier and Andrew T. Stephen (2013), "Intrinsic vs. Image-Related Utility in Social Media: Why Do People Contribute Content to Twitter?," Marketing Science, 32 (3), 368392.

Train, Kenneth (2009), Discrete Choice Methods with Simulation: Cambridge University Press.

Twardos, Michael (2011), "Probability Distribution of Song Length in a Collection of Itunes Libraries," (accessed 8 September, 2013), http://theinformationdiet.blogspot.nl/2011/ 11/probability-distribution-of-song-length.html.

Vaillant, George E. (1993), The Wisdom of the Ego. Cambridge, Mass.: Harvard University Press.

Van Doorn, Jenny, Katherine N. Lemon, Vikas Mittal, Stephan Nass, Doreen Pick, Peter Pirner, and Peter C. Verhoef (2010), "Customer Engagement Behavior: Theoretical Foundations and Research Directions," Journal of Service Research, 13 (3), 253-266.

Verhoef, Peter C. and Bas Donkers (2005), "The Effect of Acquisition Channels on Customer Loyalty and Cross-Buying," Journal of Interactive Marketing, 19 (2), 31-43.

Verhoef, Peter C., Werner J. Reinartz and Manfred Krafft (2010), "Customer Engagement as a New Perspective in Customer Management," Journal of Service Research, 13 (3), 247252.

Veronis Suhler Stevenson (2010), "Communications Industry Forecast \& Report," as cited in US Census Bureau's 2010 Statistical Abstract (Table 1094).

Villanueva, Julian, Shijin Yoo and Dominique M. Hanssens (2008), "The Impact of MarketingInduced Versus Word-of-Mouth Customer Acquisition on Customer Equity Growth," Journal of Marketing Research, 45 (1), 48-59.

Villas-Boas, J. Miguel and Russell S. Winer (1999), "Endogeneity in Brand Choice Models," Management Science, 45 (10), 1324-1338.

Wilbur, Kenneth C. (2008), "A Two-Sided, Empirical Model of Television Advertising and Viewing Markets," Marketing Science, 27 (3), 356-378,540. 



\title{
Summary
}

\author{
It's in the Way That You Use It \\ Usage Behavior, Sales Performance, and Their Interrelationships
}

How can the widespread accessibility of consumers' usage data, e.g., via online social networks or smart devices, be used to improve managerial decision-making?

In this dissertation, we use big data and advanced econometric methods to shed light on this crucial question. Specifically, we investigate the relevance of consumers' usage behavior in two settings that have recently received academic attention and spark managerial controversy.

Study 1 investigates the effectiveness of free-trial promotions to acquire new customers. Despite the omnipresence of free-trial promotions (e.g., three-month trials for digital TV), managers wonder whether customers acquired with free-trial promotions differ systematically from regular customers in terms of their usage and retention behavior, and customer lifetime value. To address this issue, we conceptualize how a consumer's retention decision is driven by marketing communication and usage. We next develop hypotheses how the effects of these drivers are moderated by the mode of acquisition, i.e., free-trial or regular. To test the hypotheses, we model a customer's retention decision and usage behavior of both flat-rate (e.g., watching TV programs), and pay-per-use services (e.g., watching videos-ondemand). The model allows for unobserved heterogeneity, selection effects, and endogenous 
marketing instruments. On the basis of panel data from a digital TV service for 16,500 customers, we demonstrate behavioral differences which make free-trial customers, on average, worth $55 \%$ less than regular customers. However, free-trial customers are more responsive to changes in marketing communication and usage rates, which offers opportunities to target marketing efforts and enhance customer equity.

In study 2 , we address the rapid digitization of the entertainment industry which urges managers to find new ways to improve marketing effectiveness and combat online piracy. While smart devices and innovative online services generate brand-related tracking data (e.g., digital usage rates, Facebook Likes), managers are unaware of how to use these big data to improve brand performance. We therefore propose a model to assess how digitally tracked customer engagement behaviors - consumer brand usage (CBU, measured by digital usage rates) and consumer brand endorsement ( $\mathrm{CBE}$, measured by Facebook Likes) drive brand sales and affect the role of piracy. We apply our framework in the U.S. music industry, and develop web scrapers and API mining scripts to collect data for 569 music artists over 66 weeks. Both $\mathrm{CBU}$ and $\mathrm{CBE}$ enhance marketing effectiveness and mediate the negative impact of piracy, though CBU is more important than CBE. When accounting for the effects of online piracy on consumer engagement, the negative effect of piracy diminishes by about $55 \%$. The overall impact of piracy on sales remains negative, but its impact can be mitigated using insights gained from digitally tracked customer engagement behaviors. 